\title{
Advanced Materials For Mercury 50 Gas Turbine Combustion System
}

\section{Final Report}

Reporting Period: July 1, 2000 - September 30, 2008

Report

SR01-R-6187-25

Issued: $\quad$ May 28, 2009

Submitted to:

Donald W. Geiling

Project Management Center

U.S. Department of Energy

National Energy Technology Laboratory

3610 Collins Ferry Rd., MS P02A

P.O. Box 880

Morgantown, WV 26507-0880

donald.geiling@netl.doe.gov

Customer Reference:

DE-FC26-00CH11049

Solar Reference

S.O. 661877
Prepared by:

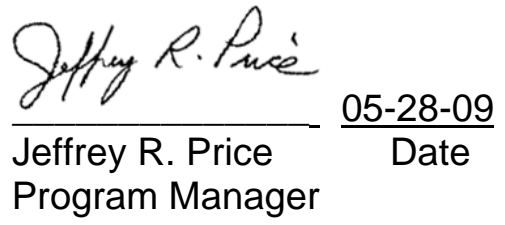

Approved by:

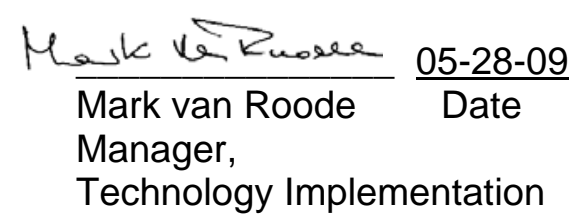

Solar Turbines Incorporated

A Caterpillar Company

2200 Pacific Highway

San Diego, California 92101 


\section{DISCLAIMER}

This report was prepared as an account of work sponsored by an agency of the United States Government. Neither the United States Government nor any agency thereof, nor any of their employees, makes any warranty (expressed or implied), or assumes any legal liability or responsibility for the accuracy, completeness, or usefulness of any information, apparatus, product, or process disclosed, or represents that its use would not infringe privately owned rights. Reference herein to any specific commercial product, process, or service by trade name, trademark, manufacturer, or otherwise does not necessarily constitute or imply its endorsement, recommendation, or favoring by the United States Government or any agency thereof. 


\section{TABLE OF CONTENTS}

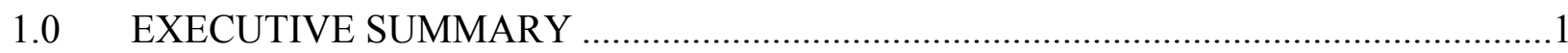

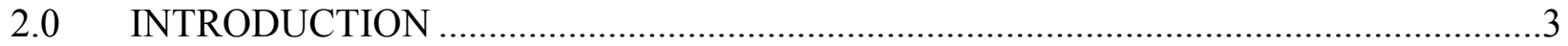

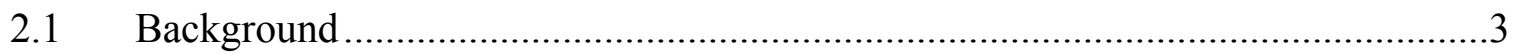

2.2 Benefits from Solar's Advanced Materials for Mercury 50 Gas

Turbine Combustion System Development Program ..........................................6

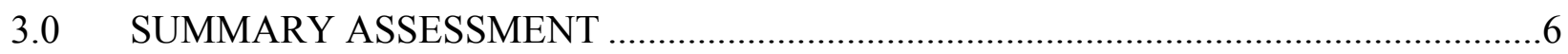

3.1 Overall Assessment of Performance ............................................................6

4.0 TECHNICAL ACCOMPLISHMENT BY TASK - CORE PROGRAM ........................7

4.1 Task 1 - Advanced Material Component Concept Design and Evaluation ............7

Subtask 1.1 Monolithic Ceramic Injector Tip .....................................

Subtask 1.2 / 1.3 Oxide Dispersion Strengthened (ODS) Alloy Injector Tip and Liner ................................................................ 8

Subtask 1.4 Thermal Barrier Coating (TBC) Development..................11

Subtask 1.5 Continuous Fiber Ceramic Composite Development ........18

Subtask 1.6 Topical Report for Subtask A .......................................20

4.2 Task 2 - Advanced Material System Optimization and Sub-scale Testing ...........20

Subtask 2.1 Higher Resistivity TBC Applied to Liner.........................21

Subtask 2.2 ODS Alloy Injector Tip ............................................22

4.3 Task 3 - Modify Gas Turbine to Accept New System

Subtask $3.1 \quad$ Topical Report for Subtask B ......................................24

4.4 Task 4 - System Fabrication and Proof Test ......................................................24

4.5 Task 5 - Commercial Demonstration............................................................25

5.0 SUBTASK 1A - EXTENDED CFCC MATERIALS DURABILITY TEST ..................27

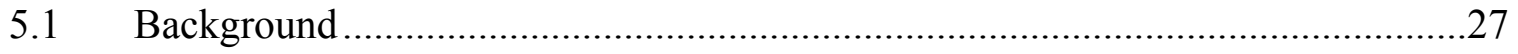

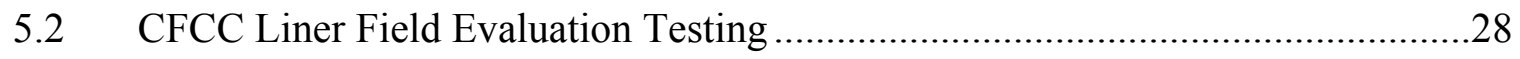

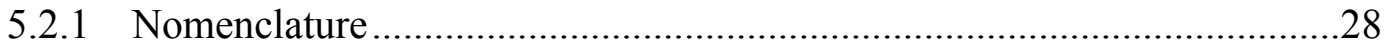

5.2.2 Introduction To Solar Engine Field Testing ….................................29 


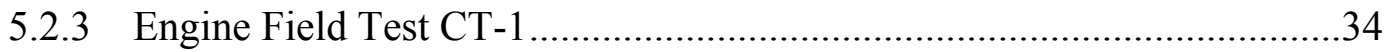

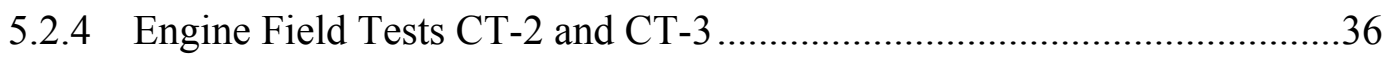

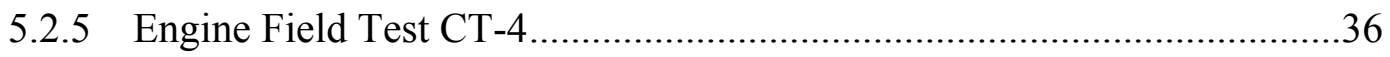

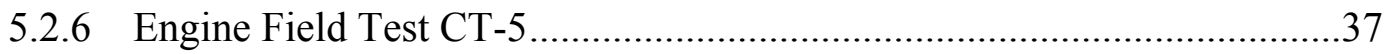

5.2.7 Engine Field Tests MM-1 and CT-6 .............................................40

5.2.8 Engine Field Test MM-2 ..........................................................42

5.2.9 Engine Field Test MM-3 ..............................................................43

5.2.10 Engine Field Test CT-7 and CT-8 ...............................................44

5.2.11 Engine Field Test CD-1 ...............................................................55

5.2.12 CFCC Engine Field Test Summary …............................................58

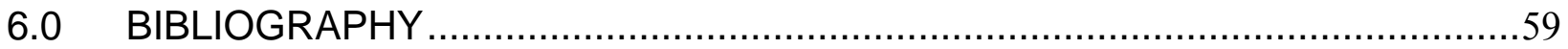




\section{FIGURES}

Figure 2.1 Schematic of Mercury 50 Combustion System Showing

Location of Liners and Fuel Injectors

Figure 4.1 Monolithic Silicon Nitride Injector Tip Installed in Centaur 50S Injector 7

Figure 4.2 Significant Oxidation Experienced on Silicon Nitride Nozzles after only 68 Hours of Engine Testing in Centaur 50S Engine............................................ 8

Figure 4.3 Cross Sections of a Braze Joint Showing Lack of Fill and a Good Braze..............9

Figure 4.4 Micrograph of Initial Laser Weld Trials Showed Inconsistent Welding of the Joint 10

Figure 4.5 MA9576 Injector Tip successfully Brazed to Hastelloy X Centerbody Material..... 10

Figure 4.6 MA 754 and PM 2000 Injector Tips Successfully Brazed to Hastelloy X Injector Centerbody Material. .11

Figure 4.7 Representative Microstructure of Mercury 50 Baseline TBC

Figure 4.8 Representative Microstructures of 40-mil Thick TBC Systems from Solar, Praxair (Zircoat), UCONN (SPPS), and UTRC 14

Figure 4.9 Thermal Conductivity for Solar's Advanced 40-mil TBC System after Aging at Various Temperatures for Exposure Times up to 5000 Hours

Figure 4.10 RAI Life Prediction Model Compared to Measured Data for Solar 15-mil TBC at 1900,2000 and $2100^{\circ} \mathrm{F}$ .16

Figure 4.11 RAI Life Prediction Model Compared to Measured Data for Solar 25-mil TBC at 1900,2000 and $2100^{\circ} \mathrm{F}$ .16

Figure 4.12 RAI Life Prediction Model Compared to Measured Data for Solar 35-mil $\mathrm{TBC}$ at 1900,2000 and $2100^{\circ} \mathrm{F}$

Figure 4.13 Comparison of Predicted TBC Life for Baseline (25 mil) and Advanced (40 mil) TBC Systems

Figure 4.14 Assembly Layout side view of Mercury 50 combustor with the Inner CFCC Liner

Figure 4.15 High-Level View of the Inner Liner Attachment Concept .19

Figure 4.16 CFCC Liner Structural Analysis - Stress Results. .20 
Figure 4.17 Subscale Combustion Liner with Thermal Paint and Instrumentation .21

Figure 4.18 Illustration of Areas with TBC Applied to Subscale Liners ..............................21

Figure 4.19 Single Injector Rig Used to Test Subscale Liners with TBC............................22

Figure 4.20 Full-Scale Mercury 50 Fuel Injector with PM 2000 ODS Alloy Tip ..................22

Figure 4.21 Single Injector, High-Pressure rig Testing of ODS Injector Tips.......................23

Figure 4.22 Full-Scale PM 2000 ODS Alloy Injector Tip with No Cooling Holes................23

Figure 4.23 PM 2000 ODS Injector Tip with No Cooling Following Test............................24

Figure 4.24 Full-scale Mercury 50 Combustor Coated with Solar Advanced 40-mil TBC

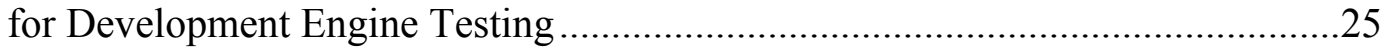

Figure 4.25 Borescope Images of the Advanced 40-mil TBC after 4360 Hours of Commercial Operation at Qualcomm Inc. with 85 Starts..................................26

Figure 4.26 "Rolled Out" Digital Images of Advanced 40-mil TBC after 20,000 Hours of Commercial Operation in the Mercury 50 Engine at Qualcomm Inc...................26

Figure 5.1 Solar's Ceramic Combustor Liner Development Strategy ...............................29

Figure 5.2 Schematic of Solar Centaur 50S Combustor with CFCC Liners ..........................30

Figure 5.3 The Chevron Texaco Bakersfield Site with Field Test Engine in Package ...........31

Figure 5.4 Centaur 50S Engine at Malden Mills Textile Facility ......................................31

Figure 5.5 Centaur 50S Engine at Cal. Dairies, Inc. Facility ..........................................32

Figure 5.6 CG Ni/PyC/E-SiC (CVI) Liners Before 100-Hour Solar Test.............................35

Figure 5.7 CG Ni/PyC/E-SiC (CVI) Inner Liner after 948-Hour Test (CT-1).....................35

Figure 5.8 Inner and Outer Liner Sections after 948-Hour Test (CT-1) ............................35

Figure 5.9 Digital Photographs of HiNi SiC/PyC/E-SiC (CVI) Outer Liner and HiNi $\mathrm{SiC} / \mathrm{BN} / \mathrm{SiC}-\mathrm{SI}$ (MI) Inner Liner after 5,016 Field Test Hours (T-4)...................37

Figure 5.10 CMC Liner Set with EBC for Field Test CT-5 ...........................................38

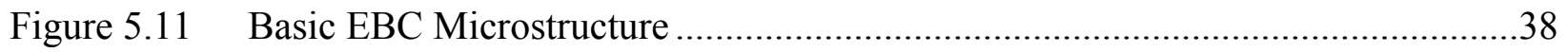

Figure 5.12 Breach in HiNi SiC/BN/SiC-Si (MI) Inner Liner after 13,937-Hour Test ............39 
Figure 5.13 Liners after 13,937-Hour Test.

Figure 5.14 Pitting on the HiNi SiC/PyC/E-SiC (CVI) Outer Liner.

Figure 5.15 Digital Photographs of HiNi/BN/SiC-Si (MI) Inner Liner and HiNi/PyC/E-SiC

(CVI) Outer Liner after 7,238-hour Field Test (MM-1).

Figure 5.16 Liners of MM-1 Field Test after Additional 5,135-hours Field Test (CT-6) Total Test Time: 12,373 Hours (CT-6). .41

Figure 5.17 Digital Photographs of TyZM/BN/SiC-Si (MI) Inner Liner and HiNi/PyC/E-SiC (CVI) Outer Liner after 15,144-hour Field Test (MM-2); ID/OD: Inner/Outer Diameter) .42

Figure 5.18 $\mathrm{SiO} 2$ Layer on $\mathrm{EBC}$ at the (Si/Mullite + BSAS) Interface - Inner Liner after 15,144-hour Test.

Figure 5.19 TyZMI/BN/SiC-Si (MI) Outer Liner and Inner Liner after 8,368-hour Field Test (MM-3) .... .43

Figure 5.20 Outer Hybrid Oxide CFCC Liner Prior to Engine Field Testing..... .44

Figure 5.21 Borescope Views of Hybrid Oxide CFCC Outer Liner at 1026 Hours/ 19 Starts, 5885 Hours/ 40 Starts, and 10,667 Hours/ 61 Starts 45

Figure 5.22 Section of the Hybrid Oxide CFCC Liner after 12,582 Hours/63 Starts Showing Surface Erosion.

Figure 5.23 SiC/SiC CFCC Inner Liner with EBC after 12,582 Hours of Engine Field Testing46

Figure 5.24 Repaired Hybrid Oxide CFCC Liner with FGI Prior to Continuation of the Field Test

Figure 5.25 New CFCC SiC/SiC (Prepreg) Inner Liner .47

Figure 5.26 Patched Area in Borescope after 16,566 Hours and 81 Starts ..... .48

Figure 5.27 Degraded Area in Borescope Taken at 22,132 Hours and 97 Starts....... .48

Figure 5.28 Hybrid Oxide CFCC Outer Liner after 25,404 Hours of Engine Testing..... .49

Figure 5.29 Repaired Section of FGI 49

Figure 5.30 Repaired Section of FGI and Exposed CFCC.............................................50

Figure 5.31 Digital Photographs after 25,404 Hours of Engine Field Testing .......................50

Figure 5.32 SiC/SiC CFCC Inner Liner after 12,822 Hours/46 Starts.................................51 
Figure 5.33 Hybrid Oxide CMC Liner Sectioning Plan ......................................................52

Figure 5.34 As-processed Hybrid Oxide CFCC Liner and Engine Field Tested Liner ...........53

Figure 5.35. Surface Textures of As-processed and Eroded Engine-tested Hybrid Oxide CFCC Outer Liner Areas

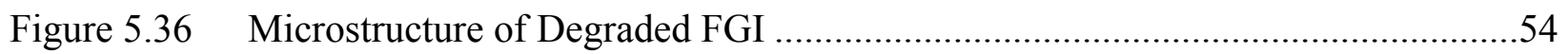

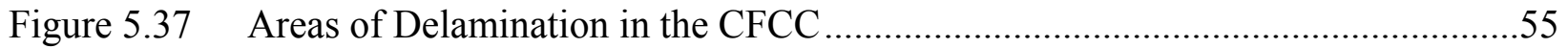

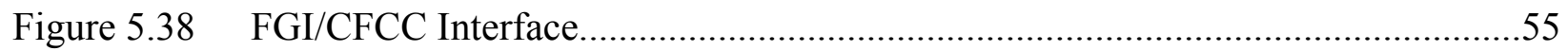

Figure 5.39 As-processed TyZMI/BN/SiC-Si MI Liner Set for Engine Field Test CD-1 …....55

Figure 5.40 Thermal Diffusivity NDE Scans for GE TyZMI/BN/SiC-Si MI Inner and Outer As-processed Liners prior to and After EBC Application .............................56

Figure 5.41 Borescope Images of TyZMI/BN/SiC-Si MI Liners After 1,250 Hours of Engine Field Testing .56

Figure 5.42 Borescope Images of TyZMI/BN/SiC-Si MI Liners After $~ 5,535$ Hours Of Engine Field Testing

Figure 5.43 Outer TyZMI/BN/SiC-Si MI Liner After 7,784-hour/43 Start Engine Test. .57

\section{TABLES}

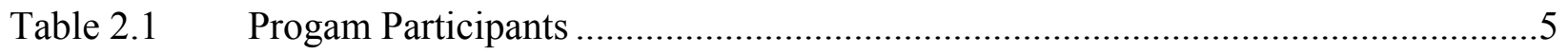

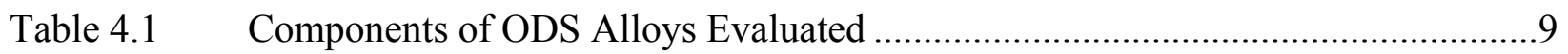

Table 4.2 Comparison of TCB Systems Cyclic Testing Results at 2,000 F.........................18

Table 5.1 Summary of Combustor Liner Engine Tests ........................................................33 


\subsection{EXECUTIVE SUMMARY}

Solar Turbines Incorporated (Solar), under cooperative agreement number DE-FC2600CH11049, has conducted development activities to improve the durability of the Mercury 50 combustion system to 30,000 hours life and reduced life cycle costs. This project is part of Advanced Materials in the Advanced Industrial Gas Turbines program in DOE's Office of Distributed Energy. The targeted development engine was the Mercury ${ }^{\mathrm{TM}} 50$ gas turbine, which was developed by Solar under the DOE Advanced Turbine Systems program (DOE contract number DE-FC21-95MC31173). As a generator set, the Mercury 50 is used for distributed power and combined heat and power generation and is designed to achieve $38.5 \%$ electrical efficiency, reduced cost of electricity, and single digit emissions.

The original program goal was 20,000 hours life, however, this goal was increased to be consistent with Solar's standard 30,000 hour time before overhaul for production engines. Through changes to the combustor design to incorporate effusion cooling in the Generation 3 Mercury 50 engine, which resulted in a drop in the combustor wall temperature, the current standard thermal barrier coated liner was predicted to have 18,000 hours life. With the addition of the advanced materials technology being evaluated under this program, the combustor life is predicted to be over 30,000 hours. The ultimate goal of the program was to demonstrate a fully integrated Mercury 50 combustion system, modified with advanced materials technologies, at a host site for a minimum of 4,000 hours. Solar was the Prime Contractor on the program team, which includes participation of other gas turbine manufacturers, various advanced material and coating suppliers, nationally recognized test laboratories, and multiple industrial end-user field demonstration sites.

The program focused on a dual path development route to define an optimum mix of technologies for the Mercury 50 and future gas turbine products. For liner and injector development, multiple concepts including high thermal resistance thermal barrier coatings (TBC), oxide dispersion strengthened (ODS) alloys, continuous fiber ceramic composites (CFCC), and monolithic ceramics were evaluated before down-selection to the most promising candidate materials for field evaluation. Preliminary, component and sub-scale testing was conducted to determine material properties and demonstrate proof-of-concept. Full-scale rig and engine testing was used to validated engine performance prior to field evaluation at a Qualcomm Inc. cogeneration site located in San Diego, California.

To ensure that the CFCC liners with the EBC proposed under this program would meet the target life, field evaluations of ceramic matrix composite liners in Centaur ${ }^{\circledR} 50$ gas turbine engines, which had previously been conducted under the DOE sponsored Ceramic Stationary Gas Turbine program (DE-AC02-92CE40960), was continued under this program at commercial end-user sites under Program Subtask 1A - Extended CFCC Materials Durability Testing. The goal of these field demonstrations was to demonstrate significant component life, with milestones of 20,000 and 30,000 hours. Solar personnel monitor the condition of the liners at the field demonstration sites through periodic borescope inspections and emissions measurements. This program was highly successful at evaluating advanced materials and down-selecting promising solutions for use in gas turbine combustions systems. The addition of the advanced materials technology has enabled the predicted life of the Mercury 50 combustion system to reach 30,000 hours, which is Solar's typical time before overhaul for production engines. In particular, a 40 mil thick advanced Thermal Barrier Coating (TBC) system was selected over various other TBC 
systems, ODS liners and CFCC liners for the 4,000-hour field evaluation under the program. This advanced TBC is now production bill-of-material at various thicknesses up to 40 mils for all of Solar's advanced backside-cooled combustor liners (Centaur 50, Taurus 60, Mars 100, Taurus 70, Taurus 65, Titan 130, Titan 250 and Mercury 50). This TBC coating system significantly outperformed all other TBC systems evaluated under the program. The initial field unit, with the 40 mil advanced TBC developed under this program, has far exceeded the 4,000-hour requirement of the program, accumulating over 20,000 hours of commercial operation at Qualcomm Inc. in San Diego, CA. The 40 mil advanced TBC remains in excellent condition, with no evidence of chipping or spalling. The engine will continue operation until the unit is due for overhaul at approximately 30,000 hours.

The Oxide Dispersion Strengthened (ODS) alloy injector tip testing and evaluation was also successful, however, the ODS injector tip development on this program was terminated, primarily due to the fact that the Mercury 50 injector tip was redesigned (Generation 3) by Combustion Engineering, which increased the overall life of the baseline Haynes 188 injector tip to 30,000 hours, minimizing the need to pursue the more expensive ODS material. The Haynes 188 injectors are in operation with the advanced TBC at Qualcomm Inc. The evaluation, however, has shown that the ODS materials could be utilized for fuel injector tips in future engines if the temperature requirements demand the higher temperature capability. Silicon nitride ceramic injector tip development was stopped early in the program due to the significant oxidation that was encountered with this material in the gas turbine environment. A suitable environmental barrier coating (EBC) will be required for silicon nitride to be further considered for this application.

For the Continuous-Fiber Reinforced Ceramic Composite (CFCC) combustor liners, over 88,000 hrs of operating experience have been acquired from field testing of CFCC combustor liners since 1997 in Solar Centaur 50S gas turbine engines. At the start of the DOE Advanced Materials program the cumulative field testing hours were about 10,000. Test durations of 15,144 hours and 13,937 hours have been logged for SiC/SiC CFCC liners with protective EBCs. An oxide/oxide CFCC liner with Friable Graded Insulation (FGI) protective coating has been tested for 25,404 hrs. NOx and CO emissions were $<15$ ppmv and $<10$ ppmv, respectively. Hybrid Oxide CFCC liners are approaching the 30,000-hour life target expected for industrial gas turbines, and could be implemented into production for future combustor liners with higher temperature capability requirements.

Demonstration of long-term durability for CFCC combustor liners is critical to the commercialization of CFCC liner materials for the Mercury 50 and other gas turbine engines. The current field test engines offered the opportunity to achieve long term testing on the CFCC material systems and EBCs through production operation in the gas turbine environment. Successful demonstration would enable the CFCC materials to be considered for other gas turbine engines.

Further details of the development activities associated with the selection of optimum technologies for the field demonstration are given in Section 4.0 - Technical Accomplishments by Task - Core Program and 5.0 - Subtask 1A - Extended CFCC Materials Durability Testing. 


\section{$2.0 \quad$ INTRODUCTION}

\subsection{Background}

Solar Turbines Incorporated (Solar), under cooperative agreement number DE-FC2600CH11049, conducted development activities to improve the durability of the Mercury 50 combustion system to 30,000 hours life and reduced life cycle costs. The original program goal was 20,000-hours life, however this goal was increased to be consistent with Solar's standard 30,000 hour time before overhaul for production engines. This project was part of Advanced Materials in the Advanced Industrial Gas Turbines program in DOE's Office of Distributed Energy. The recuperated Mercury $50(4.6 \mathrm{MW})$ is a relatively new turbine that was developed by Solar under the DOE Advanced Turbine Systems program (DOE contract DE-FC2195MC31173). As a generator set, the Mercury 50 is used for distributed power and combined heat and power generation, and is designed to achieve $38.5 \%$ electrical efficiency, reduced cost of electricity, and single digit emissions.

The primary objective of the program was to demonstrate a fully integrated Mercury 50 combustion system, modified with advanced materials technologies, at a host site for a minimum of 4,000 hours. Solar was the Prime Contractor on the program team (Table 2.1) which includes participation of other gas turbine manufacturers, various advanced material and coating suppliers, nationally recognized test laboratories, and multiple industrial end user field demonstration sites.

The program focused on a parallel path development route to define an optimum mix of technologies for the Mercury 50. For combustor liner and injector tip improvements, multiple concepts were evaluated before down-selection to a single technology strategy for field evaluation. A schematic of the Mercury 50 combustor showing the location of the liners and fuel injectors is given in Figure 2.1. The advanced material technologies that were considered are listed below:

Liner Development:

- High Thermal Resistance Thermal Barrier Coatings (TBC)

- High Temperature Superalloy - Oxide Dispersion Strengthened (ODS) alloys

- Continuous Fiber-reinforced Ceramic Composite (CFCC) with Environmental Barrier Coating (EBC)

Injector Development:

- High Temperature ODS alloy Injector Tip

- Monolithic Ceramic Tip

Preliminary component and sub-scale testing was conducted to determine material properties and demonstrate proof-of-concept. Full-scale rig and engine testing was conducted to validate component performance prior to field evaluation at a host site. 


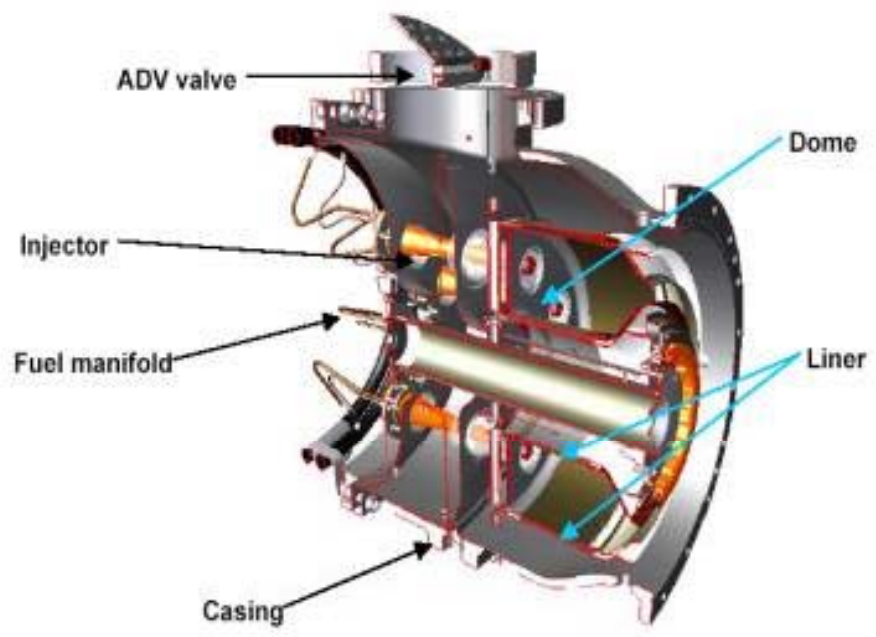

Figure 2.1 Schematic of Mercury 50 Combustion System Showing Location of Liners and Fuel Injectors

CFCC Durability Testing:

To ensure that the CFCC liners with the EBC proposed under this program would meet the target life, field evaluations of ceramic matrix composite liners in a Centaur ${ }^{\circledR} 50$ gas turbine engine, which had previously been conducted under the DOE sponsored Ceramic Stationary Gas Turbine program (DE-AC02-92CE40960), was continued under this program at commercial end user sites under Program Subtask 1A - Extended CFCC Materials Durability Testing. The goal of these field demonstrations was to demonstrate significant component life, with milestones of 20,000 and 30,000 hours. Solar personnel monitor the condition of the liners at the field demonstration sites through periodic borescope inspections and emissions measurements.

Demonstration of long-term durability for CFCC combustor liners is critical to the commercialization of CFCC liner materials for the Mercury 50 and other gas turbine engines. The current field test engines offered the opportunity to achieve long term testing on the CFCC material systems and EBCs through production operation in the gas turbine environment. Successful demonstration would enable the CFCC materials to be considered for other gas turbine engines.

The program is divided into the following five core program tasks, plus Subtask 1A as defined below:

Core Program: Advanced Materials for Mercury 50 Gas Turbine Combustion System

Task 1: Advanced Material Component Concept Design and Evaluation

Task 2: Advanced Material System Optimization and Sub-scale Testing

Task 3: Modify Gas Turbine to Accept New System

Task 4: System Fabrication and Proof Test 


\section{Task 5: Pre-Commercial Demonstration}

Subtask 1A: Extended CFCC Materials Durability Testing (Described in Section 5.0 and is distinct from the Subtask A Topical Report)

This Final Report documents the results of the program efforts by Program Task under Section 4.0. A bibliography of technical papers and presentations given under the program are listed for the Core Program and Subtask 1A in Section 6.0

Table 2.1 Program Participants

\begin{tabular}{|c|c|}
\hline Program Sponsor & U.S. Department of Energy \\
\hline Project Management & $\begin{array}{l}\text { National Energy Technology Laboratory, } \\
\text { Pittsburgh, PA }\end{array}$ \\
\hline Prime Contractor & Solar Turbines Incorporated \\
\hline Thermal Barrier Coatings & $\begin{array}{l}\text { Solar Turbines Incorporated } \\
\text { United Technologies Research Center } \\
\text { University of Connecticut } \\
\text { Praxair Surface Technologies, Inc }\end{array}$ \\
\hline TBC Life Prediction & Research Applications Inc. \\
\hline $\begin{array}{l}\text { Oxide Dispersion } \\
\text { Strengthened Alloys }\end{array}$ & $\begin{array}{l}\text { Special Metals Inc. } \\
\text { Plansee Corporation }\end{array}$ \\
\hline $\begin{array}{l}\frac{\text { Monolithic Ceramic }}{\text { Materials }} \\
\text { - AS-800 } \mathrm{Si}_{3} \mathrm{~N}_{4} \\
-\mathrm{SN}-282 \mathrm{Si}_{3} \mathrm{~N}_{4}\end{array}$ & $\begin{array}{l}\text { Honeywell Ceramic Components } \\
\text { Kyocera Industrial Ceramics Corporation }\end{array}$ \\
\hline $\begin{array}{l}\text { Ceramic Composite Liner } \\
\text { Materials } \\
\text { - SiC/SiC } \\
\text { - SiC/SiC } \\
\text { - Oxide/Oxide }\end{array}$ & $\begin{array}{l}\text { Goodrich Corporation } \\
\text { General Electric Ceramic Composite Products, } \\
\text { LLC } \\
\text { ATK COI Ceramics, Inc. }\end{array}$ \\
\hline $\begin{array}{l}\text { Environmental Protection } \\
\text { - Environmental Barrier } \\
\text { Coatings } \\
\text { - Friable Graded Insulation }\end{array}$ & $\begin{array}{l}\text { United Technologies Research Center } \\
\text { General Electric Ceramic Composite Products, } \\
\text { LLC } \\
\text { Siemens Westinghouse Corporation, ATK COI } \\
\text { Ceramics, Inc. }\end{array}$ \\
\hline Nondestructive Evaluation & $\begin{array}{l}\text { Solar Turbines Incorporated } \\
\text { Argonne National Laboratory }\end{array}$ \\
\hline Materials Testing Support & Oak Ridge National Laboratory \\
\hline $\begin{array}{l}\text { Field Demonstration End } \\
\text { Users }\end{array}$ & $\begin{array}{l}\text { ChevronTexaco Exploration \& Production Inc. } \\
\text { Malden Mills Industries } \\
\text { California Dairies Inc. } \\
\text { Qualcomm Incorporated }\end{array}$ \\
\hline
\end{tabular}




\subsection{Benefits from Solar's Advanced Materials for Mercury 50 Gas Turbine Combustion System Development Program}

By reducing life cycle costs through the incorporation of the advanced materials technologies proposed under this program, the Mercury 50 gas turbine will be more attractive to the distributed power generation and co-generation market. As the market penetration of the Mercury 50 expands in the near- and mid-terms, the U.S. will benefit from:

- Single digit NOx and $\mathrm{CO}$ emissions, NOx being a major smog precursor

- Reduced $\mathrm{CO}_{2}$ emissions (on a pound per unit of useful energy basis) due to the growth in co-generation in the near-term and the use of high efficiency gas turbine systems in the mid-term

- Lower cost electricity as the benefits of distributed power generation are realized

- More efficient use of natural gas in the U.S. and a reduced reliance on imported oil

- A more robust electric power infrastructure through distributed power generation

\subsection{SUMMARY ASSESSMENT}

\subsection{Overall Assessment of Performance}

This program was highly successful at evaluating advanced materials for use in gas turbine combustions systems. The addition, the advanced materials technology has enabled the predicted life of the Mercury 50 combustion system to reach 30,000 hours, which is Solar's typical time before overhaul for production engines. In particular, a 40-mil thick advanced Thermal Barrier Coating (TBC) system, which was selected for the 4000 hour field evaluation under the program, is now production bill-of-material at various thicknesses up to 40 mils for all of Solar's advanced, backside-cooled combustor liners (Centaur 50, Taurus 60, Mars 100, Taurus 70, Taurus 65, Titan 130, Titan 250 and Mercury 50). The initial field unit with the 40-mil advanced TBC developed under this program has accumulated over 20,000 hours of commercial operation at Qualcomm Inc. in San Diego, CA, and the 40-mil advanced TBC remains in excellent condition. The engine will continue operation until the unit is due for overhaul at approximately 30,000 hours. Qualcomm has purchased a second Mercury 50 engine, which will also contains the 40-mil advanced TBC.

While the cooled Oxide Dispersion Strengthened (ODS) alloy injector tip testing and evaluation was successful, the ODS injector tip development on this program was terminated. This was primarily due to the fact that the Mercury 50 injector tip was redesigned (Generation 3) by Combustion Engineering, which increased the overall life of the baseline Haynes 188 injector tip to 30,000 hours, minimizing the need to pursue the more expensive ODS material. However, the evaluation has shown that the ODS materials could be utilized for fuel injector tips in future engines if the temperature requirements demand the higher temperature capability.

For the Continuous-Fiber Reinforced Ceramic Composite (CFCC) combustor liners, over 88,000 hours of operating experience have been acquired from field testing of CFCC combustor liners since 1997 in Solar Centaur 50S gas turbine engines. At the start of the DOE Advanced Materials program, the cumulative field testing hours was about 10,000. Test durations of 
15,144 hours and 13,937 hours have been logged for SiC/SiC CFCC liners with protective EBCs. An oxide/oxide CFCC liner with FGI protective coating has been tested for 25,404 hours. NOx and $\mathrm{CO}$ emissions were $<15 \mathrm{ppmv}$ and $<10$ ppmv, respectively. Hybrid Oxide CFCC liners are approaching the 30,000-hour life target expected for industrial gas turbines, and could be implemented into production for future combustor liners with higher temperature capability requirements.

\subsection{TECHNICAL ACCOMPLISHMENT BY TASK - CORE PROGRAM}

\subsection{Task 1 - Advanced Material Component Concept Design and Evaluation}

The advanced materials development for the advanced combustor liners focused on improved thermal barrier coating development and application. A schematic of the Mercury 50 combustor showing the liners and injector tips was shown in Figure 2.1. Thicker TBCs $(1.0 \mathrm{~mm} / 0.040$ inch) and TBCs with lower thermal conductivity were evaluated through thermal cycling. Monolithic ceramic and ODS alloys were considered for fuel injector tip applications to help meet the 30,000 hour time-before-overhaul requirement. The early designs of the Haynes 188 injector tips (Generations 1 and 2) for the Mercury 50 combustor were projected to have insufficient life to meet the 30,000-hour requirement.

\section{Subtask 1.1: Monolithic Ceramic Injector Tip}

As with most ceramic gas turbine components, the interface/attachment between the ceramic injector tip and the adjacent metallic structures is the primary challenge. The initial plan for the monolithic injector tip development was to further evaluate silicon nitride injector tip designs (See Figure 4.1), fabricated previously under the Ceramic Stationary Gas Turbine (CSGT) Program for the Centaur 50S engine. However, a major issue arose with accelerated oxidation of silicon nitride components, requiring the development efforts to be put on hold.

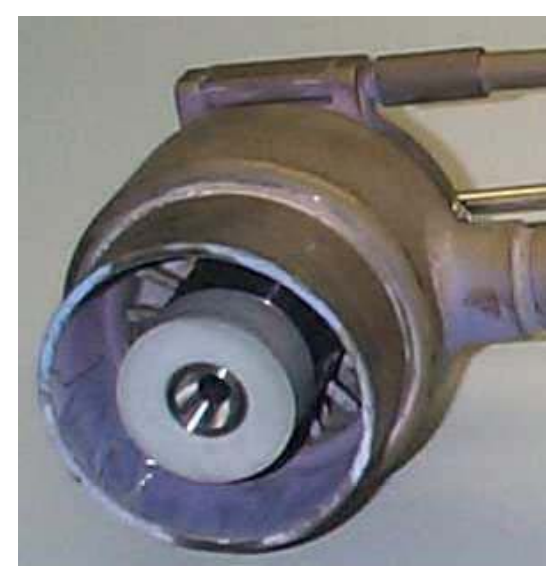

Figure 4.1 Monolithic Silicon Nitride Injector Tip Installed in Centaur 50S Injector

Significant oxidation of the silicon nitride materials, which was experienced in gas turbine nozzle applications (Figure 4.2) in the CSGT Program, indicated the need for an environmental 
barrier coating (EBC) for the injector tip application. The current Si/Mullite/BSAS-based EBC systems that have been successfully used for the $\mathrm{SiC} / \mathrm{SiC}$ combustor liner materials were not adequate, due to the lower thermal expansion of the silicon nitride materials. Solar has continued to follow the developments of EBC systems for silicon nitride materials, however the monolithic ceramic injector tip development activities under the Advanced Materials Program was stopped due to the lack of a suitable coating.

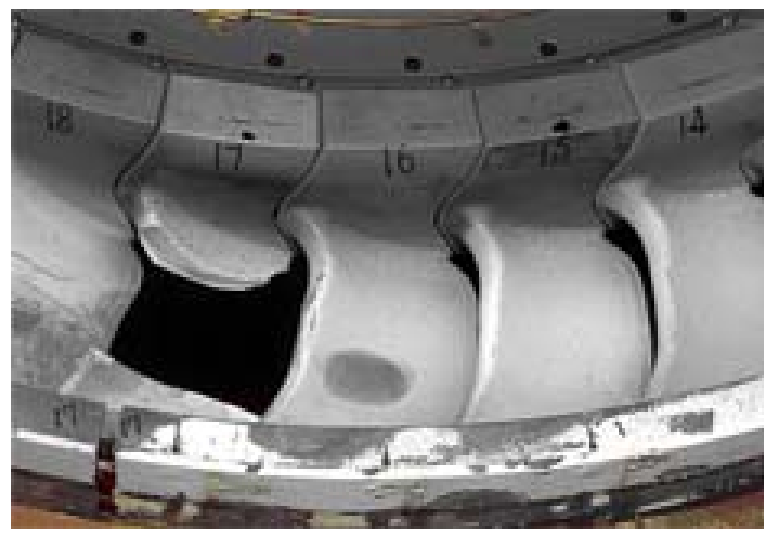

Figure 4.2 Significant Oxidation Experienced on Silicon Nitride Nozzles after only 68 Hours of Engine Testing in Centaur 50S Engine

Injector tip development for this program concentrated on ODS alloys (Subtask 1.2) since a suitable EBC or alternate ceramic material was not identified, and also due to the fact that the injector tip was redesigned (Generation 3) by Solar's Combustion Engineering Department, increasing the overall life of the baseline Haynes 188 injector tips.

\section{Subtask 1.2/1.3: Oxide Dispersion Strengthened (ODS) Alloy Injector Tip and Liner}

ODS alloys were considered for application in the Mercury 50 combustor as a substitute for the currently used TBC-coated Haynes 230 alloy. An ODS alloy may be used for this application, potentially eliminating the need for a TBC. ODS alloys were also considered as a candidate material for replacing metallic injector tips, potentially reducing the cooling requirements for the tips and increasing the durability.

ODS alloys have oxide particles, typically yttria, finely dispersed throughout the material, providing exceptional high temperature strength and creep resistance. The oxide particles are stable and the alloy forms a coherent thin alumina layer for excellent high temperature oxidation and corrosion resistance. Improved fatigue properties can also be obtained at very high temperatures when the grains are oriented along appropriate crystallographic axes. Both Ironbased and Nickel-based alloys were evaluated. Iron-based alloys have a higher-temperature operating range and better oxidation resistance.

Nickel based alloys have better strength and rupture properties at intermediate to high temperature range. Although the ODS alloys have excellent high temperature properties, joining 
is a serious concern with ODS alloys, as the joint strength by conventional welding could be $50 \%$ or lower than the base metal strength.

Three ODS alloys were selected for evaluation - MA 754 and MA 956 made by Special Metals Corporation, and PM 2000 made by Plansee. The composition of these alloys is given in Table 4.1. Brazing trials to join MA 754 ODS alloy to MA 754 or Haynes 230 sheet metal were completed using four different brazing alloys. Based on the metallographic evaluation of the brazed samples, three promising brazing alloys were selected for further evaluation. Preliminary assessment was successfully made to control brazing gap thickness between two sheets. Cross sections of braze joints with lack of fill and a good braze joint showing proper fill are shown in Figure 4.3. This process that obtained proper fill was used to prepare brazed samples for injector tip testing.

Table 4.1 Composition of ODS Alloys Evaluated

\begin{tabular}{|c|c|c|c|c|c|c|c|}
\hline $\begin{array}{c}\text { ODS } \\
\text { Alloy }\end{array}$ & $\begin{array}{c}\text { Base } \\
\text { Metal }\end{array}$ & Cr & Al & Ti & C & Fe & $\mathbf{Y}_{\mathbf{2}} \mathbf{O}_{3}$ \\
\hline MA 754 & Ni- Bal & 20 & 0.3 & 0.5 & 0.05 & 1 & 0.5 \\
\hline MA 956 & Fe- Bal & 20 & 4.5 & 0.5 & 0.05 & -- & 0.5 \\
\hline PM 2000 & Fe- Bal & 19 & 5.5 & 0.5 & -- & -- & 0.5 \\
\hline
\end{tabular}

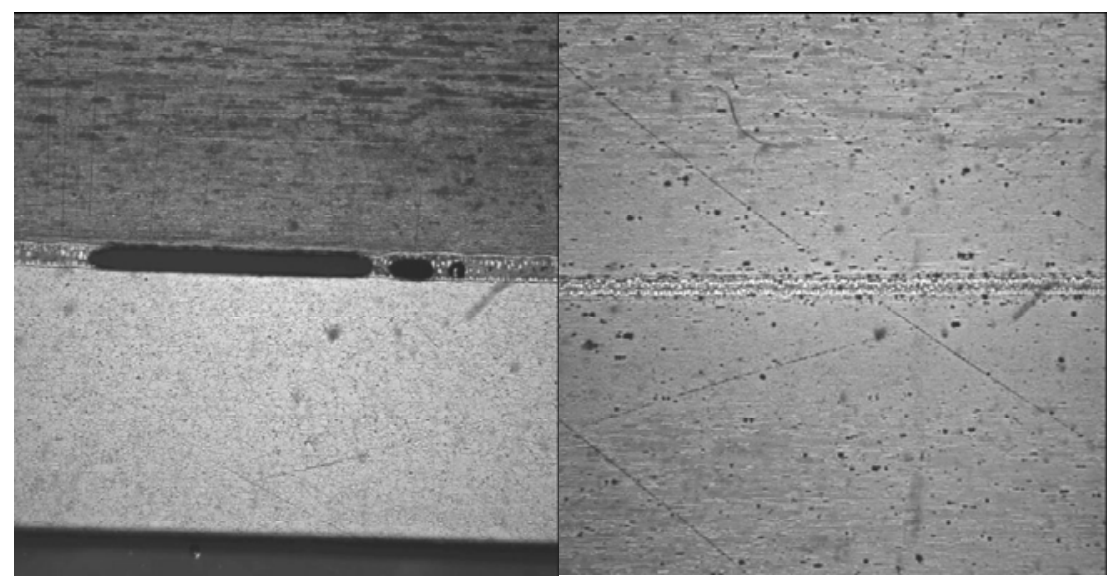

Figure 4.3 Cross Sections of a Braze Joint Showing Lack of Fill (Left) and a Good Braze (Right)

A couple of sheet specimens of MA754 and MA956 were used to evaluate the potential of laser welding as a joining method. Various laser power and speed settings were used. These joints were cross-sectioned for microscopic observation of the joint integrity. The initial laser weld trials showed inconsistent welding of the joints as shown in Figure 4.4. More trials were needed to optimize laser power and speed to obtain suitable joints. However, due to the success with the braze joints, the laser welding was no longer pursued. 


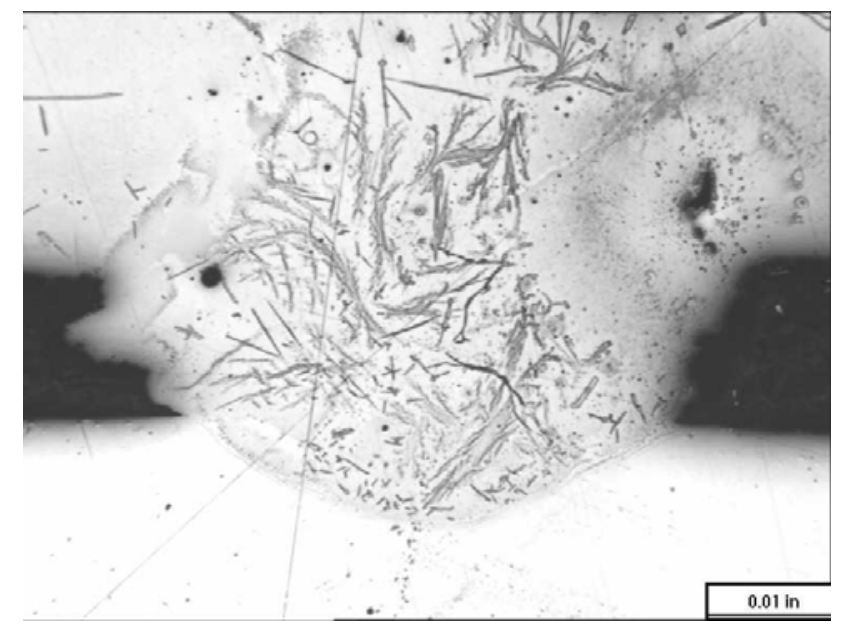

Figure 4.4 Micrograph of Initial Laser Weld Trials Showed Inconsistent Welding of the Joint

After initial evaluation of the ODS alloys, the decision was made to evaluate them for the injector tip application only. The ODS liner application was terminated, in part due to fabrication and joining issues, but primarily because of the success of the advanced TBC development described under Subtask 1.4.

A simplified effusion cap design was created matching the overall dimensions of the Mercury 50 Haynes 188 injector tips. A MA956 tip was fabricated and brazed to the Hastelloy X injector centerbody material using the braze technique that resulted in the proper fill shown in Figure 4.3. The MA956 tip material experienced a crack during machining prior to brazing to the centerbody material (Figure 4.5). Evaluation of the bar stock material used to fabricate the tip revealed that the material did not have the proper microstructure and grain size. The MA956 supplier, Special Metals Inc., found potential material processing problems with the lot of material. A second bar of MA956 alloy was found to have processing issues. Despite the crack, the MA956 tip was successfully brazed to the Hastelloy X injector centerbody material.

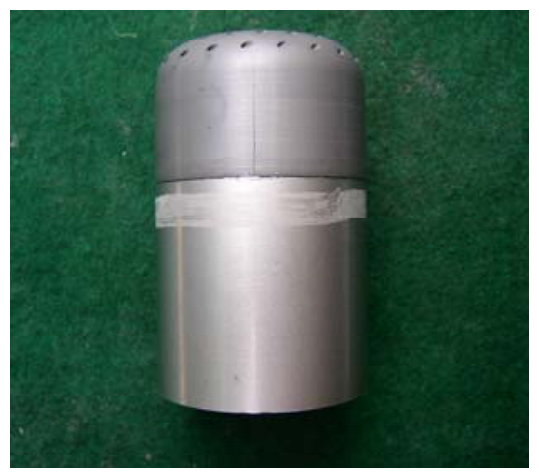

Figure 4.5 MA956 Injector Tip Successfully Brazed to Hastelloy X Centerbody Material 
Full-scale Mercury 50 fuel injector tips were fabricated from two ODS alloys (PM 2000, Ironbased ODS alloy from Plansee Corporation and from MA 754, Nickel-based ODS alloy from Special Metals) for comparison against the current Mercury 50 injector tip material (Haynes 188). Both ODS alloys were successfully brazed to the injector centerbody material as shown in Figure 4.6, with no cracking of the injector tip. The PM 2000 injector tip was assembled in a full scale Mercury 50 injector for cyclic testing in Solar's single injector test facility. A PM 2000 injector tip without cooling holes was also tested in the single injector test facility. Details of the testing are given under Task 2 of the program.

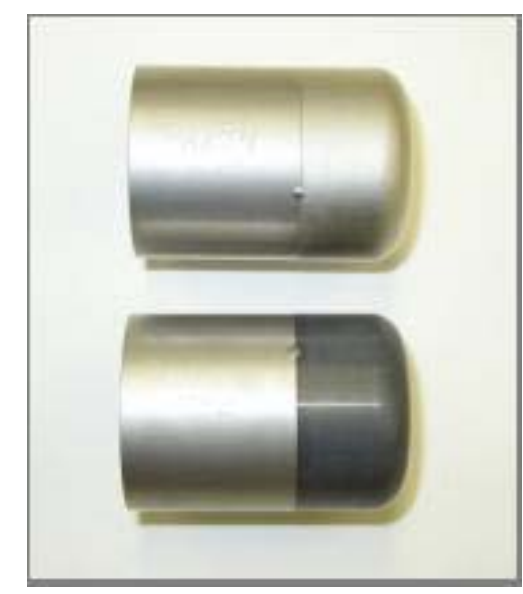

Figure 4.6 MA754 (Top) and PM 2000 (Bottom) Injector Tips Successfully Brazed to Hastelloy X Injector Centerbody Material

\section{Subtask 1.4: Thermal Barrier Coating (TBC) Development}

This task was aimed at increasing the thermal resistance of TBC systems by developing thicker coatings (40 mil thick) and/or coatings with lower thermal conductivity $(0.4-0.5 \mathrm{~W} / \mathrm{mK})$. Efforts included bond coat development, coating application techniques, thermal cycling of test specimens, development of a life prediction model, and examination of nondestructive evaluation techniques.

Numerous high thermal resistance TBC systems from various suppliers (UTRC, UCONN, Praxair and Solar) were evaluated through cyclic furnace testing at 1038,1093 , and $1149^{\circ} \mathrm{C}$ $\left(1900,2000\right.$ and $\left.2100^{\circ} \mathrm{F}\right)$. These systems included thick yttria-stabilized zirconia (YSZ) coatings and coating compositions with lower thermal conductivity. Comparisons of cyclic life, microstructural evaluation, thermal conductivity measurements and life prediction were used to down-select the best coating system for use in the Task 5 - 4000-hour Field Evaluation. The coating systems evaluated isothermal cyclic furnace testing were:

- Various Solar Deposited 40 mil YSZ TBCs

- Praxair 40 mil dense vertically cracked YSZ TBC (Zircoat)

- United Technologies 40 mil YSZ TBC

- United Technologies 20 mil YSZ TBC (low thermal conductivity system)

- UCONN Solution Plasma Sprayed TBC 
- 25 mil Low thermal expansion TBC (UCONN/Solar)

\section{Solar In-house Development}

Various coating systems were deposited at Solar for comparison against the 25 mil yttriastabilized zirconia (YSZ) baseline TBC (Figure 4.7) used in the Mercury 50. In all cases, the bond coat was a MCrAlY material deposited at a thickness of 6-8 mils. The objective was to increase the projected life of the Mercury 50 combustion system to 30,000 hours. The 25 mil TBC was projected to have approximately 18,000 hours life. The various bondcoat/topcoat systems were deposited using a $3 \mathrm{M}$ plasma spray gun, a SG-100 plasma spray gun and a Diamond Jet high-velocity oxy-fuel gun. The result of cyclic testing is detailed below. Representative micrographs of the 40-mil TBCs from Solar as well as Praxair, UTRC, UCONN, and Praxair are shown in Figure 4.8.

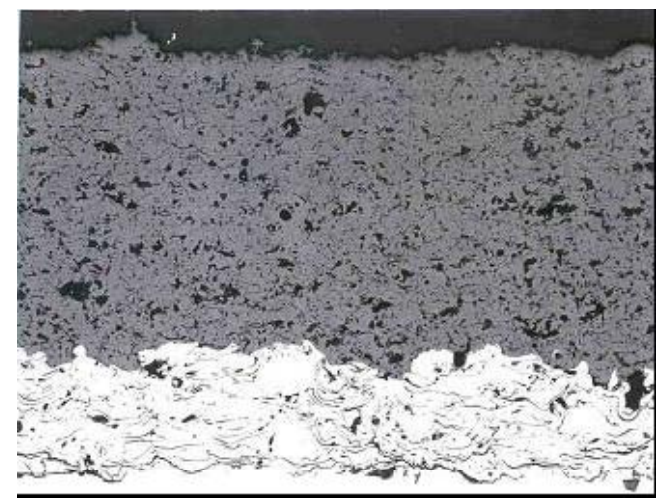

Figure 4.7 Representative Microstructure of Mercury 50 Baseline TBC

3M plasma spray gun: Spraying of 15, 25, 35 and 40 mils thick TBC was completed. Thermal cycling was completed at $2000^{\circ} \mathrm{F}$, with some specimens tested at $1900^{\circ} \mathrm{F}$ and $2100^{\circ} \mathrm{F}$. Results (cycles until failure) on 1-inch round coupons are given below (10-hour cycles). Each value represents one specimen. The 40-mil specimens are designated by letters A through E. The details of these coatings are proprietary to Solar. One ring with OD coating was tested at $2000^{\circ} \mathrm{F}$ for 750 hours (one cycle).

\begin{tabular}{|l|l|l|l|}
\hline \multicolumn{1}{|c|}{ Thickness (mils) } & \multicolumn{1}{|c|}{$\mathbf{1 9 0 0}^{\mathbf{0}} \mathbf{F}$} & \multicolumn{1}{c|}{$\mathbf{2 0 0 0}^{\mathbf{0}} \mathbf{F}$} & \multicolumn{1}{c|}{$\mathbf{2 1 0 0}^{\mathbf{0}} \mathbf{F}$} \\
\hline $\mathbf{1 5}(\mathbf{A r} / \mathbf{H} 2)$ & & 419,419 & \\
\hline $\mathbf{2 5}$ & $>753$ & 350,377 & 108,106 \\
\hline $\mathbf{3 5}$ & & $30,30,100$ & $74 *,>350^{* *}$ \\
\hline $\mathbf{3 5}(\mathbf{N} 2 / \mathbf{H} 2)$ & & $156,156,222$ & \\
\hline $\mathbf{4 0}(\mathbf{A})$ & & 12,20 & \\
\hline $\mathbf{4 0}(\mathbf{B})$ & & 172 & \\
\hline $\mathbf{4 0}(\mathbf{C})$ & & 162 & \\
\hline $\mathbf{4 0}(\mathbf{D})$ & & 220 & \\
\hline $\mathbf{4 0}(\mathbf{E})$ & & 244 & \\
\hline
\end{tabular}

* Coating on OD of a 5" ring 


\section{Coating on ID of a 5" ring. TBC did not fail, but the metal ring deformed and caused the ring to elongate in shape.}

SG-100 gun: Similar TBC systems were deposited using the Praxair SG-100 extension gun with optimized parameters to facilitate the use of robotics on the Mercury 50 liner. Results showed about $25 \%$ life improvement over the $3 \mathrm{M}$ gun. 10-hour cyclic tests were conducted at 1900, 2000 and $2100^{\circ} \mathrm{F}$. Cycles until failure for each specimen are given below:

\begin{tabular}{|l|l|l|l|}
\hline \multicolumn{1}{|c|}{ Thickness (mils) } & \multicolumn{1}{|c|}{$\mathbf{1 9 0 0}^{\mathbf{0}} \mathbf{F}$} & \multicolumn{1}{|c|}{$\mathbf{2 0 0 0}^{\mathbf{0}} \mathbf{F}$} & \multicolumn{1}{c|}{$\mathbf{2 1 0 0}^{\mathbf{}} \mathbf{F}$} \\
\hline 15 & $>753$ & $508,508,508$ & 176,208 \\
\hline 25 & $>753$ & $400,426,466$ & 146,156 \\
\hline 35 & 143 & $20,28,252$ & 2,4 \\
\hline
\end{tabular}

HVOF Bond Coating: A TBC system using a MCrAlY bond coating applied by a high velocity DJ HVOF gun was thermally cycled. Inadequate roughness of the bond coating surface resulted in poor mechanical adhesion with this system. Thermal cycling tests were conducted. The cycles until failure for each specimen are given below. CAT Advanced Materials Technology (AMT) attempted to develop parameters for a HVOF, dense bond coat with a rough surface finish for improved TBC adherence using the JP-5000 high velocity gun, which Solar has purchased. Typical HVOF bond coating surfaces are smooth, yielding poor adherence of the TBC top coat. While CAT was able to achieve bond coat surface roughness close to that of an air plasma sprayed bond coat with the JP-5000 system, the coating integrity was compromised, yielding a poor coating microstructure.

\begin{tabular}{|l|l|l|}
\hline \multicolumn{1}{|c|}{ Thickness (mils) } & \multicolumn{1}{|c|}{$\mathbf{2 0 0 0}^{\mathbf{}} \mathbf{F}$} & $\mathbf{2 1 0 0}^{\mathbf{}} \mathbf{F}$ \\
\hline 20 & $24,38,38$ & 6,6 \\
\hline 36 & $12,12,12$ & 4,4 \\
\hline
\end{tabular}

Praxair: Specimens with 20,40, and 80 mils dense/microcracked TBCs were procured from Praxair using Solar's bond coating chemistry. The coupons were thermal cycled every 10 hours. The number of cycles until failure for each specimen is given below:

\begin{tabular}{|l|l|l|l|}
\hline Thickness (mils) & \multicolumn{1}{|c|}{$\mathbf{1 9 0 0}^{\mathbf{O}} \mathbf{F}$} & \multicolumn{1}{|c|}{$\mathbf{2 0 0 0}^{\mathbf{}} \mathbf{F}$} & \multicolumn{1}{|c|}{$\mathbf{2 1 0 0}^{\mathbf{}} \mathbf{F}$} \\
\hline 20 & - & $108,112,132$ & 62,64 \\
\hline 40 & 418 & $104,106,112$ & 54,56 \\
\hline 80 & $>406$ & $86,102,124$ & 54,62 \\
\hline
\end{tabular}

Further testing at 1900 and $2000^{\circ} \mathrm{F}$ for 100 -hour cycles were conducted on all specimens. The following table summarizes the results.

\begin{tabular}{|l|l|l|}
\hline Thickness (mils) & \multicolumn{1}{|c|}{$\mathbf{1 9 0 0}^{\mathbf{0}} \mathbf{F}$} & \multicolumn{1}{c|}{$\mathbf{2 0 0 0}^{\mathbf{0}} \mathbf{F}$} \\
\hline 20 & $>34$ & 31 \\
\hline 40 & 25 & $>34$ \\
\hline 80 & $>34$ & 31 \\
\hline
\end{tabular}

UTRC/PWA: A program was initiated to evaluate two production plasma sprayed TBC systems. Both systems use HVOF bond coatings and YSZ plasma sprayed ceramic top coatings at 20 (more porous and lower thermal conductivity) and 40 mils (standard TBC). 20 coupons were 
delivered to Solar in November 2001. Thermal cycling testing was conducted, and the initial results (cycles until failure) are shown below.

\begin{tabular}{|l|l|l|l|}
\hline Thickness (mils) & $\mathbf{1 9 0 0}^{\mathbf{0}}$ F/10-hour & $\mathbf{2 0 0 0}^{\mathbf{0}}$ F/100-hour & $\mathbf{2 1 0 0}^{\mathbf{}}$ F/10-hour \\
\hline 20 & $>62$ & 2 & 12 \\
\hline 40 & $>62$ & 2 & 12 \\
\hline
\end{tabular}

UCONN: Two approaches to high thermal resistance TBC were investigated. A Solution Precursor Plasma Spray (SPPS) nano-structured TBC for improved durability and a low thermal conductivity ceramic material (gadolinium zirconate).

UCONN submitted coupons (containing Solar's bond coat) with a nano-structured YSZ TBC via Solution Plasma Spraying at thicknesses of 25, 40 and 80 mils. The objective of the coating is to provide enhanced durability and thermal insulation. These coupons were subjected to the same cyclic testing as the other TBC systems for comparison. While initial testing at UCONN appeared very promising for 15 mil thick coatings, the coatings did not perform as well in the Solar exposures at $2100^{\circ} \mathrm{F}$, particular compared to Solar's best performing coatings. Evaluation revealed differences in the bond coat surface roughness (smoother than the earlier specimens), which is believed to have resulted in the reduction in cycle life.

UCONN provided $13 \mathrm{lbs}$ of plasma spray grade gadolinium-modified zirconia, which has lower thermal conductivity than yttria-stabilized zirconia. UCONN down-selected this composition based on work conducted under an AGTSR program. Solar applied the coatings in house and conducted cyclic testing at 1900,2000 and $2100^{\circ} \mathrm{F}$. Solar's initial spray trials yielded an excellent TBC microstructure, however the gadolinium-modified zirconia coatings performed poorly in thermal cycling, surviving only 2 cycles at each temperature. Representative micrographs of the 40 mil TBCs from Solar, Praxair, UTRC, UCONN, and Praxair is given in Figure 4.8.
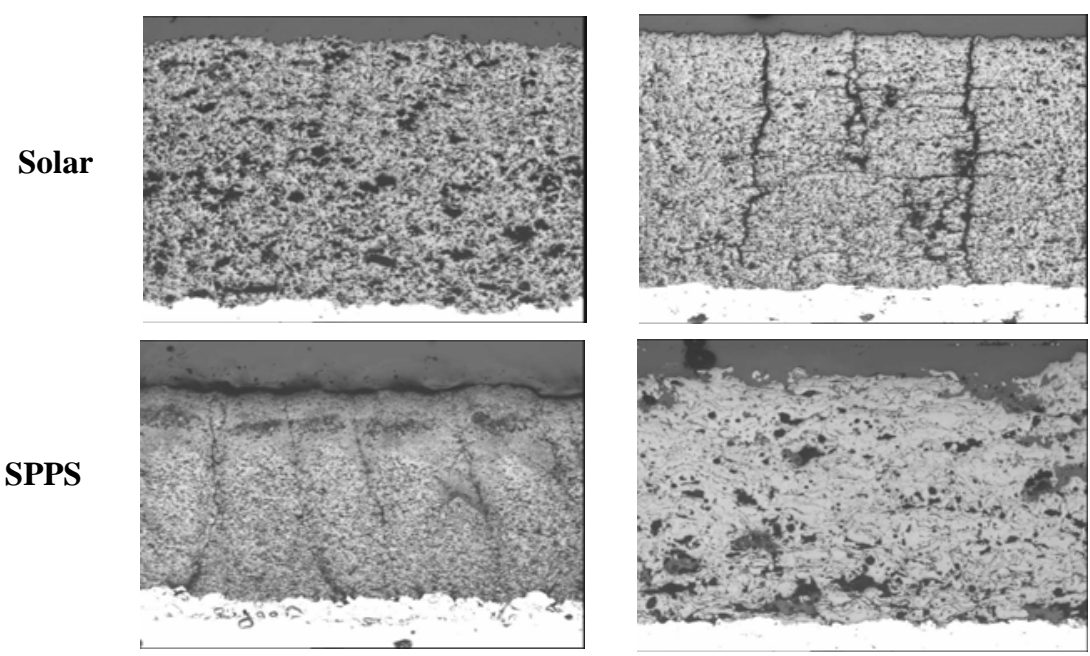

Zircoat

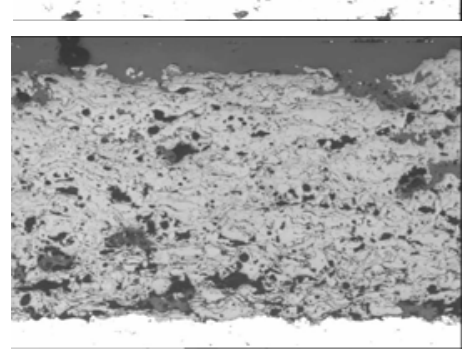

UTRC

Figure 4.8 Representative Microstructures of 40-mil Thick TBC Systems from Solar, Praxair (Zircoat), UCONN (SPPS), and UTRC 
Thermal Conductivity Measurements: Thermal conductivity measurements for Solar's in-house 40 mil advanced TBC tested at various furnace temperatures and durations were completed at Oak Ridge National Laboratory under its support contract for the DOE Advanced Materials programs. Measurements were made for TBC specimens, which were aged at various temperatures for exposure times of up to 5000 hours. Plots of thermal conductivity versus time and aging temperatures have been received from ORNL (Figure 4.9). They have helped quantify the change in the thermal conductivity during exposure and predict the life of the TBC in service.

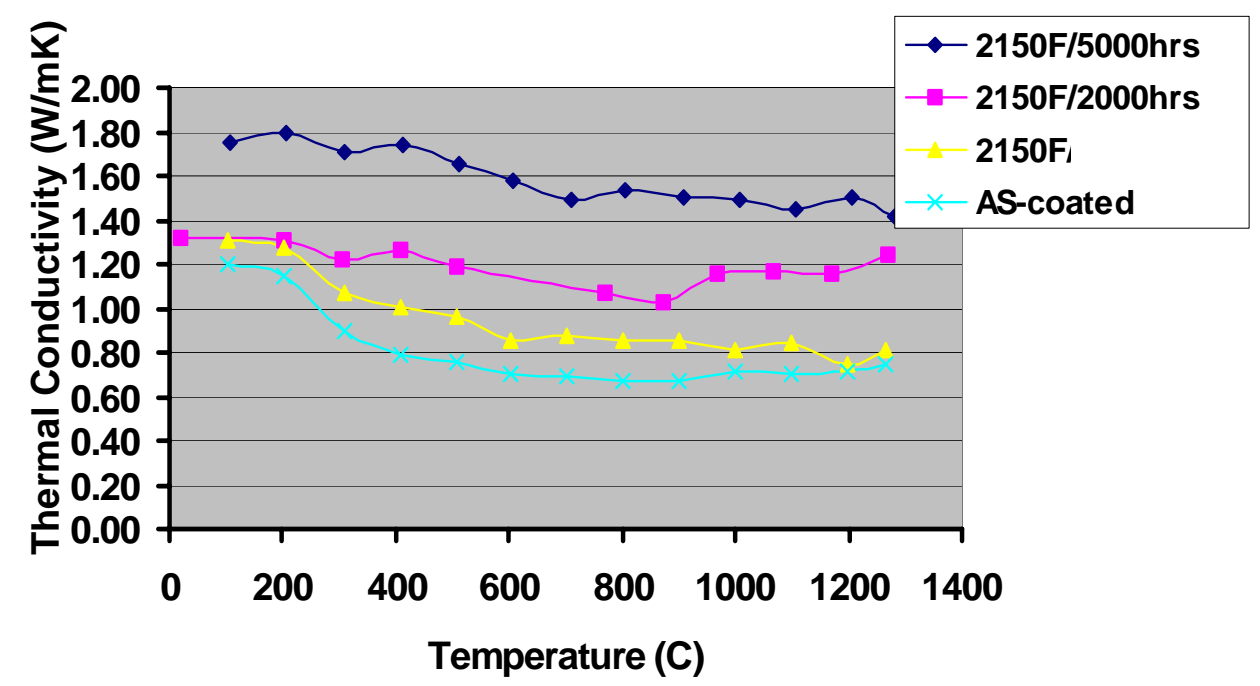

Figure 4.9 Thermal Conductivity for Solar's Advanced 40-mil TBC System after Aging at Various Temperatures for Exposure Times up to 5000 Hours

RAI Life Prediction: A program was initiated with Research Applications Inc. (RAI) to modify their T-CLIP life prediction model to accommodate Mercury 50 materials and design data. The model also considered the effects of ID and OD on TBC life as well as coating thickness and cycle time. Figures $4.10-4.12$ show the life prediction compared to measured values for cyclic testing at 1900,2000 and $2100^{\circ} \mathrm{F}$ for TBC thicknesses of 15,25 and 35 mils, respectively. The life prediction model agreed very well with the measured data for the 15 and 25 mil thick TBCs, however the 35 mil life prediction date did not agree. RAI concluded that the failure mechanism for the thicker TBC is obviously different, and that further evaluation would be required to establish this mechanism and further refine the model for thicker ( $>25$ mil) TBCs. 


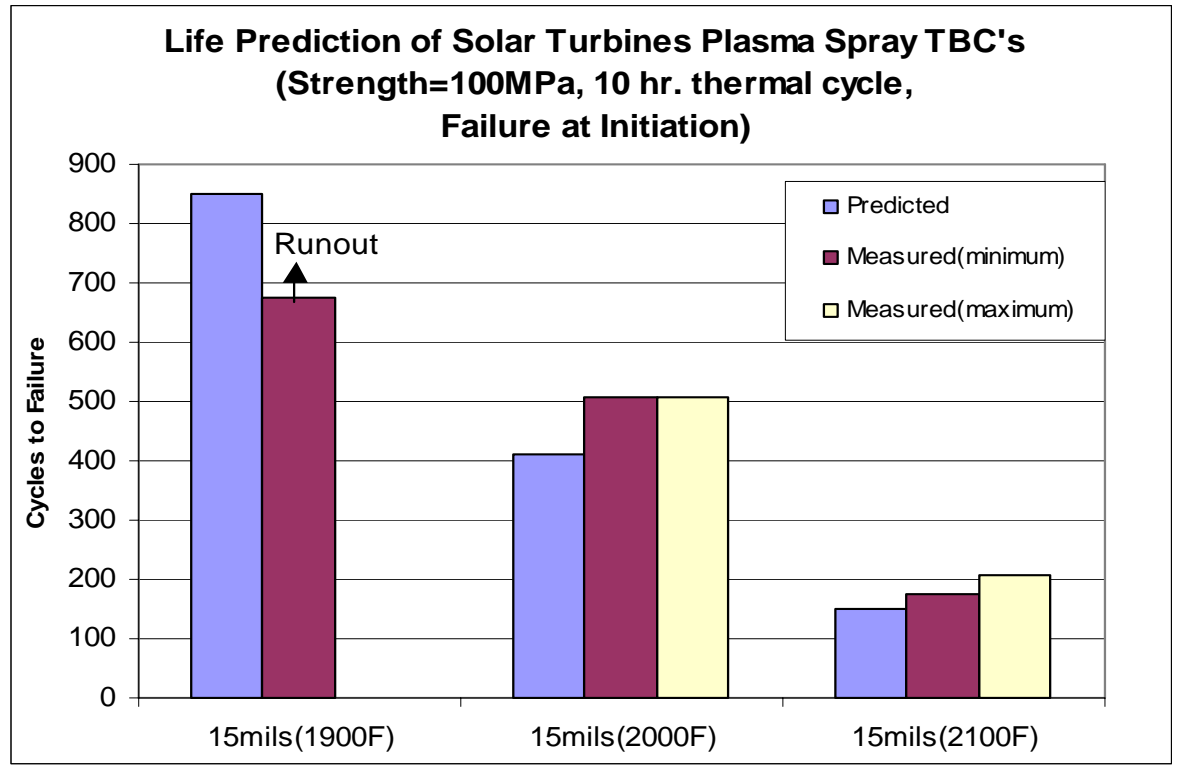

Figure 4.10 RAI Life Prediction Model Compared to Measured Data for Solar 15-mil TBC at 1900,2000 and $2100^{\circ} \mathrm{F}$

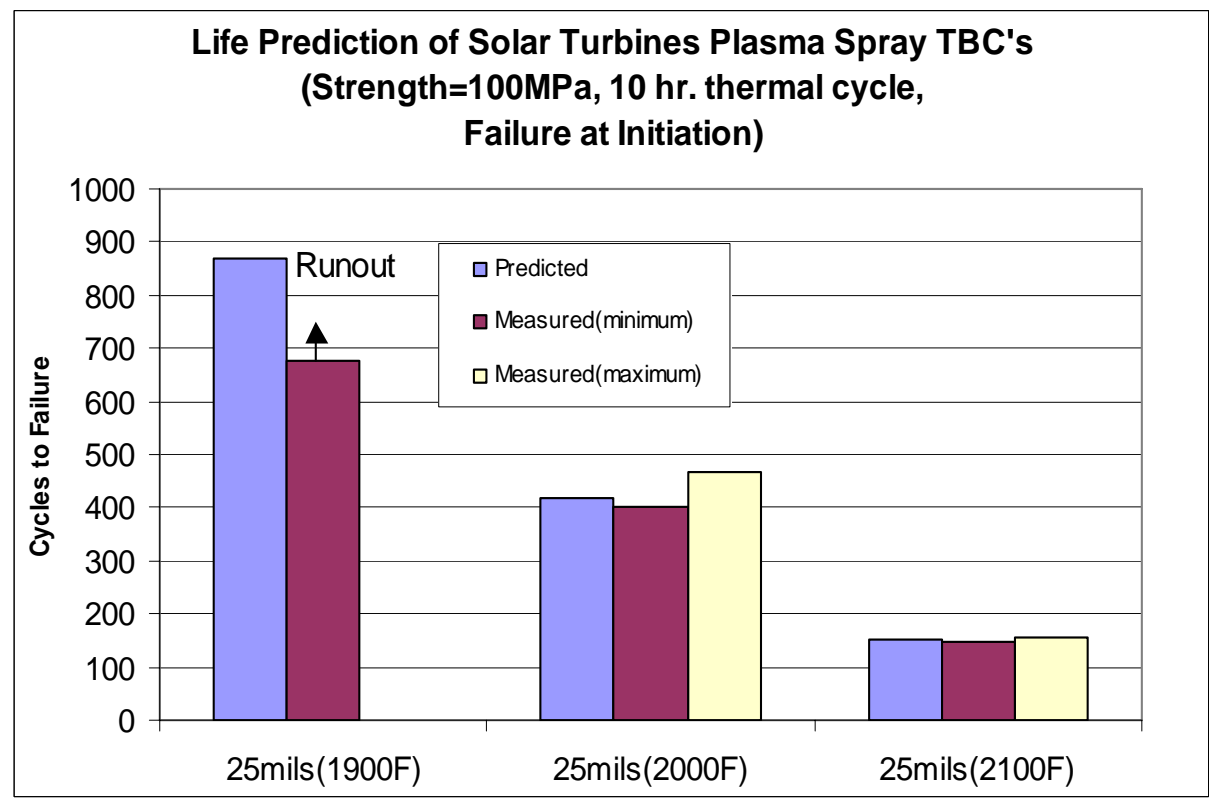

Figure 4.11 RAI Life Prediction Model Compared to Measured Data for Solar 25-mil TBC at 1900, 2000 and $2100^{\circ} \mathrm{F}$ 


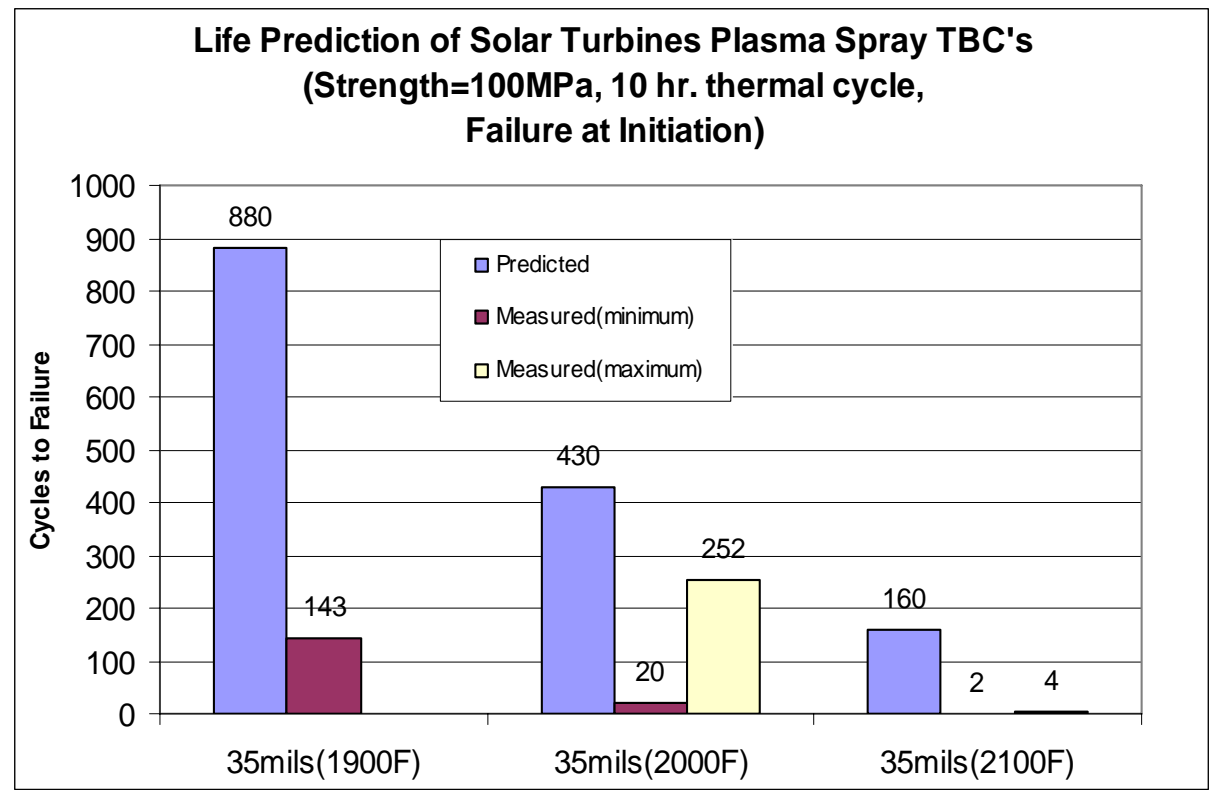

Figure 4.12 RAI Life Prediction Model Compared to Measured Data for Solar 35-mil TBC at 1900, 2000 and $2100^{\circ} \mathrm{F}$

TBC Selection for Field Demonstration: Solar selected the internally developed advanced 40 mil yttria-stabilized zirconia TBC for further evaluation under the program. This system performed superior to all other systems tested and has surpassed the cyclic life $\left(205\right.$ cycles at $\left.2100^{\circ} \mathrm{F}\right)$ of the baseline $25 \mathrm{mil}$ TBC system $\left(107\right.$ cycles at $\left.2100^{\circ} \mathrm{F}\right)$ currently used for the Mercury 50 combustor. Table 4.2 summarizes the results of the various $\mathrm{TBC}$ systems evaluated at $2000^{\circ} \mathrm{F}$. Thermal cycling was completed at $2000^{\circ} \mathrm{F}$ with 560 cycles for the Solar advanced 40 mil TBC. The baseline 25 mil TBC failed after 364 cycles at $2000^{\circ} \mathrm{F}$.

Based on the cyclic testing results at 1900,2000 and $2100^{\circ} \mathrm{F}$ for various $\mathrm{TBC}$ thickness, Solar and RAI established the life prediction curves shown in Figure 4.13 for Solar's baseline TBC and the 40 mil advanced TBC that was selected for field testing under the program. As can be seen in Figure 4.13, the predicted life of the advanced 40-mil TBC is significantly better than that of the baseline 25 mil TBC. None of the other coating systems achieved cyclic results equal to or better than the current baseline system. Based on results of thermal cyclic testing and thermal conductivity measurements with time and temperature, the coating life is predicted to exceed 30,000 hours, which is Solar's typical time between overhauls. A 30,000-hour goal was therefore adopted to replace the initial 20,000-hour program goal. The advanced 40-mil TBC system was applied to the full-scale Mercury 50 liner, which was used in the 4000+ hour field demonstration at Qualcomm Inc. in San Diego, under Task 5 of the program. 
Table 4.2 Comparison of TBC Systems Cyclic Testing Results at $2000^{\circ} \mathrm{F}$

\begin{tabular}{|l|l|c|l|}
\hline \multicolumn{1}{|c|}{$\begin{array}{c}\text { COATING } \\
\text { SUPPLIER }\end{array}$} & \multicolumn{1}{|c|}{ COATING } & $\begin{array}{c}\text { RESULTS OF FURNACE } \\
\text { TEST @ 2000 }\end{array}$ F/10 HRS & \multicolumn{1}{|c|}{ MICROSTRUCTURE } \\
\hline UTRC & UTRC-40 & 40 & Dense \\
\hline PRAXAIR & Zircoat & 107 & Dense with Vertical Cracks \\
\hline UCONN & SPPS-40 & 228 & Vertical Cracks \\
\hline SOLAR & $\begin{array}{l}\text { TBC }- \text { Baseline } \\
25 \text { mil thick }\end{array}$ & 364 & Standard \\
\hline $\begin{array}{l}\text { SOLAR } \\
\text { ADVANCED }\end{array}$ & $\begin{array}{l}\text { TBC Advanced } \\
40 \text { mil selection }\end{array}$ & 560 & Porous \\
\hline
\end{tabular}

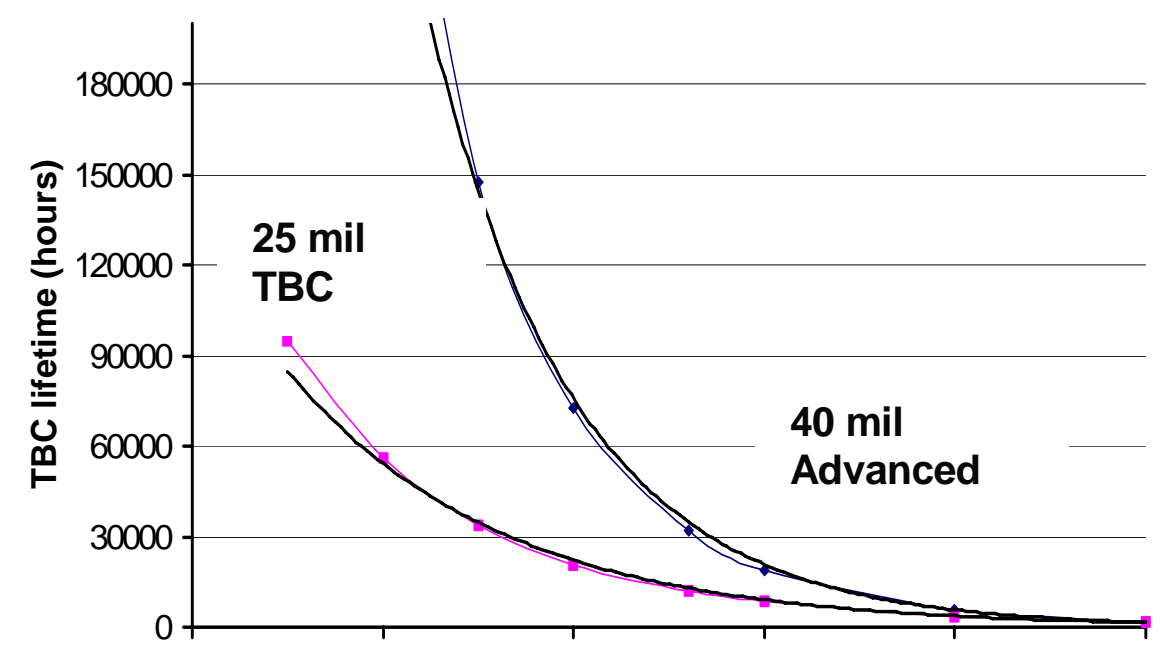

TBC/bond coat interface temperature $\left({ }^{\circ} \mathrm{F}\right)$

Figure 4.13 Comparison of Predicted TBC Life For Baseline (25 mil) and Advanced (40 mil) TBC Systems

\section{Subtask 1.5: Continuous Fiber Ceramic Composite Development}

A CFCC liner attachment design for a Mercury $50 \mathrm{SiC} / \mathrm{SiC}$ inner combustor liner was completed with the support of the Agilis Group, Inc. The CFCC material used for this effort was Hi-Nicalon $\mathrm{SiC} / \mathrm{SiC}$ fabricated by melt infiltration. Agilis had previous experience with the Mercury 50 combustion system and had some prior experience designing for ceramic and composite materials. Several attachment concepts aimed at minimizing the mechanical loads experienced by the CFCC while reducing or eliminating leakage at the $\mathrm{CFCC} /$ metal attachment were examined. Minimizing the leakage was critical for achieving single digit gas turbine emissions. Figure 4.14 shows the assembly layout side view of the Mercury 50 combustor with the inner 
CFCC liner. Figure 4.15 shows a high level view of the inner liner attachment design concept. Agilis completed the conceptual design, 3-D modeling and finalized the stress analysis (Figure 4.16) and the final detailed attachment design for the Mercury 50 CFCC inner liner. Details of the actual attachment concepts and complete mechanical and thermal analysis are proprietary to Solar and not included in the report.

Due to the success of the thermal barrier coatings, the continued durability testing of CFCC liners in the Centaur 50 under Task 1A, and the necessity to down-select for the 4000-hour field demonstration, the decision was made to terminate the evaluation of the CFCC inner liner for the Mercury 50 under this program.

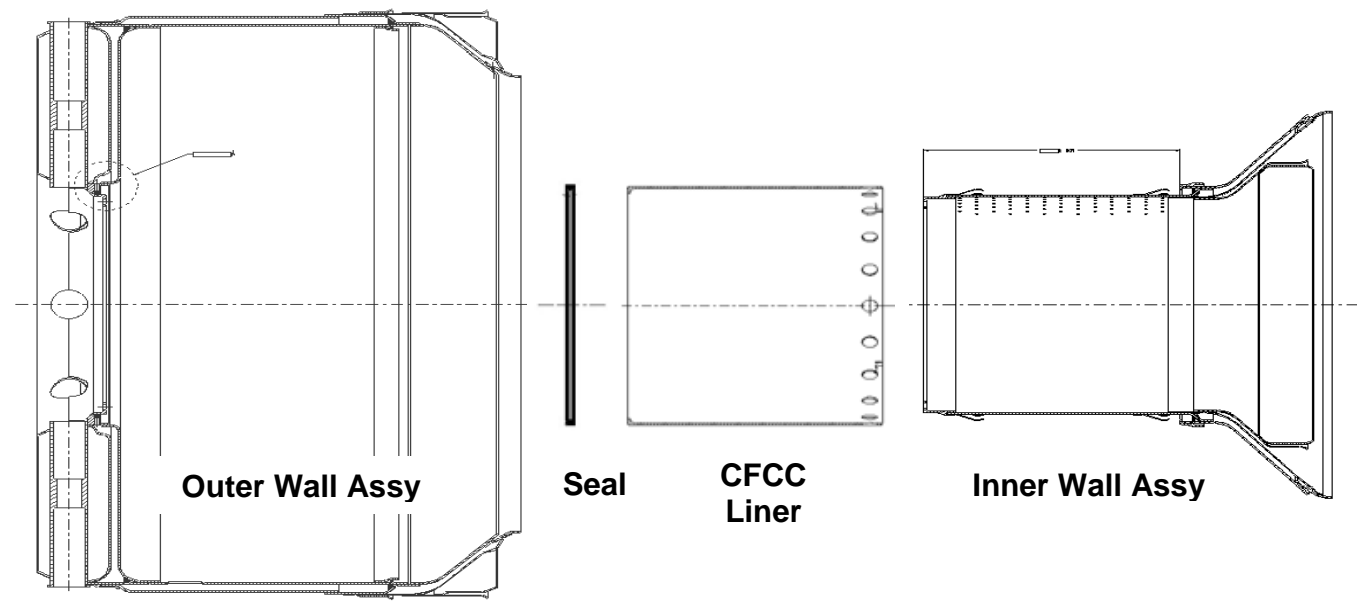

4.14 Assembly Layout Side View of Mercury 50 Combustor with the Inner CFCC Liner

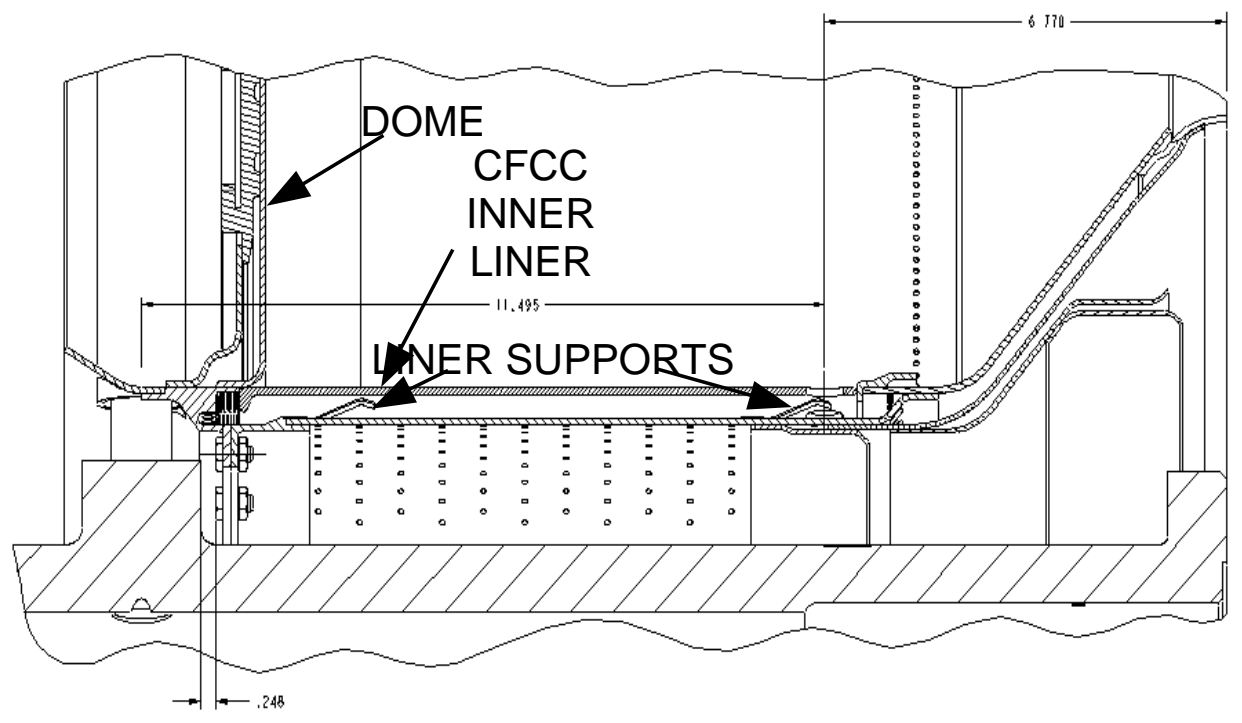

Figure 4.15 High-Level View of the Inner Liner Attachment Concept 


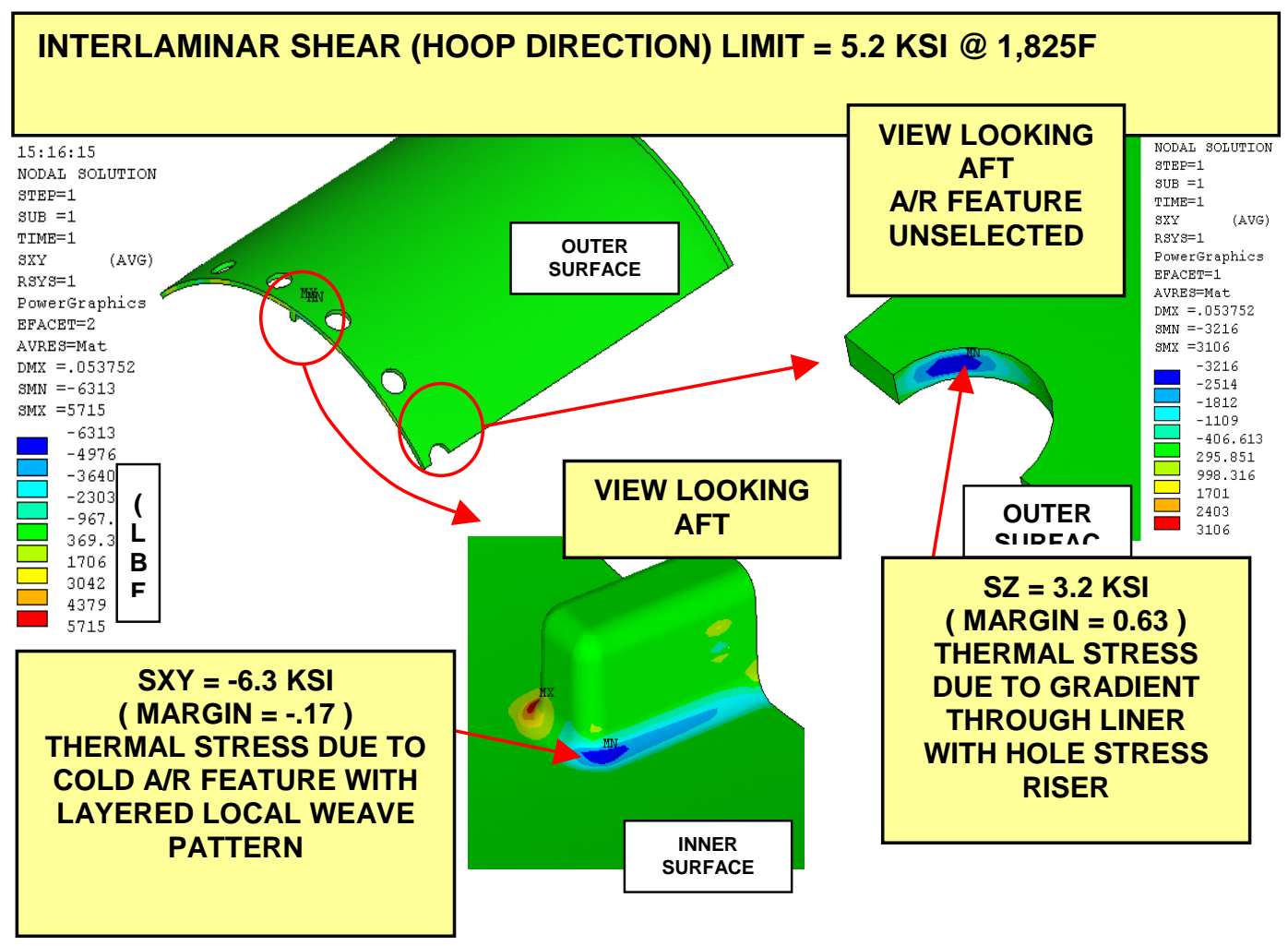

Figure 4.16 CFCC Liner Structural Analysis - Stress Results

\section{Subtask 1.6: Topical Report for Subtask A}

This subtask involves conducting a market study for the defining the market potential for the Mercury 50 gas turbine engine based on the advanced materials technology improvements for Mercury 50 combustion system. This study compared improved advanced industrial gas turbine system with existing installations for retrofit and replacement opportunities. The study considered completed distribution and combined heat and power applications, with emphasis (but not limited to) industries of the future.

Onsite Energy Corporation, under subcontract to the Advanced Materials program, submitted the "Market Impact Assessment for Mercury Advanced Materials Program" September 4, 2001. Following review at Solar, the detailed report (Report No. SR01-R-6187-03) was submitted to DOE.

\subsection{Task 2 - Advanced Material System Optimization and Sub-scale Testing}


This task involved subscale testing of advanced materials technologies down selected from Task 1. Testing primarily involved sub-scale single injector rig testing, including TBC cyclic performance and evaluation of attachment concepts for ODS injector tips.

\section{Subtask 2.1: Higher Resistivity TBC Applied to Liner}

Subscale Haynes 230 combustor liners were fabricated for evaluation of improved thermal resistance TBC systems. Subscale liners were coated, instrumented and painted with temperature sensitive paint in preparation for testing (Figure 4.17). The effectiveness of the advanced TBC system at reducing the metallic liner wall temperature was measured during the sub-scale combustion testing. The liners had an uncoated section, a section coated with the baseline TBC, and a section with the advanced 40 mil TBC for comparison of the temperature reduction achieved by each coating system as illustrated in Figure 4.18.

Rig testing of the coated sub-scale liner ( 8 inch diameter $\mathrm{x} 12$ inch long) was completed in Solar's single injector rig (Figure 4.19), with the optimized 0.040 inch TBC with heat treatment, which was down-selected for field evaluation testing, performing the best. The liner was tested at engine operating conditions for 50 hours with 6 start cycles. The rig testing of the coated subscale liners was used to verify temperature reductions for the combustor liner with 25 and 40 mil thick advanced TBC systems. The temperature for the 40 mil advanced TBC was $50-70^{\circ} \mathrm{F}$ cooler that for the 25 mil baseline TBC. These tests helped confirm the down-selection to the 40 mil advanced TBC system for the 4000-hour field demonstration.

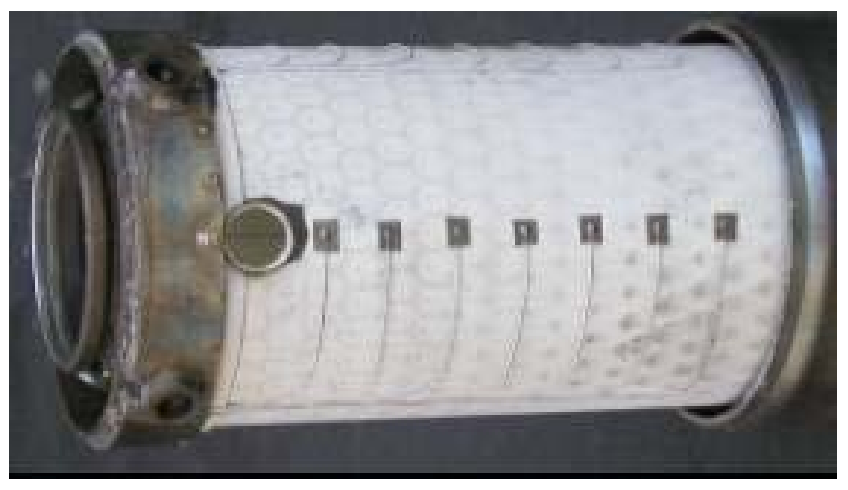

Figure 4.17 Subscale Combustor Liner with Thermal Paint and Instrumentation

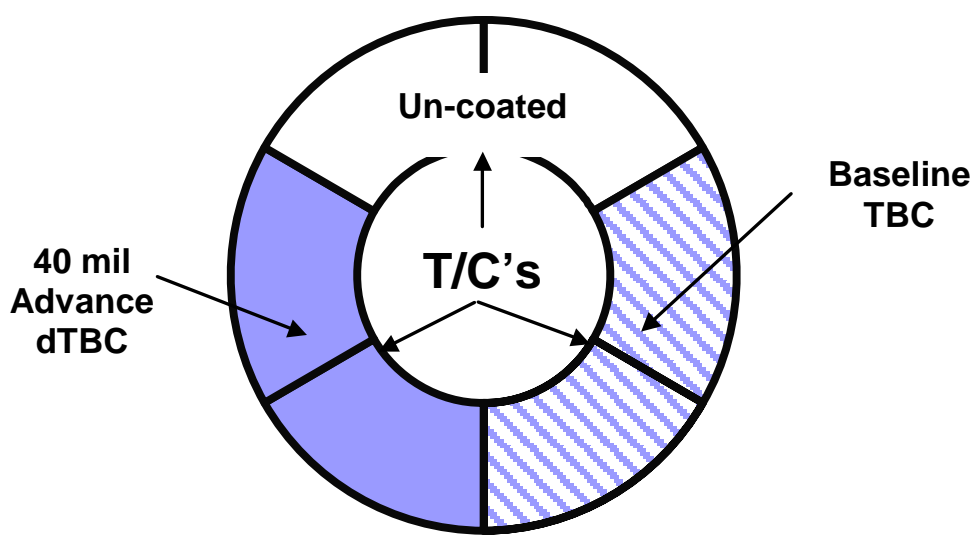

Figure 4.18 Illustration of Areas with TBC Applied to Subscale Liners 


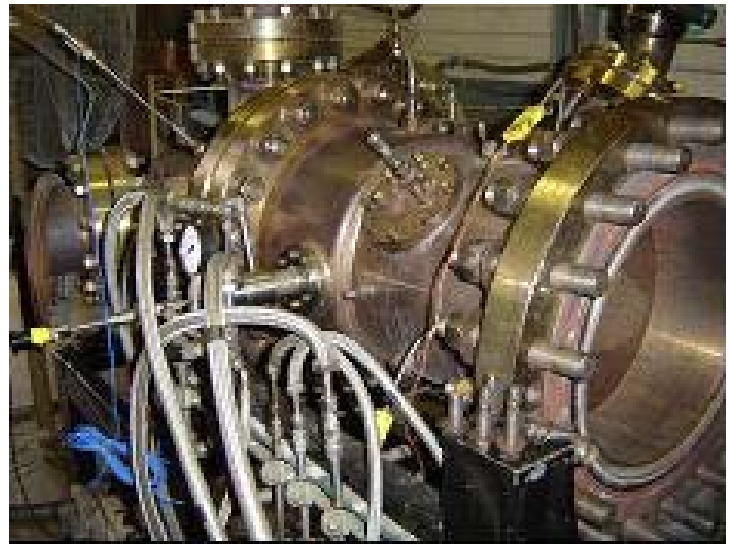

Figure 4.19 Single Injector Rig Used to Test Subscale Liners with TBC

\section{Subtask 2.2: ODS Alloy Injector Tip}

Single injector rig testing of full-scale M50 fuel injector tips made of PM 2000 ODS alloy (Ironbased ODS alloy from Plansee Corporation) under Program Subtask 1.2 was conducted for comparison against the current Mercury 50 injector tip material (Haynes 188). Two configurations were tested. The first was identical to the current production Mercury 50 fuel injector with no change to the tip cooling. The ODS injector tips were successfully brazed to the injector centerbody material. The PM 2000 injector tip was assembled in a full scale Mercury 50 injector as shown in Figure 4.20. The injector was flow tested prior to the testing. Solar's single injector, high-pressure facilities (Figure 4.21) were used to evaluate the performance of the ODS tip injector. Emissions mapping was done over several operating conditions to generate a NOx vs. $\mathrm{T}_{\mathrm{PZ}}$ (primary zone temperature) curve for comparison to the M50 production baseline. Total test time was 50 hours, with 8 starts. Test results show that NOx emissions were about the same with levels in the 2 ppmv range. Tip temperatures were not measured but are not expected to be any different than those of the production M50 tip since the cooling remained the same.

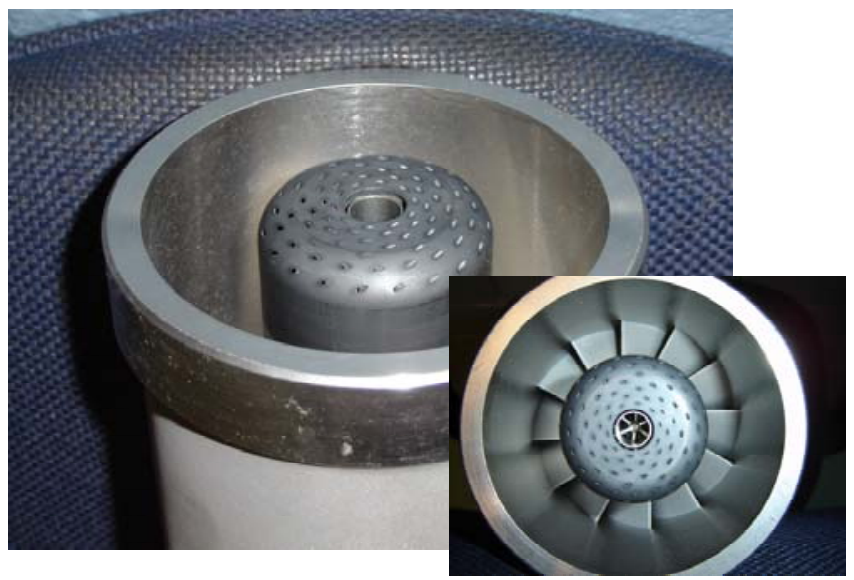

Figure 4.20 Full-Scale Mercury 50 Fuel Injector with PM 2000 ODS Alloy Tip 

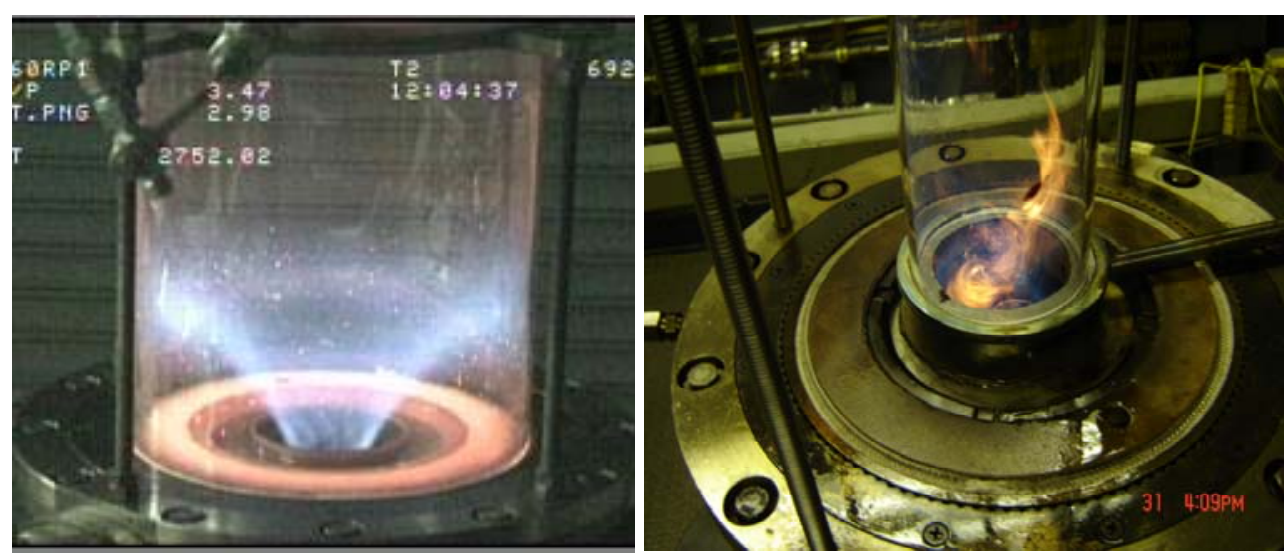

Figure 4.21 Single Injector, High-Pressure Rig Testing of ODS Injector Tips

The second configuration tested was a PM 2000 tip fabricated with no cooling holes as shown in Figure 4.22. The no-cooling configuration was to be compared to both the production baseline M50 and PM2000 M50 fuel injectors to try and identify any emissions performance enhancements. The single injector, high pressure facility was again used to evaluate the performance of the uncooled ODS tip injector. The no-cooling hole configuration did not perform well (Figure 4.23), due to the excessive temperature experienced on the tip. The cooling air actually pushes the flame away from the surface of the injector tip, resulting in significantly lower tip temperature. With no cooling, the flame rested on the surface of the tip resulting in burn-through of the material.

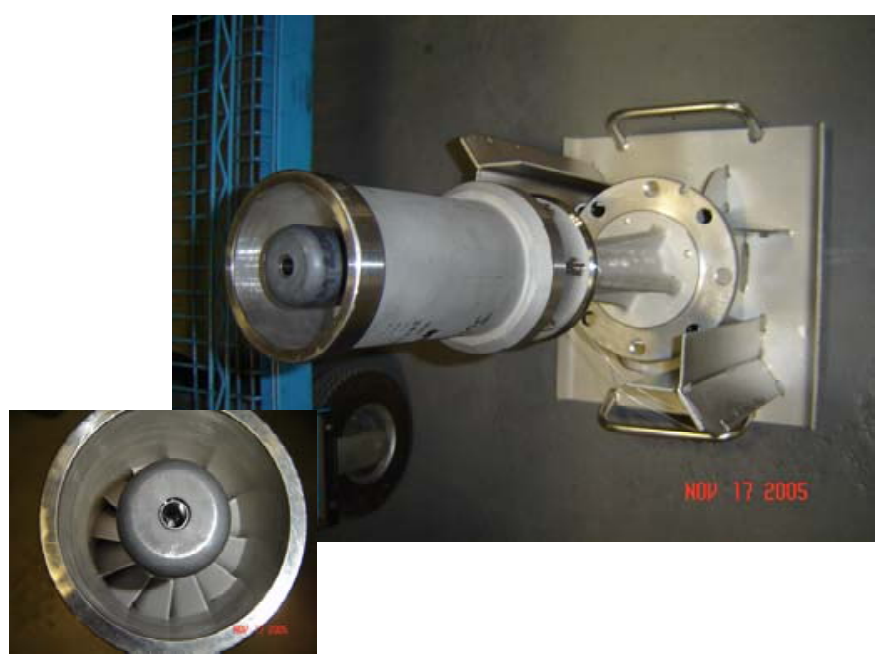

Figure 4.22 Full-Scale PM 2000 ODS Alloy Injector Tip with No Cooling Holes 


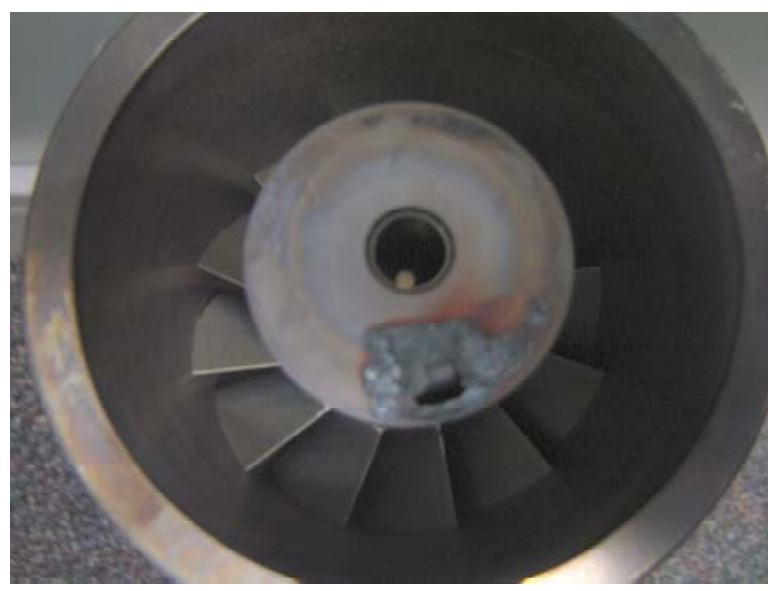

Figure 4.23 PM 2000 ODS Injector Tip with No Cooling Following Test

While the cooled ODS alloy injector tip testing appeared promising, the ODS injector tip development on this program was terminated, primarily due to the fact that the Mercury 50 injector tip was redesigned (Generation 3) by Combustion Engineering, which increased the overall life of the baseline Haynes 188 injector tips to 30,000 hours, minimizing the need to pursue a more expensive material.

\subsection{Task 3 - Modify Gas Turbine to Accept New System}

This task involved modifying the Mercury 50 unit to accept the new advanced material technology. Minimal engine adaptations were required (only additional instrumentation) for the field demonstration of the advanced thermal barrier coatings systems. No changes in control logistics or operating procedures were required.

\section{Subtask 3.1: Topical Report for Subtask B}

Subtask B Topical Report, the commercialization plan with the primary objective of commercial implementation of an efficient, clean and cost effective advanced material system incorporated in an advanced industrial turbine, was required under Task 3 of the program. This report, "Commercialization Plan for Advanced Materials for Mercury 50 Gas Turbine Combustion System Program" was submitted to DOE September 15, 2003. This document was marked "Proprietary, Company Sensitive Data of Solar Turbines Incorporated" and therefore will not be discussed in this report.

\subsection{Task 4 - System Fabrication and Proof Test}

Two engine tests were conducted prior to acceptance for the field endurance testing.

The first test was a cyclic test of the 40 mil advanced TBC on the combustor liners and dome. A full-scale Mercury 50 combustor (inner liner, outer liner and dome) was coated with the Solar 40 mil advanced TBC (Figure 4.24) developed and tested under Task 1 and 2 of the program. The 
liner was installed in a Mercury 50 development engine and installed in a test cell at Solar's Kearny Mesa facility. The engine ran for 200 hours with 60 shutdown cycles. Following engine exposure the TBC remained in excellent condition, with no signs of chipping or spalling. This short term test with 60 thermal cycles contributed greatly to the decision to incorporate the advanced TBC into the Mercury 50 engine.

The second test was a short thermal paint test to verify the temperature reduction experienced with the advanced TBC. The Solar advanced TBC developed under Task 1 of the program was applied to a developmental full scale Mercury 50 combustor (dome and liners). Instrumentation and thermal paint were applied to the backside of the metallic components. The combustor was tested in the Mercury 50 engine to evaluate the effectiveness of the TBC in actual operating conditions. The temperatures encountered on the backside of the dome and liners (inner and outer) were very encouraging. The predicted life of the TBC and combustor exceed the 30,000hour goal of the program. Based on these results, a full-scale combustor was coated for the 4000 field demonstration under Program Task 5, Commercial Demonstration.

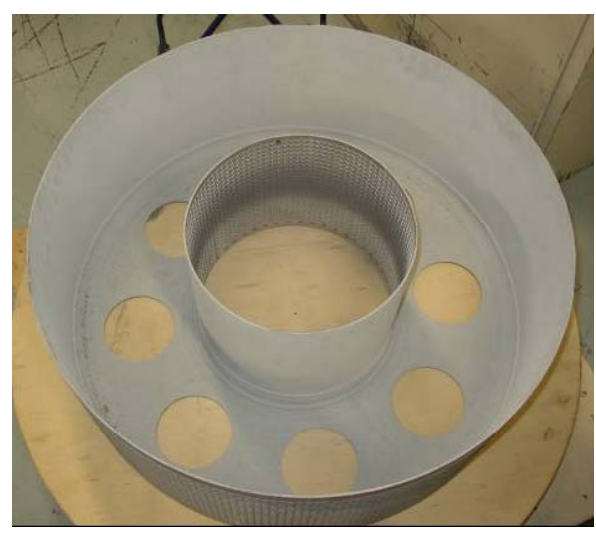

Figure 4.24 Full-scale Mercury 50 Combustor (Inner Liner, Outer Liner and Dome) Coated with Solar Advanced 40-mil TBC for Development Engine Testing

\subsection{Task 5: Commercial Demonstration}

This task involved a 4000-hour (minimum) field demonstration of the advanced materials technologies down-selected under this program. Based on the results of the furnace testing in Task 1, the rig testing in Task 2, and the full-scale engine test in Task 4, the advanced 40-mil thick TBC was applied to a full-scale combustor for the 4000-hour field demonstration at Qualcomm Incorporated in San Diego, CA. The fuel injector for the field demonstration utilized the redesigned Haynes 188 injector tips, which are expected to achieve 30,000 hours life. The engine was commissioned and will begin commercial operation in August 2006.

The combustor was inspected by borescope on January 6, 2007, after accruing 4360 hours of commercial operation with 85 starts. Figure 4.25 shows images from the borescope inspection. The advanced 40-mil TBC appeared in excellent condition with no cracking or spalling of the TBC. The program goal of 4000+ hours had been achieved, however Solar's goal is 30,000 hours, which is Solar's typical time before overhaul. Therefore the combustor was allowed to remain at Qualcomm for continued commercial operation. Solar continued to monitor the status 
of the TBC through periodic borescope inspections. In December 2008, the engine was returned to Solar for overall engine inspection after 20,000 hours of commercial operation. The combustor was removed and photographically documented, as shown in Figure 4.26. The advanced 40 mil TBC still remained in excellent condition, with no signs of cracking or spalling. The combustor was reassembled into the engine and returned to Qualcomm Inc. for continued operation. The advanced 40 mil TBC system will be destructively inspected after the engine surpasses the 30,000 hour time before overhaul requirement. This advanced coating system is now bill-of-material at various thicknesses up to 40 mils for all of Solar's advanced, backside cooled combustor liners (Centaur 50, Taurus 60, Mars 100, Taurus 70, Taurus 65, Titan 130, Titan 250 and Mercury 50).
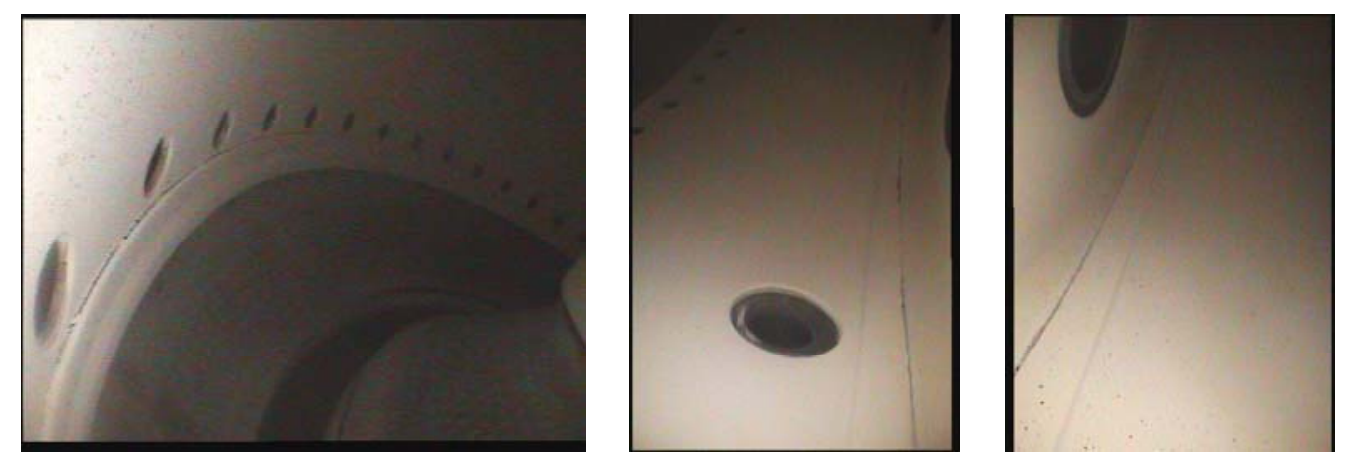

Figure 4.25 Borescope Images of the Advanced 40-mil TBC after 4,360 Hours of Commercial Operation at Qualcomm Inc. with 85 Starts.

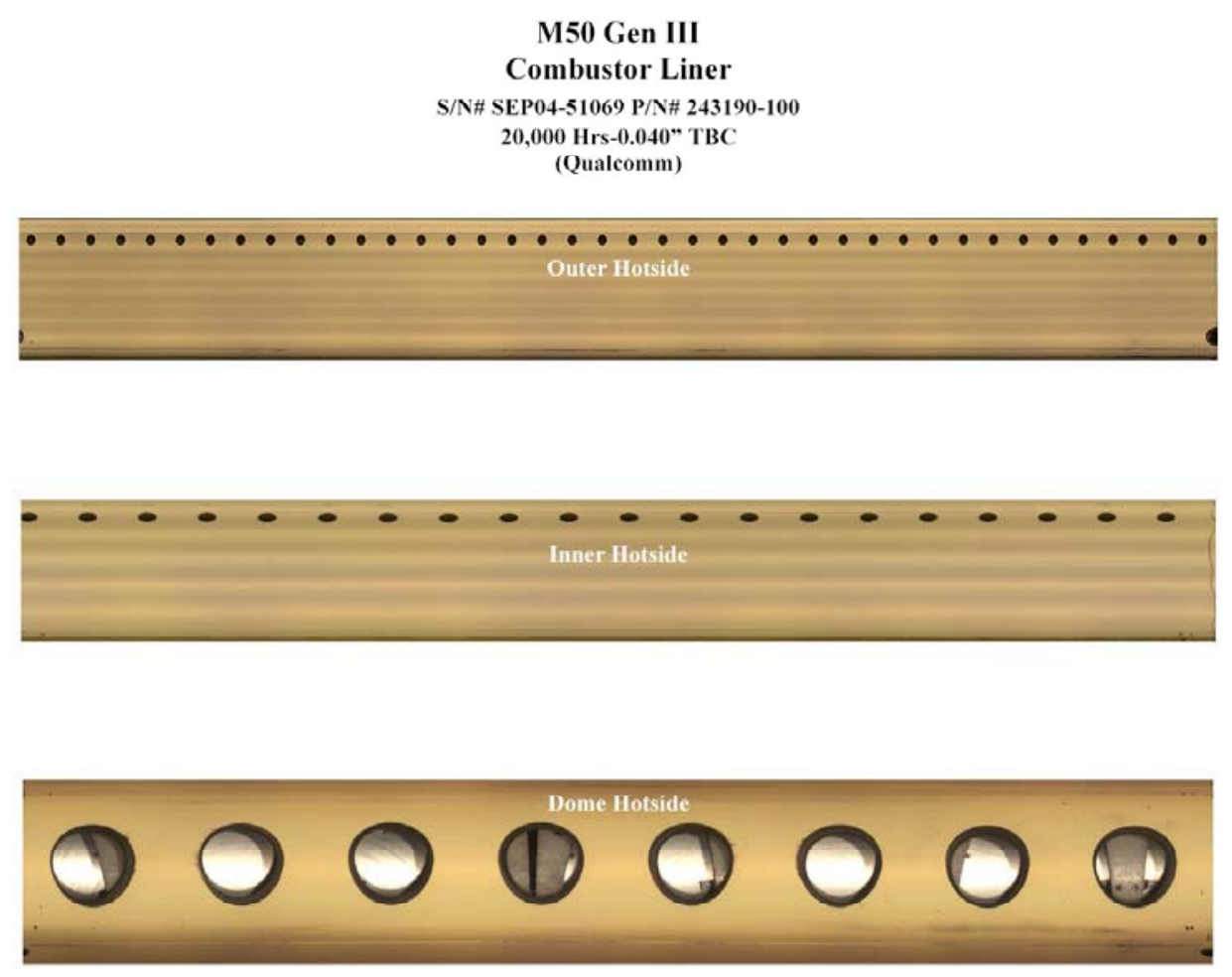

Figure 4.26 “Rolled Out” Digital Images of Advanced 40-mil TBC after 20,000 Hours of Commercial Operation in the Mercury 50 Engine at Qualcomm Inc. 


\subsection{SUBTASK 1A - EXTENDED CFCC MATERIALS DURABILITY TEST}

\subsection{Background}

The Advanced Materials program core proposal included the incorporation of a ContinuousFiber Reinforced Ceramic Composite (CFCC) inner combustor liner with protective Environmental Barrier Coating (EBC) as an alternate path in case the preferred option, a TBCcoated metal liner could not meet design durability requirements. Solar had gained considerable design and engine operating experience from the DOE Ceramic Stationary Gas Turbine (CSGT) program in which $\mathrm{SiC} / \mathrm{SiC}$ CFCC liners with and without protective EBCs had been tested at two industrial sites in Solar's Centaur $50 S \circledR$ engines. Engine testing of CFCC liners has started in May 1997 and a SiC/SiC CMC outer liner without protective coating had operated for over 5,000 hours at the Chevron Texaco industrial cogeneration site in Bakersfield, California. Subsequently, a set of EBC-coated CFCC liners was being evaluated since April 1999. A second test site at the textile plant of Malden Mills in Lawrence, Massachusetts had been initiated in 2000. At the time of the program proposal over 15,000 hours of engine field test time had been accumulated at these two sites.

An optional subtask 1A was therefore incorporated into the proposed Advanced Materials program aimed at continuing the engine testing of CFCC combustor liners by demonstrating 20,000 hours of target life, in support of the Mercury 50 20,000-hour life goal. It was hoped that eventually 30,000 hours of engine operating life, a standard TBO (time-between-overhauls) for Solar's engines would be achievable.

Under the program the CFCC liner engine field testing was structured in Subtask 1A Option: Extended CFCC Materials Durability Test. This proposed element of Task 1 contained the following elements:

- Extended durability testing of EBC-coated CFCC liners at the Texaco, Bakersfield, California, field test site. It was expected that 10,000 hours of running time would have accumulated on the Centaur 50S engine test bed at the completion time of the CSGT program. It was envisioned that the field testing program would be continued to achieve 20,000-hour and 30,000-hour milestones. The testing would be conducted under continuous operating conditions with about 30-40 start/stops for each 10,000 hours of operation. Liners would be periodically expected by borescoping and liner materials were to be evaluated destructively and nondestructively upon completion of the testing.

- Extended durability testing of EBC-coated CFCC liners at the Lawrence, MA, field test site. Under the CSGT program the two engines at Malden Mills would have accumulated about $6000 \mathrm{hrs}$ and $2000 \mathrm{hrs}$ of operating time, respectively. The plan was to operate the engines each for an additional $8,000 \mathrm{hrs}$ to accumulate cyclic durability data. It was expected that the engines would each experience 300-400 start/stop cycles for the 8,000-hour duration. Liners would be periodically inspected by borescoping and liner materials would be evaluated destructively and nondestructively upon completion of the testing.

- Pratt \& Whitney and United Technologies Research Center (UTRC) would apply EBC coatings to various CFCC liner sets and support the evaluation of the liners by participating in the analysis of the data from borescoping, and destructive and 
nondestructive testing. EBC coating recommendations would be made based on the analysis data.

- Oak Ridge National Laboratory (ORNL) would assist with the evaluation of the Texaco and Malden Mills liners through destructive analysis.

- Argonne National Laboratory (ANL) would evaluate EBC-coated CFCC liners by thermal diffusivity and air-coupled ultrasonic transmission.

- Liner procurement. A provision was made under the optional work for additional liner procurement.

- $\mathrm{CFCC} / \mathrm{EBC}$ recommendations. The results of the $\mathrm{CFCC} / \mathrm{EBC}$ endurance tests would flow directly to the main program tasks. Any modifications to the $\mathrm{CFCC} / \mathrm{EBC}$ system would be made under the main program.

- The impact of the findings of this optional task on Subtasks A and B of the program would be directly addressed under these subtasks in the main body of the program.

- Management and reporting for the optional work was included as a separate activity under the optional subtask.

\section{$5.2 \quad$ CFCC Liner Field Evaluation Testing}

\subsubsection{Nomenclature}

Throughout this section reference will be made to CFCC compositions, various EBC systems, and related materials and conditions. Also, the term Ceramic Matrix Composite (CMC) is used frequently in the literature as a synonym for CFCCs, although a wider class of materials, including whisker- and particulate-reinforced composites is included within the CMC class of materials. Throughout this section the term CFCCs will be used as in other sections of this report. A summary of acronyms used in this section is provided in the nomenclature summary below.

ACI) AlliedSignal Composites, Inc.; $\left(\mathrm{Al}_{2} \mathrm{O}_{3}\right)$ alumina; $\left(\mathrm{Al}_{2} \mathrm{O}_{3} / \mathrm{Al}_{2} \mathrm{O}_{3}\right)$ alumina/alumina CMC; (ANL) Argonne National Laboratory; (ARCO) Atlantic Richfield Corporation; (AS800) silicon nitride from Honeywell Ceramic Components; (ATP) Advanced Technology Program of NIST; (BFG) BF Goodrich Aerospace (currently Goodrich Corp.); (BN) boron nitride fiber-matrix interface coating; (BSAS) barium strontium aluminum silicate; (CD-1) field test conducted at California Dairies, Inc., Tipton, California, $\left(\right.$ Centaur $^{\circledR}$ 50S) Solar Centaur ${ }^{\circledR} 50$ gas turbine with SoLoNOx combustor; (CG-Nicalon) ceramic grade Nicalon SiC fibers of Nippon Carbon Company; (CFCC) Continuous Fiber- reinforced Ceramic Composite, (CMC) ceramic matrix composite; (CO) carbon monoxide; (COIC) ATK COI Ceramics; (CSGT) Ceramic Stationary Gas Turbine; (CT-) field tests conducted at ARCO, Texaco, and ChevronTexaco Bakersfield, California; (CVD) chemical vapor deposition; (CVI) chemical vapor infiltration; (DLC) DuPont Lanxide Composites Inc.; (DOE) U.S. Department of Energy; (EBC) environmental barrier coating; (EPM) Enabling Propulsion Materials program of NASA; (E-SiC) enhanced-SiC CVI matrix in DLC CMCs; (FGI) Friable Graded Insulation; (GE) General Electric Company; (GRC) GE Global Research Center; (HACI) Honeywell Advanced Composites, Inc.; $\left(\mathrm{H}_{2} \mathrm{O}\right)$ water; (Hi-Nicalon, HiNi) Hi-Nicalon grade $\mathrm{SiC}$ fibers of Nippon Carbon Company; (ID) inner diameter; (Malden Mills) Malden Mills 
Industries, Lawrence, Massachusetts; $\left(\mathrm{K}_{1 \mathrm{C}}\right)$ fracture toughness; (MI) melt infiltration; (MM-) field tests conducted at Malden Mills; (NASA) National Aeronautics \& Space Administration; (NDE) nondestructive evaluation; (NOx) oxides of nitrogen; (Nextel) fibrous materials supplied by 3M; (NIST) National Institute of Standards and Technology; (OD) outer diameter; (ORNL) Oak Ridge National Laboratory; (oxide/oxide) CMC with oxide fiber and oxide matrix; (ppmv) parts per million by volume; (PSC) GE Power Systems Composites; (PyC) pyrolytic carbon fiber-matrix interface coating; (RAMD) reliability, availability, maintainability, durability; (SAS) strontium aluminum silicate; (SCG) slow crack growth; $(\mathrm{Si})$ silicon; $(\mathrm{SiC})$ silicon carbide; $(\mathrm{SiC} / \mathrm{SiC}) \mathrm{CMC}$ with $\mathrm{SiC}$ fiber reinforcement and $\mathrm{SiC}$ matrix; $\left(\mathrm{Si}_{3} \mathrm{~N}_{4}\right)$ silicon nitride; $\left(\mathrm{SiO}_{2}\right)$ silicon dioxide; (Solar) Solar Turbines Incorporated; $\left(\right.$ SoLoNOx $\left.{ }^{\mathrm{TM}}\right)$ Solar's lean-premixed, dry, low NOx combustion system; (SWPC) Siemens Westinghouse Power Corp., (TBO) time between overhaul; (TRIT) turbine rotor inlet temperature; TyZM(I) Tyranno ZM(I) SiC fibers of Ube Industries, Ltd.; (UTRC) United Technologies Research Center.

\subsubsection{Introduction To Solar Engine Field Testing}

Figure 5.1 summarizes the steps in Solar's ceramic combustor liner development strategy, which involves sequential short term testing of promising ceramic materials and combustor designs. The test sequence includes: rig testing of subscale combustors, full scale liner tests in atmospheric and high pressure combustor rigs, and in-house and field testing in actual production engines. The rig and in-house engine tests are typically of short duration (1-100 hrs), and include steady state operation and thermal cycling. An in-house engine acceptance test is the final qualification for endurance testing at a field site. The ultimate field test goal is to achieve $30,000 \mathrm{hrs}$ of operation, which is the typical time between overhaul (TBO) for Solar's gas turbine engines. Rig and engine testing at Solar first qualified $\mathrm{SiC} / \mathrm{SiC} \mathrm{CMC}$ combustor liners for field testing in 1997. In 2003 an oxide/oxide CMC liner was qualified.

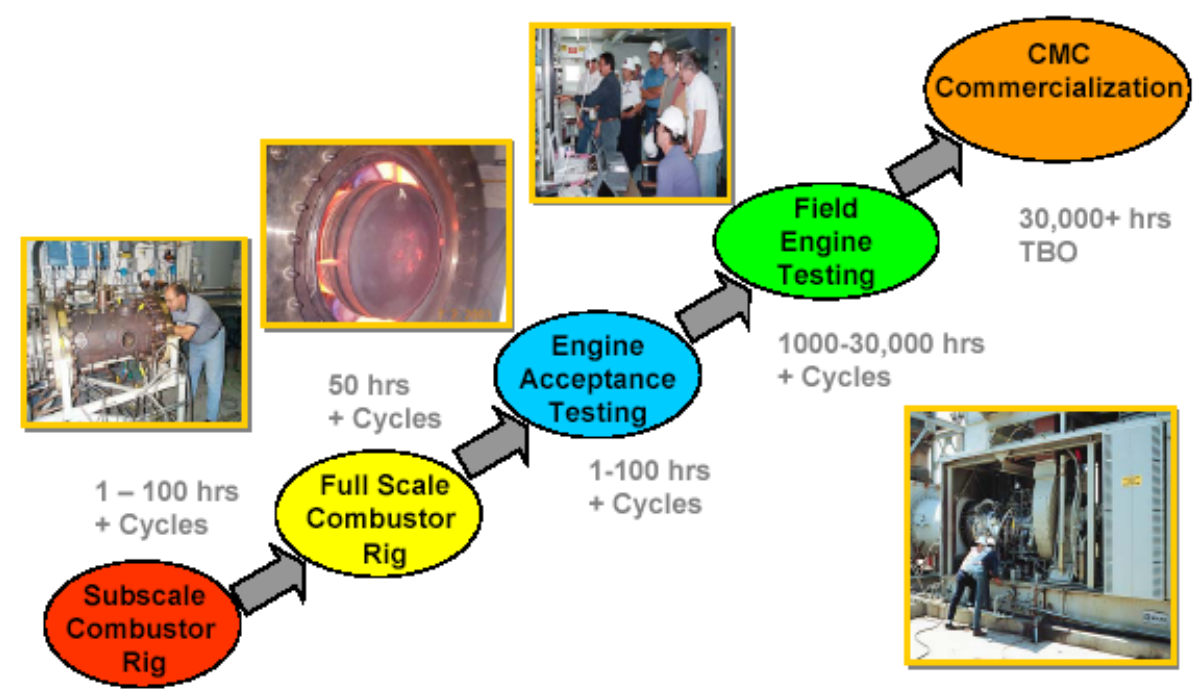

Figure 5.1 Solar's Ceramic Combustor Liner Development Strategy 
Solar Centaur ${ }^{\circledR} 50 S$ gas turbines, which operate at a baseline turbine rotor inlet temperature (TRIT) of $1010^{\circ} \mathrm{C}\left(1850^{\circ} \mathrm{F}\right)$ and have an output power of $\sim 4 \mathrm{MW}$, have been used as the test engines for ceramic component development. These engines use the Solar lean premix SoLoNOx ${ }^{\mathrm{TM}}$ combustion technology system to limit emissions to less than 25 ppmv NOx and 50 ppmv $\mathrm{CO}\left(15 \% \mathrm{O}_{2}\right)$, respectively. A schematic of the Centaur $50 \mathrm{~S}$ engine and the hot section with combustor are shown in Fig. 5.2. Under the CSGT program the SoLoNOx combustor was redesigned to incorporate $\mathrm{SiC} / \mathrm{SiC} \mathrm{CFCC}$ liner components. As shown in Fig. 2 the cylindrical, metallic louver-cooled primary zone walls were replaced with CFCC components. The diameters of the outer and inner liner are $\sim 76 \mathrm{~cm}$ and $\sim 33 \mathrm{~cm}$, respectively, and liner length is $\sim 20 \mathrm{~cm}$ (during the program, the length of the outer liner was shortened to $\sim 17.5 \mathrm{~cm}$ ). The nominal wall thickness is in the $0.2-0.3 \mathrm{~cm}$ range for $\mathrm{SiC} / \mathrm{SiC} \mathrm{CFCCs}$ and $\sim 0.7 \mathrm{~cm}$ for oxide/oxide CFCCs with FGI. The liners are contained within a metallic housing that includes the upstream dome, the downstream conical sections, and metallic support cylinders. A layer of compliant (Nextel) insulation between the CFCC liners and the metal cylinders mitigates radial contact stresses. Small axial gaps between the ends of the CFCC cylinders and the metal housing prevent end loads. The CFCC liners experience only thermal stresses from material temperature gradients. Stresses from mechanical loading have been eliminated in this design. A maximum local stress of $\sim 76 \mathrm{MPa}$ was predicted near the upstream edge of the cylinders, well within the stress limits of the $\mathrm{SiC} / \mathrm{SiC} \mathrm{CMCs}$ selected for this design. Solar in-house engine testing in the 1995-1997 timeframe validated the $\mathrm{CFCC}$ combustor liner design and short-term durability of the $\mathrm{SiC} / \mathrm{SiC}$ CFCC liners. Emissions measured during in-house testing were excellent with NOx and CO levels typically below 15 ppmv and 10 ppmv, respectively.

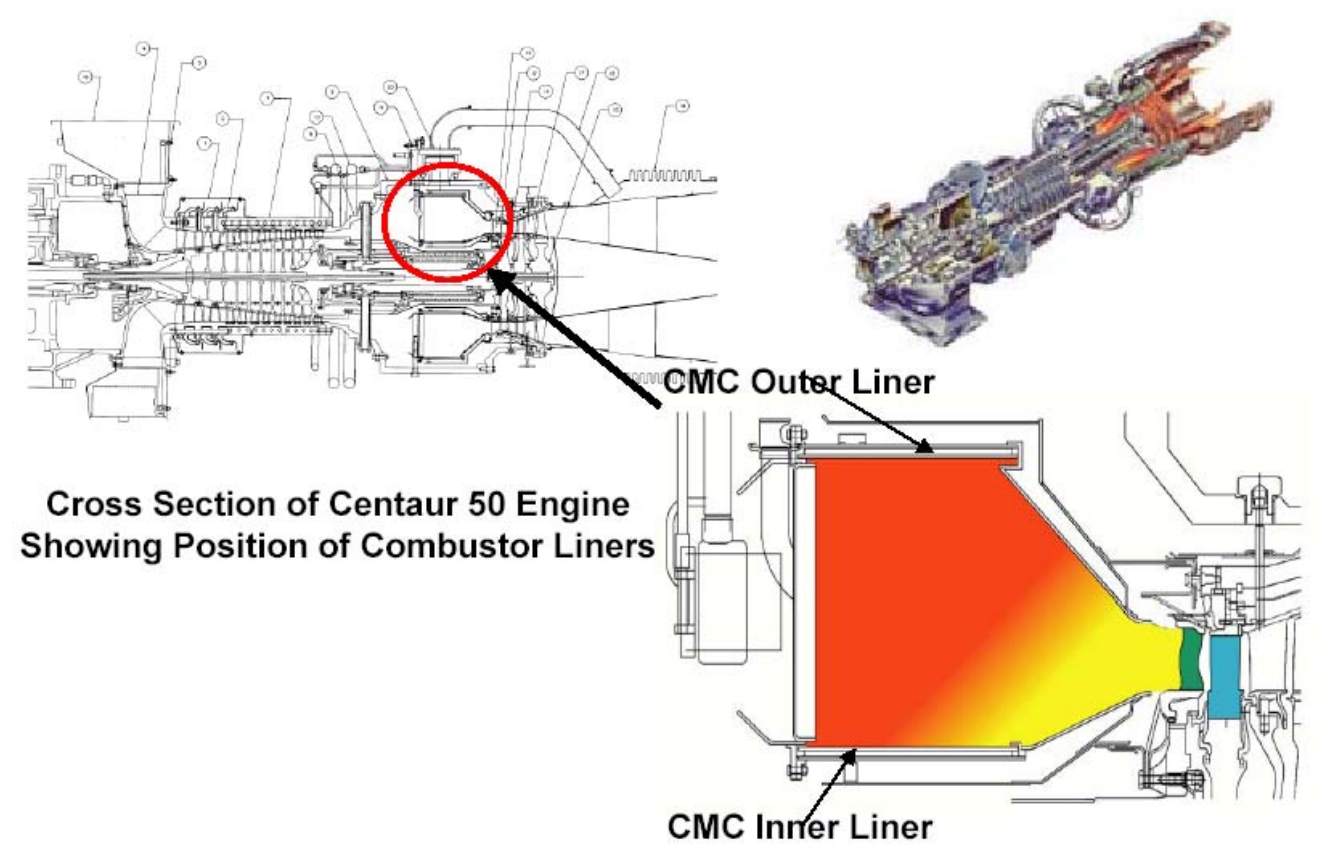

Figure 5.2 Schematic of Solar Centaur 50S Combustor with CFCC Liners 
Solar started field testing of Centaur 50S ceramic engines in May 1997 at the oil exploration site of ARCO Western Energy in Bakersfield, California. Ownership of the site transferred to Texaco and subsequently to ChevronTexaco after the merger of Texaco with Chevron. Figure 5.3 shows one of the test sites at the ChevronTexaco concession. For the field test the customer's Centaur 50 engine is replaced with a Centaur 50S engine fitted with CFCC liners, supplied by Solar. A second test site, utilized from 1999 through 2003, was the Malden Mills textile factory in Lawrence, Massachusetts. The Malden Mills site has two Centaur 50S engines, both of which have been used for CFCC liner testing (Fig. 5.4). At the Malden Mills site the standard SoLoNOx combustors with metal liners were replaced with pre-assembled combustors fitted with CFCC liners for the purpose of the field tests.

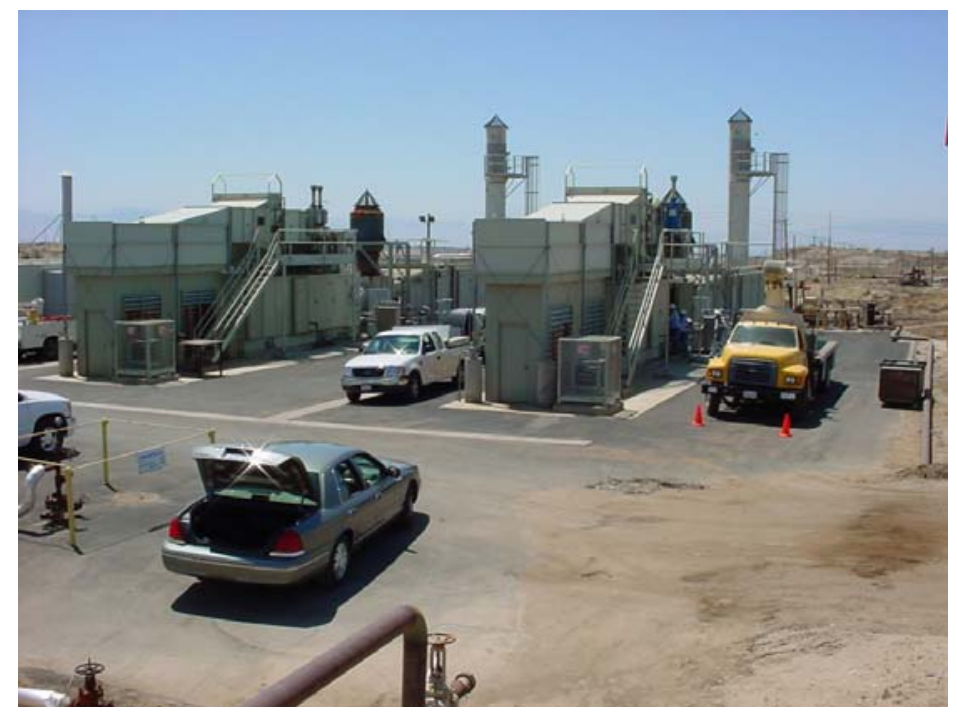

Figure 5.3 The ChevronTexaco Bakersfield Site with Field Test Engine in Package on the Right

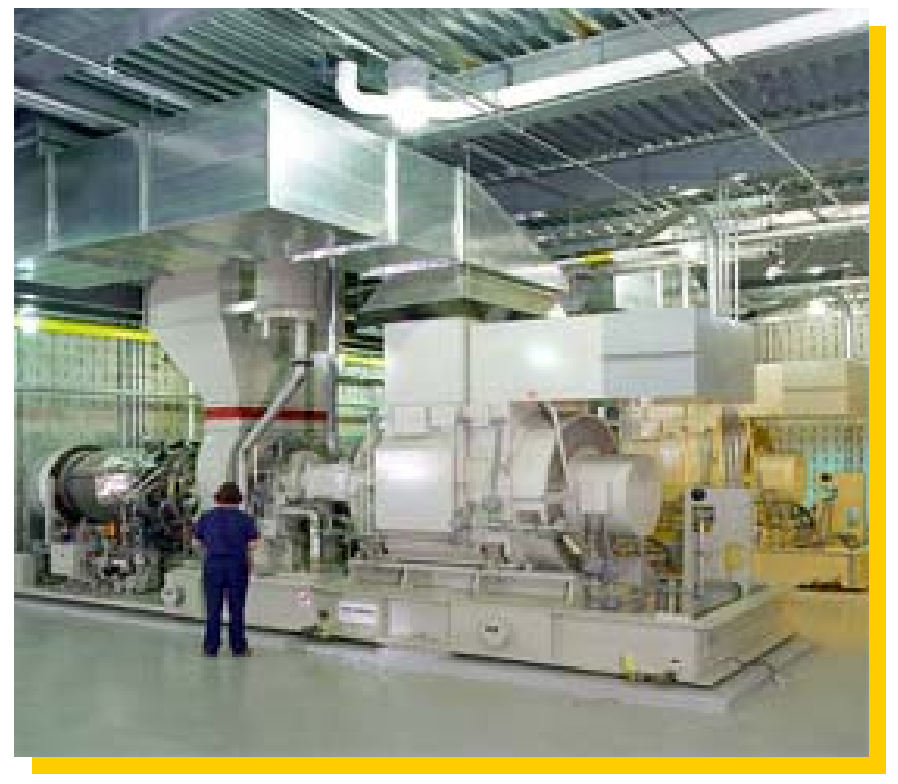

Figure 5.4 Centaur 50S Engine at Malden Mills Textile Facility 
Testing at the Malden Mills site had to be halted in 2004 because the Centaur 50S gas turbines availability for engine testing had ceased. An alternate test site became available at the Tipton, California, facility of Cal. Dairies Inc. (CDI), and an engine test was started which lasted about 12 months. The CDI site is shown in Figure 5.5.

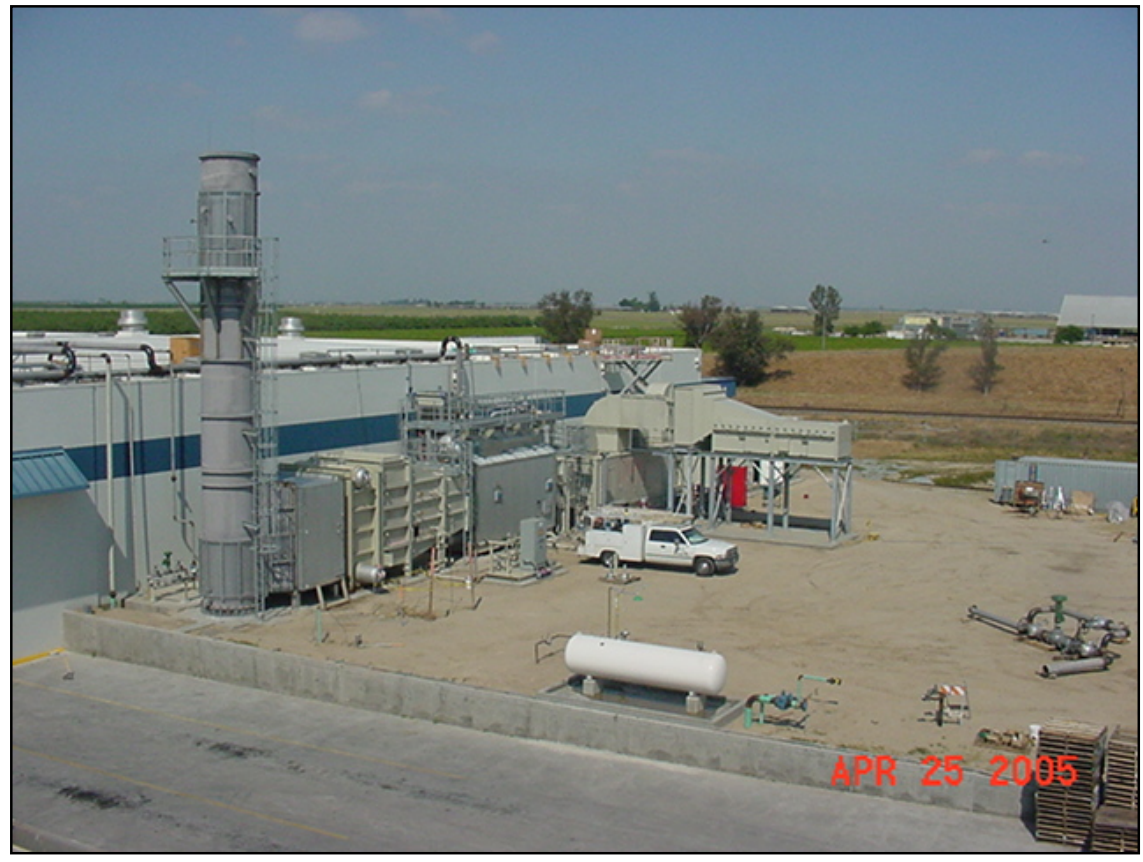

Figure 5.5 Centaur 50S Engine at Cal. Dairies, Inc. Facility

Extensive CFCC liner field testing has been conducted under the Advanced Materials Program. At the conclusion of the testing in November 2006, the total accumulated engine field operating time with CFCC liners since the first test in May 1997 was over 88,000 hours. NOx and CO turbine exhaust emissions measured were consistently $<15 \mathrm{ppmv}$ and $<10 \mathrm{ppmv}$, respectively. The longest field test for a set of $\mathrm{SiC} / \mathrm{SiC} \mathrm{CFCC}$ liners lasted 15,144 hours. Not envisioned at the start of the Advanced Materials program was the evaluation of and oxide-based CFCC liner. This materials option, initially started under an Advanced Technology (ATP) program of the National Institute of Standards and Technology (NIST), was incorporated into the program in the summer of 2003, as described below. The engine testing of this oxide liner was highly successful. It operated for 25,000 hours in two consecutive field tests with only a minor refurbishment at the halfway point.

A summary of Solar's CFCC liner engine field testing under the DOE CSGT programs has been presented in the Phase III Final Report [1]. Numerous presentations, including work under the DOE Advanced Materials and the NIST ATP program have been presented at conferences and related publications [2-23]. Table 5.1 summarizes the engine field testing of CFCC liners, starting with Solar in-house testing in 1995 through the end of the field testing in November 2006. The table and subsequent narrative sections expand a summary of testing through 2005 presented at an ASME conference [2]. Listed are compositions of the CFCCs (fiber/interface coating/matrix) and of the EBCs or FGI (Friable Graded Insulation) used for protection of the CFCCs in these tests, the duration of the tests, number of engine starts, and comments summarizing key lessons learned during the field tests. The engine field tests have been 
designated with CT, MM, or CD. CT represents all tests at the ChevronTexaco Bakersfield site conducted in the 1997 - 2006 timeframe, MM the tests at the Malden Mills facility in the 1999 2003 period, and CD, a single test at Cal. Dairies, Inc. during 2006 and 2007.

Table 5.1 Summary of Combustor Liner Engine Tests* (Adapted from Ref. [2])

\begin{tabular}{|c|c|c|c|c|}
\hline Time & Site/Test & Hrs (Starts) & Liner CFCC's, EBCs & Comments \\
\hline $\begin{array}{l}10 / 95 \\
{[3,4]}\end{array}$ & Solar & $18(10)$ & 3D CG Ni SiC/PyC/SiC CVI (BFG) & $\begin{array}{l}\text { * First CMC liner engine test } \\
* \text { Validated design } \\
*<15 \text { ppmv NOx }\left(15 \% \mathrm{O}_{2}\right)\end{array}$ \\
\hline $\begin{array}{l}4 / 97 \\
{[3,7]}\end{array}$ & Solar & $\sim 100$ (27) & $\begin{array}{l}\text { CG Ni SiC/PyC/E-SiC CVI } \\
\text { SiC seal coat (DLC) }\end{array}$ & * Qualified CMC liners for field testing \\
\hline $\begin{array}{l}5-7 / 97 \\
{[3,5,7,9-11]}\end{array}$ & CT-1 & $948(15)$ & $\begin{array}{l}\text { CG Ni SiC/PyC/E-SiC CVI } \\
\text { SiC seal coat (DLC) }\end{array}$ & $\begin{array}{l}\text { * First CMC field test } \\
*<15 \text { ppmv NOx, }<10 \text { ppmv CO } \\
* \text { CMC degradation/surface recession } \\
\text { * ORNL Keiser rig duplicates CMC } \\
\text { degradation/surface recession in Solar } \\
\text { engine tests }\end{array}$ \\
\hline $\begin{array}{l}2-3 / 98 \\
{[5,6,7,12]}\end{array}$ & CT-2 & $352(31)$ & \multirow{2}{*}{$\begin{array}{l}\text { Inner Liner - HiNi SiC/BN/E-SiC CVI } \\
\text { Outer Liner - HiNi } \mathrm{SiC} / \mathrm{PyC} / \mathrm{E}-\mathrm{SiC} \text { CVI } \\
\text { SiC seal coat (DLC) }\end{array}$} & \multirow{3}{*}{$\begin{array}{l}\text { * Improved (HiNi) fiber } \\
\text { * Improved conduction path } \\
\text { * } 5016 \text { hrs on outer liner } \\
\text { * First test with MI inner liner } \\
\text { * MI CMCs degrade less than CVI CMCs }\end{array}$} \\
\hline $\begin{array}{l}5-8 / 98 \\
{[6,9,10,12]}\end{array}$ & CT-3 & $1906(46)$ & & \\
\hline $\begin{array}{l}12 / 98-4 / 99 \\
{[5,6,8,13]}\end{array}$ & CT-4 & $2758(26)$ & $\begin{array}{l}\text { Inner Liner - HiNi } \mathrm{SiC} / \mathrm{BN} / \mathrm{SiC}-\mathrm{Si} \mathrm{MI} \\
\mathrm{SiC} \text { seal coat }(\mathrm{BFG}) \\
\text { Outer Liner }-\mathrm{HiNi} / \mathrm{PyC} / \mathrm{E}-\mathrm{SiC} \mathrm{CVI} \\
\mathrm{SiC} \text { seal coat }(\mathrm{DLC})\end{array}$ & \\
\hline $\begin{array}{l}4 / 99-11 / 00 \\
{[5,6,8,14-17]}\end{array}$ & CT-5 & $13,937(61)$ & $\begin{array}{l}\text { Inner Liner - HiNi SiC/BN/SiC-Si MI } \\
\mathrm{SiC} \text { seal coat (ACI) } \\
\mathrm{Si} / \text { mullite/BSAS EBC (UTRC) } \\
\text { Outer Liner - HiNi SiC/PyC/E-SiC CVI } \\
\text { SiC seal coat (ACI) } \\
\mathrm{Si} / \text { mullite+BSAS/BSAS (Mixed-Layer) } \\
\text { EBC (UTRC) }\end{array}$ & $\begin{array}{l}\text { * First test with EBCs } \\
* \text { 2-3x improved liner life } \\
* \text { NDE: EBC defects - correlate with inner } \\
\text { liner degradation } \\
* \text { Degradation of outer liner EBC at surface } \\
\text { asperities } \\
\text { * BSAS surface degradation } \\
\text { * Mullite phase separation } \\
\text { * Mixed-layer EBC superior } \\
\end{array}$ \\
\hline $\begin{array}{l}8 / 99-10 / 00 \\
{[16,17]}\end{array}$ & MM-1 & $7,238(159)$ & $\begin{array}{l}\text { Inner liner }-\mathrm{HiNi} / \mathrm{BN} / \mathrm{SiC}-\mathrm{Si} \mathrm{MI} \\
\mathrm{SiC} \text { seal coat }(\mathrm{BFG}) \\
\mathrm{Si} / \text { mullite+BSAS/BSAS EBC (UTRC) } \\
\text { Outer liner }-\mathrm{HiNi} / \mathrm{PyC} / \mathrm{E}-\mathrm{SiC} \text { CVI } \\
\mathrm{SiC} \text { seal coat }(\mathrm{ACI}) \\
\mathrm{Si} / \text { mullite+BSAS/BSAS EBC (UTRC) }\end{array}$ & $\begin{array}{l}* \text { EBC in good condition following test } \\
* \text { EBC stripped and refurbished for CT- } 6 \text { test }\end{array}$ \\
\hline $\begin{array}{l}9 / 01-5 / 02 \\
{[17,18]}\end{array}$ & CT-6 & $5,135(43)$ & $\begin{array}{l}\text { Inner liner }-\mathrm{HiNi} / \mathrm{BN} / \mathrm{SiC}-\mathrm{Si} \mathrm{MI} \\
\mathrm{SiC} \text { seal coat }(\mathrm{BFG}) \\
\mathrm{Si} / \mathrm{BSAS} \mathrm{EBC}(\mathrm{UTRC}) \\
\text { Outer liner }-\mathrm{HiNi} / \mathrm{PyC} / \mathrm{E}-\mathrm{SiC} \mathrm{CVI} \\
\mathrm{SiC} \text { seal coat }(\mathrm{ACI}) \\
\text { Si/mullite+BSAS/BSAS EBC (UTRC) }\end{array}$ & $\begin{array}{l}\text { * Same liners as in MM-1 } \\
\text { * Test with refurbished EBC } \\
\text { * 12,373 hrs/202 starts total on CFCCs } \\
\text { * Accelerated degradation of two-layer } \\
\text { Si/SAS EBC }\end{array}$ \\
\hline $\begin{array}{l}8 / 00-7 / 02 \\
{[19]}\end{array}$ & MM-2 & $15,144(92)$ & $\begin{array}{l}\text { Inner liner - TyZM/BN/SiC-Si MI } \\
\mathrm{SiC} \text { seal coat (BFG) } \\
\mathrm{Si} / \text { mullite+BSAS/BSAS EBC (UTRC) } \\
\text { Outer liner - HiNi/PyC/E-SiC CVI } \\
\mathrm{SiC} \text { seal coat (HACI) } \\
\mathrm{Si} / \text { mullite+BSAS/BSAS EBC (UTRC) }\end{array}$ & $\begin{array}{l}\text { * Longest field test with } \mathrm{SiC} / \mathrm{SiC} \text { CFCCs } \\
\text { * Use less expensive Tyranno ZM fiber } \\
\text { * EBC application on liner edges }\end{array}$ \\
\hline
\end{tabular}




\begin{tabular}{|c|c|c|c|c|}
\hline $\begin{array}{l}7 / 02-7 / 03 \\
{[20]}\end{array}$ & MM-3 & $8,368(32)$ & $\begin{array}{l}\text { Inner liner - TyZMI/BN/SiC-Si MI } \\
\text { (HACI) } \\
\text { Si/SAS EBC (UTRC) } \\
\text { Outer liner - TyZMI/BN/SiC-Si MI } \\
\text { (HACI) } \\
\text { Si/mullite+SAS/SAS EBC (UTRC) }\end{array}$ & $\begin{array}{l}\text { * Less expensive Tyranno ZMI fiber } \\
\text { * First test with SAS EBC } \\
\text { * No CVD seal coat } \\
\text { * Two-layer Si/SAS EBC: heavy degradation } \\
\text { * Mixed layer EBC: good condition } \\
\text { * Heavy degradation on cold side liners } \\
\end{array}$ \\
\hline $\begin{array}{l}5 / 03-11 / 04 \\
{[2,21-23]}\end{array}$ & CT-7 & $12,582(63)$ & $\begin{array}{l}\text { Inner liner:HiNi/BN/E-SiC CVI, SiC seal } \\
\text { coat }(\mathrm{ACI}) \\
\mathrm{Si} / \text { mullite/BSAS EBC }(\mathrm{UTRC}) \\
\text { Outer liner }-\mathrm{Al}_{2} \mathrm{O}_{3} / \mathrm{Al}_{2} \mathrm{O}_{3} \text {, Aluminosilicate } \\
\text { FGI (COIC/SWPC) }\end{array}$ & $\begin{array}{l}\text { * First test on oxide/oxide CMC with FGI } \\
\text { * Oxide/oxide-CMC and FGI in relatively } \\
\text { good condition } \\
\text { * Continued testing planned with new } \\
\text { HiNi } \mathrm{SiC} / \mathrm{BN} / \mathrm{SiC}-\mathrm{Si} \mathrm{MI} \text { inner liner }\end{array}$ \\
\hline$[2,21-23]$ & CT-8 & $12,822(46)$ & $\begin{array}{l}\text { Inner liner: } \mathrm{HiNi} / \mathrm{BN} / \mathrm{E}-\mathrm{SiC} \text { (prepreg), } \mathrm{SiC} \\
\text { seal coat }(\mathrm{GRC} / \mathrm{CPP}) \\
\mathrm{Si} / \text { mullite }+\mathrm{BSAS} / \mathrm{BSAS} \text { EBC (GRC) } \\
\text { Outer liner: } \mathrm{Al}_{2} \mathrm{O}_{3} / \mathrm{Al}_{2} \mathrm{O}_{3} \text {, Aluminosilicate } \\
\text { FGI (COIC/SWPC) }\end{array}$ & $\begin{array}{l}\text { * Longest field test with oxide/oxide CFCC } \\
\text { * Oxide/oxide CFCC survived test with } \\
25,404 \mathrm{hrs} / 109 \text { starts } \\
\text { * Prepreg } \mathrm{SiC} / \mathrm{SiC} \text { CFCC liner in acceptable } \\
\text { condition after test }\end{array}$ \\
\hline $6 / 06-5 / 07$ & CD-1 & $7,784(43)$ & $\begin{array}{l}\text { Inner liner - TyZMI/BN/SiC-Si MI } \\
\text { Si/mullite/SAS EBC } \\
\text { Outer liner - TyZMI/BN/SiC-Si MI } \\
\text { Si/YS EBC }\end{array}$ & $\begin{array}{l}\text { * New Si/Y-silicate EBC on outer liner in } \\
\text { good condition } \\
\text { * Si/SAS EBC on inner liner mostly } \\
\text { degraded - test was halted }\end{array}$ \\
\hline
\end{tabular}

* Hours shown for field tests do not include engine acceptance testing at Solar

The findings for each of the field tests have been summarized in the sections below. For completeness sake the tests that had been completed or started under the CSGT program have been included in the summaries. Detailed accounts of the Solar in-house testing and tests CT-1 through CT-6 have been provided in the Final Report for Phase III of CSGT program [1].

\subsubsection{Engine Field Test CT-1}

CFCC liners with a Ceramic Grade Nicalon fiber reinforcement and enhanced-SiC (E-SiC) Chemical Vapor Infiltrated (CVI) matrix and pyrolytic carbon (PyC) interface coating (CG $\mathrm{Ni} / \mathrm{PyC} / \mathrm{E}-\mathrm{SiC}$ - DuPont Lanxide Composites, DLC) from a previous 100-hour Solar in-house test were used in the first field test at the Bakersfield site. The liners prior to in-house testing are shown in Fig.5.6 [7]. This first field test was conducted over the period May-July, 1997. The test was halted after $948 \mathrm{hrs}$ and 15 starts because of failure of the AS800 $\mathrm{Si}_{3} \mathrm{~N}_{4}$ first stage turbine blades, resulting from impact damage, possibly from metal debris upstream of the combustor. While the liners were intact, early oxidation noted in the 100-hr Solar test was much more severe after 948 hrs of field operation. Surface recession, evidenced by a heavy glassy deposit, was as much as $0.5 \mathrm{~mm}$ on the inner liner and $<0.1 \mathrm{~mm}$ on the outer liner. Room temperature residual strength of the two liners was approximately $40-60 \%$ of the original material strength. Based on surface recession values it was speculated that the inner liner operated at a temperature of $1260^{\circ} \mathrm{C}\left(2300^{\circ} \mathrm{F}\right)$ or higher. Emission levels, measured at $50-100 \%$ load operation, were $<15$ ppmv NOx and $<10$ ppmv CO, respectively. Figure 5.7 shows the inner liner after the $948 \mathrm{hr}$ field test. Figure 5.8 shows representative microstructures of sections of the inner and outer liner [9]. 


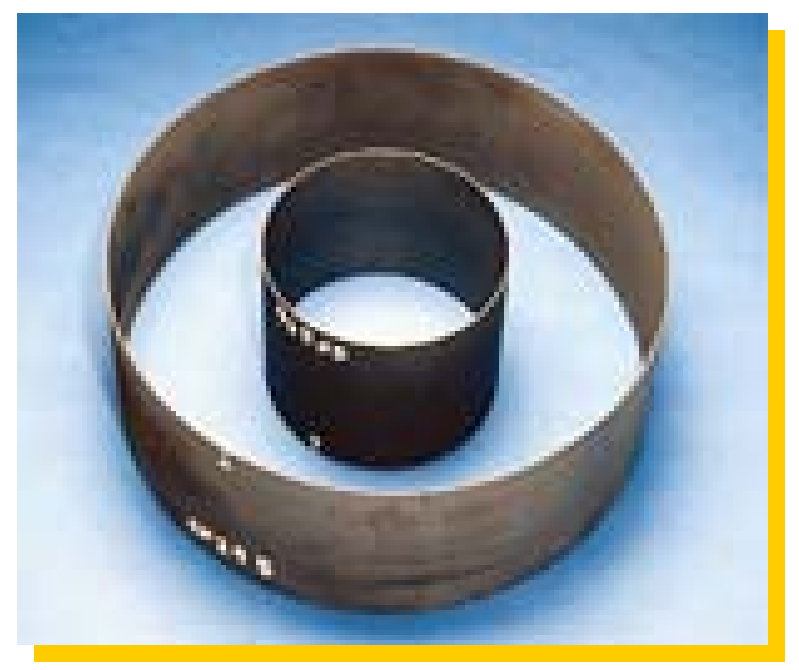

Figure 5.6 CG Ni/PyC/E-SiC (CVI) Liners before 100-Hour Solar Test

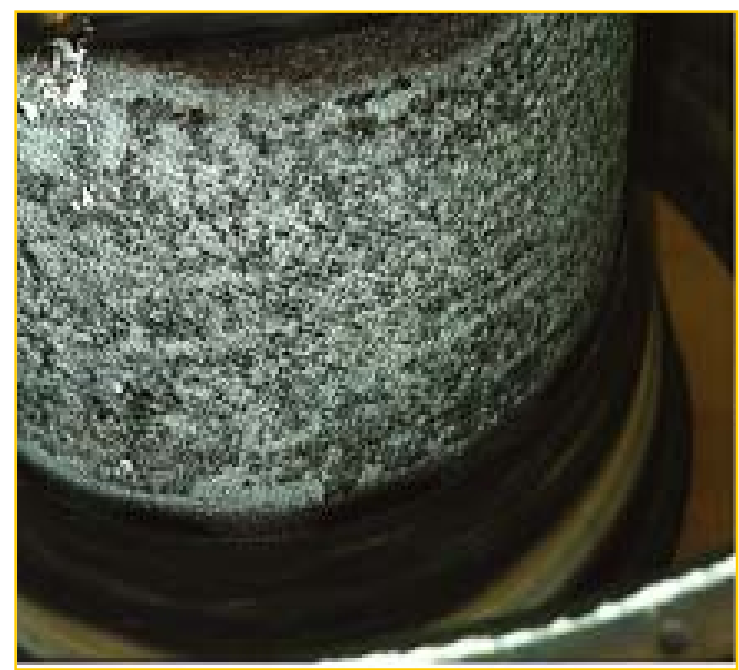

Figure 5.7 CG Ni/PyC/E-SiC (CVI) Inner Liner after 948-Hour Test (CT-1)
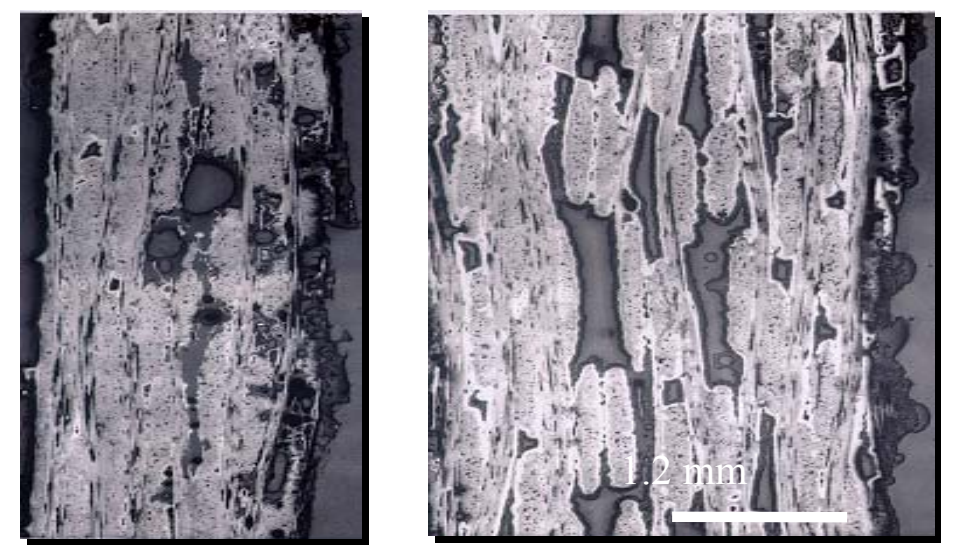

Figure 5.8 Inner (left) and Outer Liner (Right) Sections after 948-Hour Test (CT-1) 
The inner liner underwent post-test NDE (thermal diffusivity and air-coupled ultrasound) at Argonne National Laboratory (ANL) prior to destructive evaluation at ORNL (Oak Ridge National Laboratory). Interestingly, the degradation/recession duplicated that encountered in simulated gas turbine environmental exposure testing at ORNL [10]. Therefore, the lower cost ORNL Keiser test rig testing can be used to effectively screen various CMC liner systems. The environmental degradation is attributed to accelerated oxidation of $\mathrm{SiC}$ due to the presence of $\mathrm{H}_{2} \mathrm{O}$ in the combustion environment [11].

\subsubsection{Engine Field Tests CT-2 and CT-3}

These two tests are discussed together since the same set of liners was used for both. They were conducted over the period February through August 1998. Following the first field test at the Bakersfield site several changes were made to the combustor liner system to reduce the oxidation of the $\mathrm{SiC} / \mathrm{SiC}$ CFCC liners. Design changes to the conduction path from the CFCC liners to the metallic housings resulted in reduced liner wall temperatures. Changes to the CFCC liners themselves included using Hi-Nicalon (HiNi) fibers, which have improved strength and higher thermal conductivity, compared to the previously used Ceramic Grade Nicalon fibers, increasing the CMC density, and increasing the thickness of the protective SiC CVD seal coat $[5,7,12]$. For CT-2 and CT-3 the inner and outer liner CFCC were HiNi/BN/E-SiC and HiNi/PyC/E-SiC (CVI matrix), respectively, supplied by DLC. The interfacial coatings were different, BN for the inner liner and PyC for the outer liner. CT-2 ended after $352 \mathrm{hrs}$ because of failure of the AS800 turbine blades. The liners were reinserted in the test engine for the subsequent CT-3 test which was terminated after $1906 \mathrm{hrs}$ to evaluate the oxidized vs. unoxidized areas of the CMC liners. Both liners showed surface oxidation at the fuel injector impingement locations. The inner liner underwent post-test NDE (thermal diffusivity and air-coupled ultrasound) at ANL prior to destructive evaluation at ORNL. The maximum recession was approximately $0.2 \mathrm{~mm}$, with a highest temperature recorded of $1175^{\circ} \mathrm{C}\left(2147^{\circ} \mathrm{F}\right)$. In the ORNL Keiser rig recession of a $\mathrm{SiC}$ seal coat was measured as $0.05 \mathrm{~mm} / 500 \mathrm{hrs}$. Again, as in CT-1 material degradation closely matched that encountered in simulated gas turbine environmental exposure testing at ORNL $[6,9,10,12]$.

\subsubsection{Engine Field Test CT-4}

In this test, conducted from December, 1998, through April, 1999, the HiNi SiC/PyC/E-SiC (CVI) outer liner of tests CT-2/3 was used with a new HiNi SiC/BN/SiC-Si melt-infiltrated (MI) liner from BF Goodrich Aerospace (BFG). This was the first test with an MI liner. The test was conducted for a total of $2758 \mathrm{hrs}$ with 26 starts. During an acceptance test at Solar a maximum temperature of $1260^{\circ} \mathrm{C}\left(2300^{\circ} \mathrm{F}\right)$ was recorded on both liners, but it was estimated that the liner temperatures during the field test were at least $20^{\circ} \mathrm{C}\left(36^{\circ} \mathrm{F}\right)$ lower. Following the completion of test CT-4 the outer liner had been field tested for a total of $5016 \mathrm{hrs}$ (total exposure time including Solar acceptance testing was 5,028 hrs), and the inner liner had a field total of 2,758 hrs $(2,762 \mathrm{hrs}$ if the acceptance test is included) [6]. Digital photographs of the liner set following completion of the field test are shown in Fig. 5.9 [5,8,13]. 

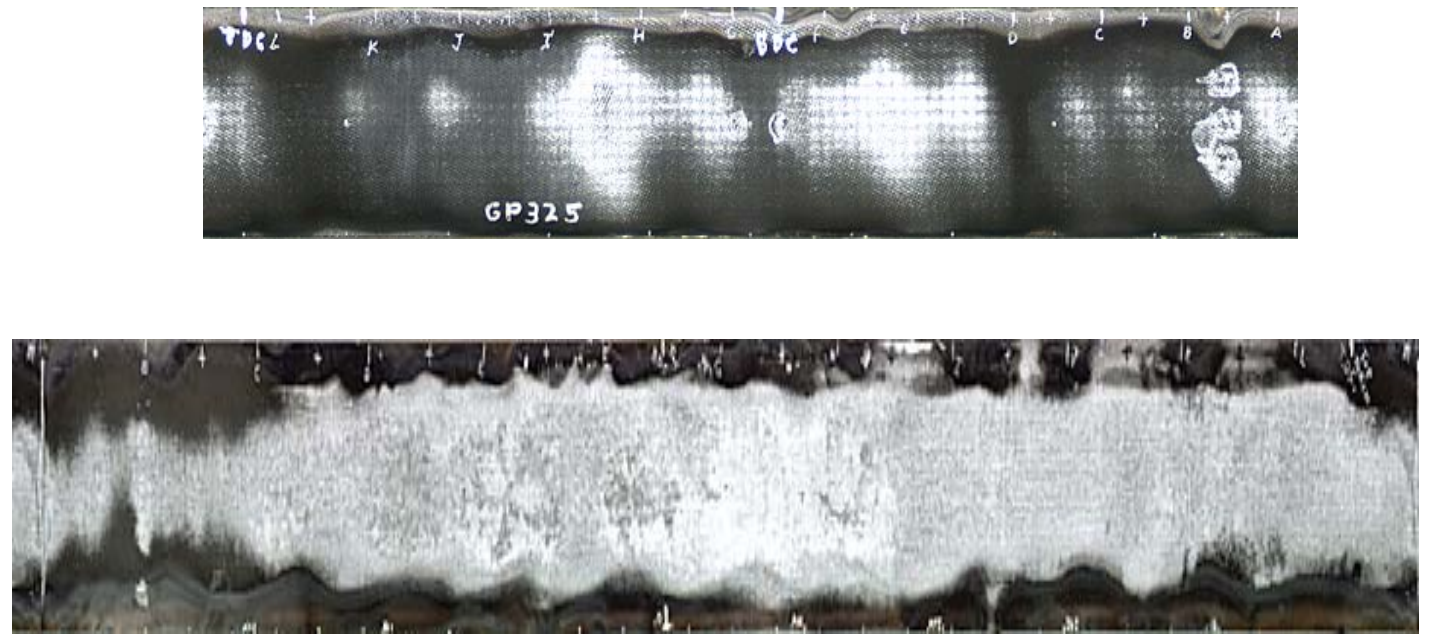

\section{Figure 5.9 Digital Photographs of HiNi SiC/PyC/E-SiC (CVI) Outer Liner (top) and HiNi} SiC/BN/SiC-SI (MI) Inner Liner (bottom) after 5,016 Field Test Hours (CT-4)

The HiNi/BN/SiC-Si MI inner liner appeared in better condition than both the CVI inner and outer $\mathrm{SiC} / \mathrm{BN}, \mathrm{PyC} / \mathrm{SiC} \mathrm{CFCC}$ liners after the completion of test CT-3. The outer liner was heavily degraded, having lost about $80 \%$ of its wall thickness in certain areas. The residual tensile strength of the liner was about $50 \%$ of the original material strength at room temperature and $1200^{\circ} \mathrm{C}\left(2192^{\circ} \mathrm{F}\right)$. Fiber pullout was still observed on specimen fracture surfaces, indicating composite behavior of the material, even after $5,028 \mathrm{hrs}$ of engine exposure $[5,6,8,13]$. Because of the unacceptable degradation it appears that 5,000 hrs is the approximate durability limit for $\mathrm{HiNi} / \mathrm{PyC} / \mathrm{E}-\mathrm{SiC}$ CVI CMC liners in the Centaur 50S gas turbine hot section. To increase life significantly, it was decided to apply protective environmental barrier coatings (EBCs) in subsequent engine field tests.

\subsubsection{Engine Field Test CT-5}

A new set of CFCC liners was fabricated by AlliedSignal Composites, Inc. (ACI), which had acquired DLC in 1998, for the fifth field test at the Bakersfield site. The compositions were $\mathrm{HiNi} / \mathrm{BN} / \mathrm{SiC}-\mathrm{Si}(\mathrm{MI})$ and $\mathrm{HiNi} / \mathrm{PyC} / \mathrm{E}-\mathrm{SiC}(\mathrm{CVI})$, for the inner and outer liner, respectively. The CFCC liners were protected with EBCs supplied by United Technologies Research Center (UTRC). The EBC, a 3-layer coating system with composition $\mathrm{Si} /$ mullite + (BSAS)/BSAS, deposited by air plasma spray, was originally developed under the NASA Enabling Propulsion Materials (EPM) program, and optimized for the CSGT program [5,6,8,14]. Each coating layer was nominally $125 \mu \mathrm{m}$ thick. The liner set prior to testing is shown in Fig. 5.10, and a micrograph of the basic EBC in Fig. 5.11 [15]. The EBC for the inner liner had the basic $\mathrm{Si} /$ mullite/BSAS composition. The outer liner EBC had a mixture of mullite and BSAS in the intermediate layer. 


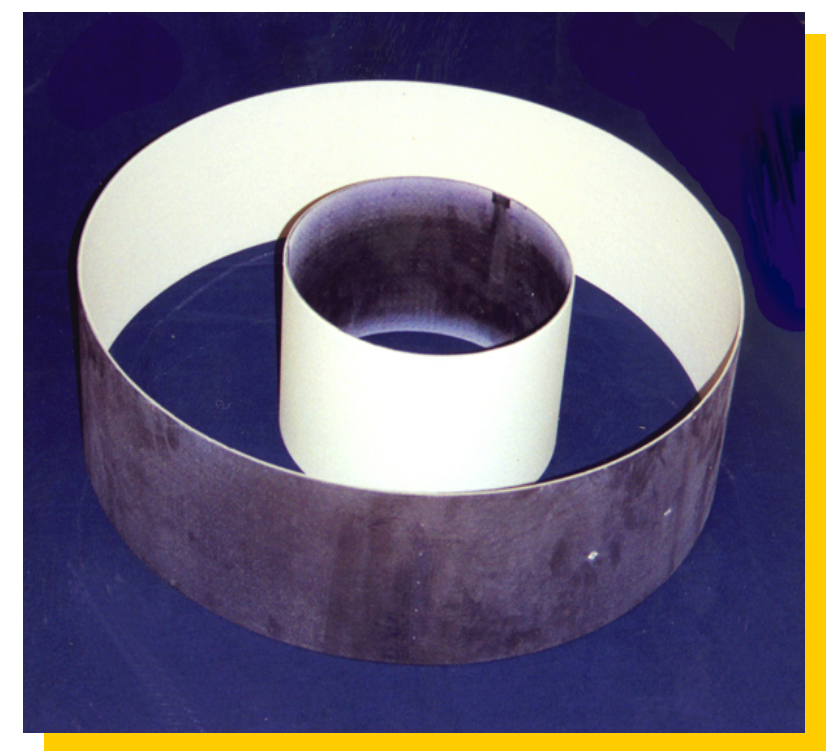

Figure 5.10 CMC Liner Set with EBC for Field Test CT-5

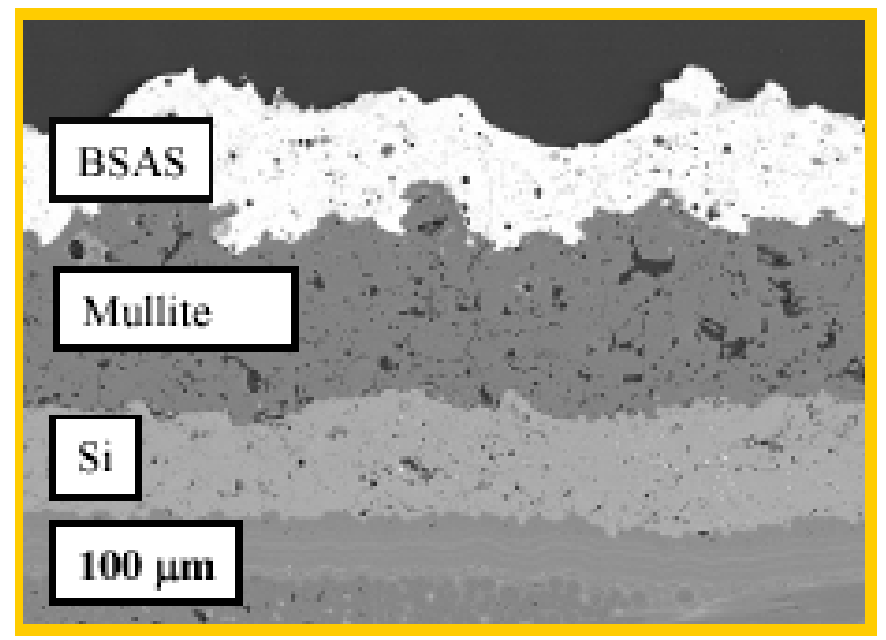

Figure 5.11 Basic EBC Microstructure

The field test was conducted between April 1999 and November 2000. Periodic borescope inspections showed degradation of the EBC and underlying substrate but the liners remained functional until a borescope inspection at 13,937 hrs/61 starts revealed a breach of the inner liner (see Fig. 5.12) [5,16,17]. The engine was subsequently shut down and sent to Solar in San Diego for teardown and inspection. Figures $5.13 \mathrm{a}$ and $5.13 \mathrm{~b}$ are digital photographs of the inner and outer liner, respectively, after the engine test. There is heavy degradation of the EBC and of the underlying CFCCs in areas where the EBC had debonded. Notwithstanding the degradation it is evident that the EBC had provided significant protection to the CFCCs with most of the surfaces fully intact, thereby extending their useful life by a factor of 2-3. Post-test evaluation showed the mixed layer EBC (mullite + BSAS intermediate layer) on the outer CFCC liner to be more protective than the EBC with the single mullite intermediate layer on the inner CFCC liner [15]. This observation correlated with the results of specimen testing in the ORNL Keiser rig under 
simulated gas turbine conditions that showed that the $\mathrm{SiO}_{2}$ layer formed on $\mathrm{Si}$ was $5 \mathrm{x}$ thicker for $\mathrm{Si} /$ mullite/BSAS than that formed for $\mathrm{Si} /$ mullite+BSAS/BSAS [15]. The reduced rate of $\mathrm{SiO}_{2}$ formation was attributed to the absence of excessive microcracking in the mixed-layer EBC, and therefore less oxygen ingress to the Si layer, compared to the Si/mullite/BSAS baseline.

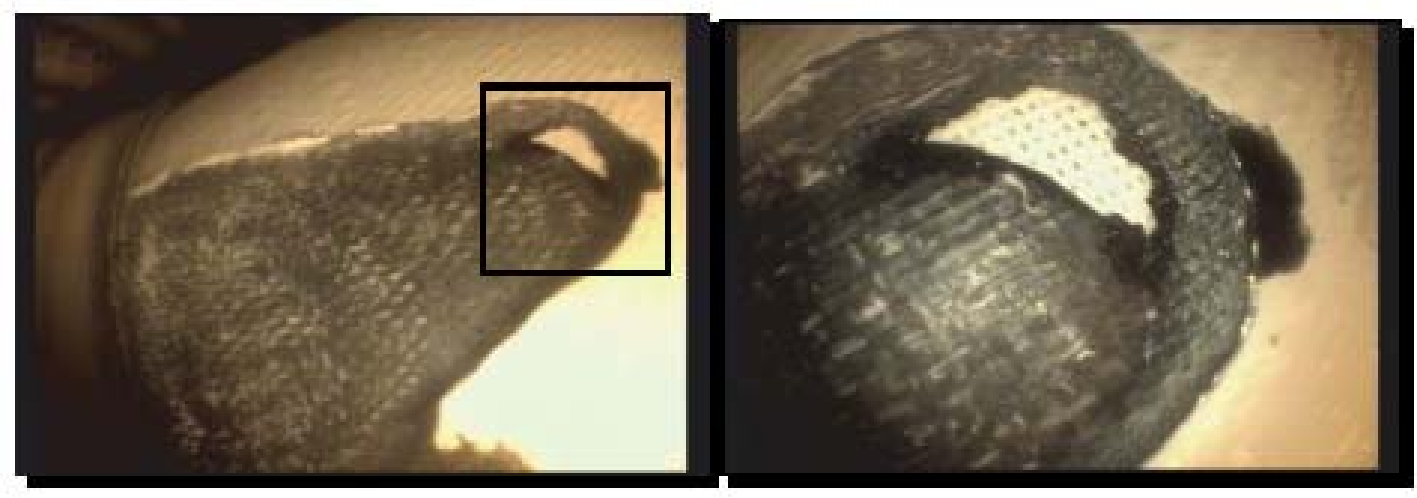

Figure 5.12 Breach in HiNi SiC/BN/SiC-Si (MI) Inner Liner after 13,937-hour Test

(a)

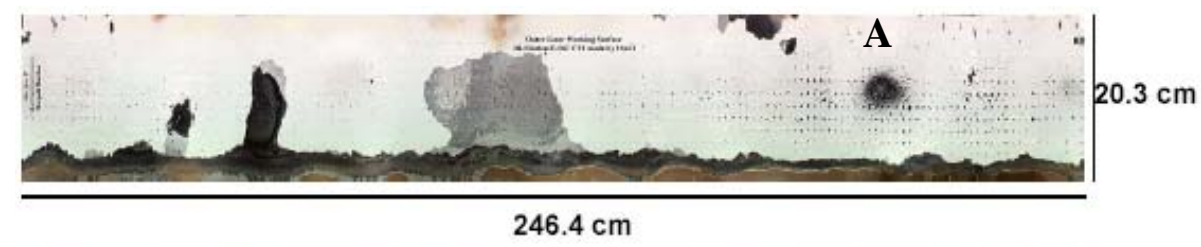

(b)

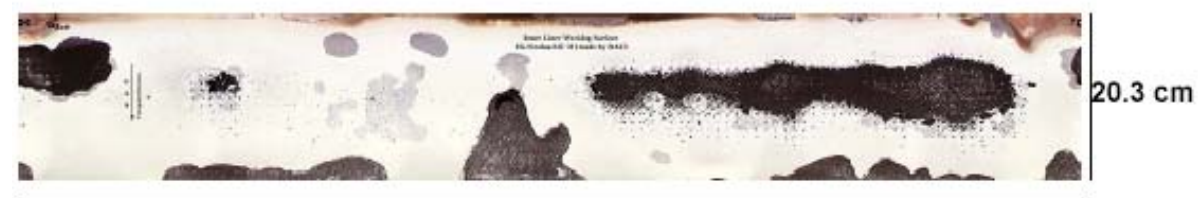

$101.6 \mathrm{~cm}$

(c)

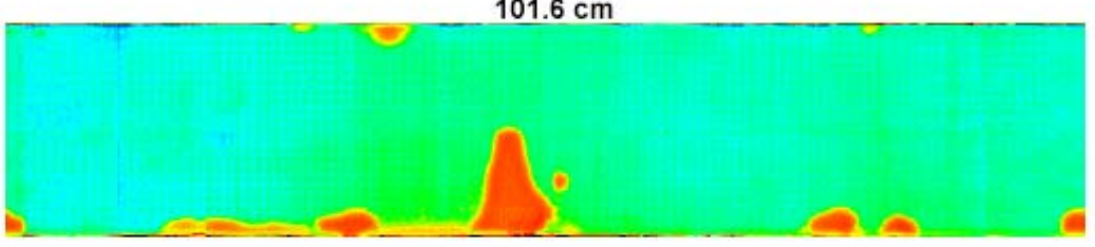

Figure 5.13 Liners after 13,937-hour Test, (a) HiNi SiC/PyC/E-SiC (CVI) Outer Liner, (b) HiNi SiC/BN/SiC-Si (MI) Inner Liner, (c) Thermal Diffusivity Scan of Inner Liner before Test

Extensive NDE was conducted by ANL on the liners as part of pre- and post-test materials evaluation. The purpose of the NDE was two-fold: (1) detecting defects in the as-received liner CFCC, before and after EBC application, prior to field testing, and (2) obtain information on liner CMC and EBC degradation upon completion of the field test, or after interim engine teardowns. Figure $5.13 \mathrm{c}$ is a thermal diffusivity NDE scan of the inner liner prior to the engine field test [5]. Note that there are low diffusivity areas that coincide with areas of degradation on 
the digital photographs (Fig. 5.13b). The NDE suggests possible defects at the inner liner EBCCFCC interface, which subsequently could have led to debonding of the EBC from the substrate.

Other modes of degradation with time included: (1) pitting near surface asperities from processing tooling marks (Figs. 5.14a and 5.14b), (2) surface recession of the BSAS topcoat (which was more severe for the highest temperature regions of the $\mathrm{EBC}$, eventually resulting in localized removal of the BSAS), (3) phase separation of the mullite $\left(3 \mathrm{Al}_{2} \mathrm{O}_{3} \cdot 2 \mathrm{SiO}_{2}\right)$ intermediate layer into $\mathrm{Al}_{2} \mathrm{O}_{3}$ and $\mathrm{SiO}_{2}$ upon exposure to the combustion environment following BSAS removal, and (4) oxidation of the $\mathrm{EBC}$ Si bond coat. It was noted that $\mathrm{EBC}$ spallation tends to occur at the interface of the $\mathrm{SiO}_{2}$ layer formed through oxidation of the $\mathrm{Si}$, and the mullite intermediate layer. It was observed that regions of the BSAS topcoat that were most heavily degraded were enriched in strontium aluminum silicate (SAS) suggesting that the Sr-phases were more stable [15].

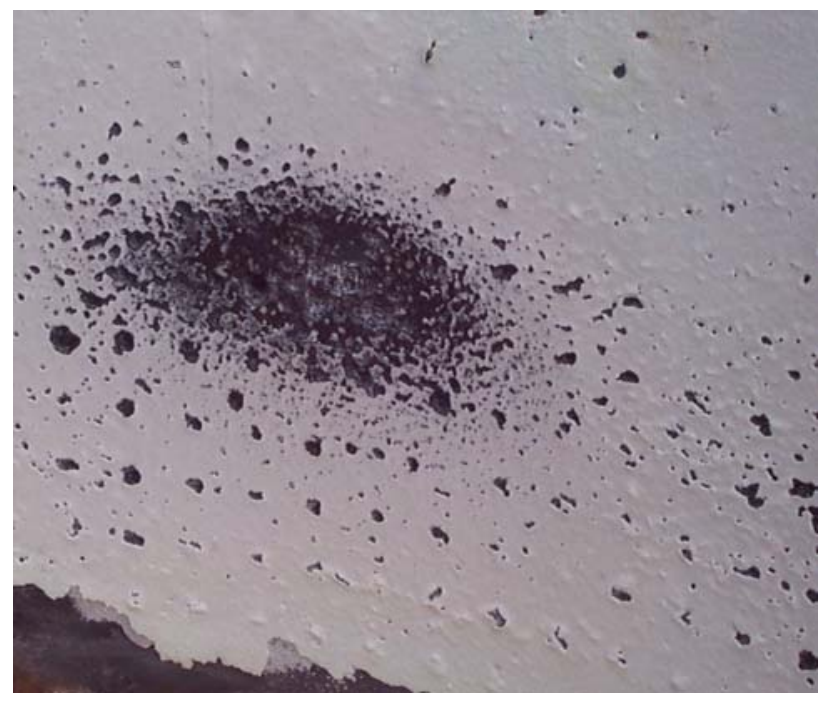

(a)

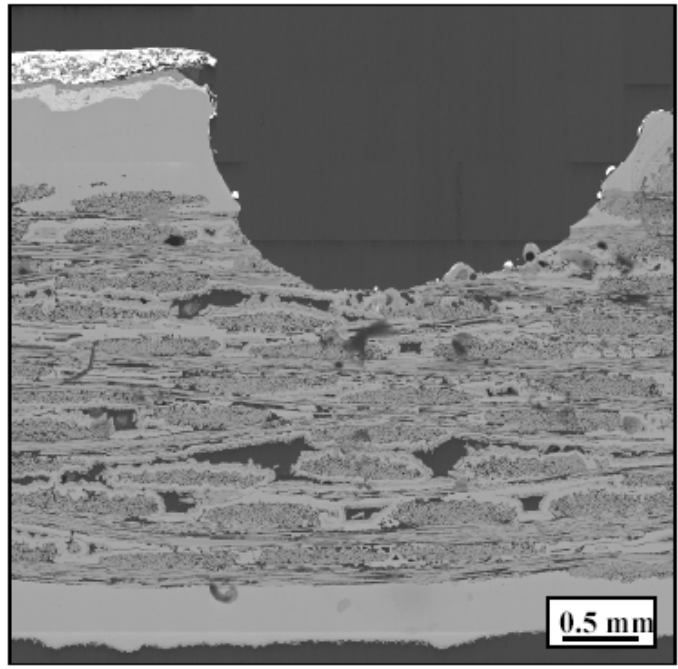

(b)

\section{Figure 5.14 Pitting on the HiNi SiC/PyC/E-SiC (CVI) Outer Liner (a) Area A in Figure 5.13a (b) Pitting Microstructure after 13,937-hour Test (CT-5)}

As was observed for the previous tests there was significant loss of strength in the CFCC/EBC system. Residual tensile strength at room temperature of specimens sectioned from the liner after the $13,937-\mathrm{hr}$ test was $40-60 \%$ of the original material strength, depending on the extent of oxidation [17]. Interestingly, mechanical analysis at ORNL established that even sections of field tested liners for which the $\mathrm{CMC}$ and $\mathrm{EBC}$ appeared to be in good condition had significantly lower strength compared to the as-received component $\mathrm{CMC}$, presumably because of oxidative degradation of the $\mathrm{CMC}$ constituents.

\subsubsection{Engine Field Tests MM-1 and CT-6}

The first test at the Malden Mills site (MM-1), which started in August 1999, was the second test in which the CFCC liners were protected with EBCs. The outer liner $\mathrm{CMC}$ was a $\mathrm{HiNi} / \mathrm{PyC} / \mathrm{E}-$ $\mathrm{SiC}(\mathrm{CVI})$ from $\mathrm{ACI}$ and the inner liner CFCC was a $\mathrm{HiNi} / \mathrm{BN} / \mathrm{SiC}-\mathrm{Si}(\mathrm{MI})$ from BFG. The $\mathrm{EBC}$ was $\mathrm{Si} /$ mullite $+\mathrm{BSAS} / \mathrm{BSAS}$, similar to the $\mathrm{EBC}$ on the outer liner CFCC in the CT-5 
engine field test. This mixed-layer EBC was selected because it provided better protection than the baseline Si/mullite/BSAS EBC. The test was terminated in October 2000 after 7,238 hrs and 159 starts due to an engine problem not associated with the CFCC liners. Composite digital photographs of inner and outer liner are shown in Fig. $5.15[5,16]$. The outer liner had significantly more EBC spallation than the inner liner. The CFCCs were in relatively good condition since the EBCs had been largely protective, and a decision was made to strip the EBCs from the CFCC liners, recoat the liners with new EBCs, and resume liner testing [17,18]. The refurbished EBC for the outer liner was similar to that for the MM-1 test, but the inner liner had a Si/BSAS EBC, to evaluate if the mullite layer could be eliminated, since which would simplify the EBC application process.

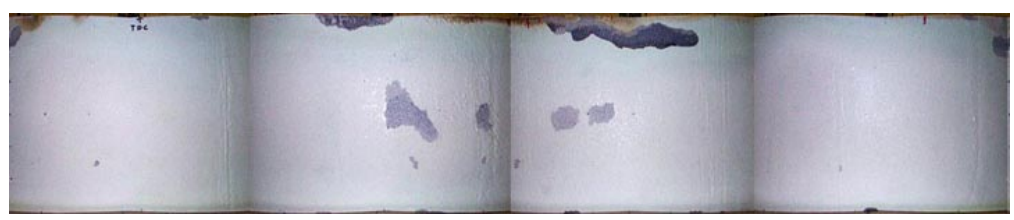

(a)

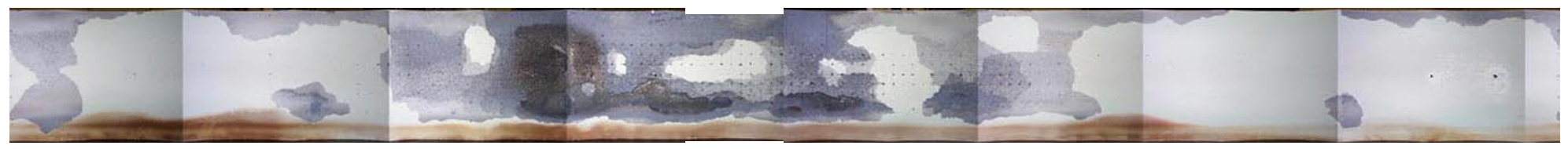

(b)

Figure 5.15 Digital Photographs of (a) HiNi/BN/SiC-Si (MI) Inner Liner and (b) HiNi/PyC/E-SiC (CVI) Outer Liner after 7,238-Hour Field Test (MM-1)

The refurbished liners were field tested (CT-6) for an additional 5,135 hrs at the Bakersfield site between September 2001 and May 2002, to give a cumulative total of 12,373 hrs and 202 starts. The liners in the combustor housing after teardown at Solar in San Diego are shown in Fig. 5.16. There was EBC degradation for both liners, but the localized degradation of the inner liner was more severe, possibly because of a eutectic reaction between the $\mathrm{SiO}_{2}$ oxidation product from the Si bond coat and the BSAS layer at the higher temperature areas of the inner liner. The presence of mullite in the intermediate layer prevents the eutectic reaction, and its incorporation into the $\mathrm{EBC}$ is therefore beneficial.

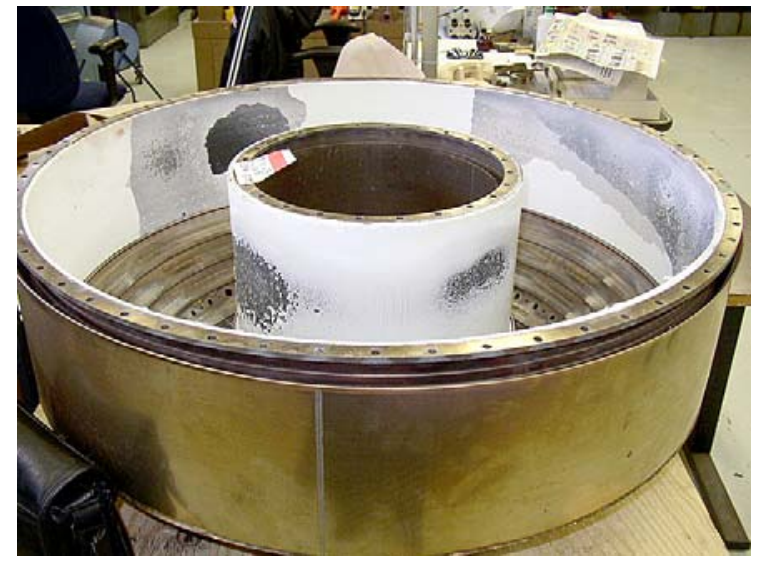

Figure 5.16 Liners of MM-1 Field Test after Additional 5,135-Hours Field Test (CT-6)Total Test Time: 12,373 Hours (CT-6) 


\subsubsection{Engine Field Test MM-2}

This test, conducted between August 2000 and July 2002, was the longest to-date with 15,144 hrs and 92 starts. The outer liner CMC was a HiNi/PyC/E-SiC (CVI) liner from Honeywell Advanced Composites, Inc. (HACI - the successor to ACI in 1999 after the merger of AlliedSignal with Honeywell), while the inner liner was a TyZM/BN/SiC-Si (MI) liner from BFG. This was the first test in which the Hi-Nicalon fiber in the inner liner was replaced with the less expensive Tyranno ZM fiber. A SiC seal coat had been applied to both liners. The SiC seal coat is a dense surface coat which slows down ingress of oxidative species into the underlying more porous $\mathrm{CMC}$. Both liners had the mixed-layer Si/mullite+BSAS/BSAS EBC [19].

The MM-2 field test was stopped because of circumferential and lateral cracks in the inner liner that had progressed through the CFCC thickness (Fig. 5.17). While the EBC was still present on the majority of the liner surface, there was severe EBC degradation in the hottest areas, in close proximity to the fuel injectors. Aft edge spallation of the EBC observed in previous tests (e.g. Fig. 12 - outer liner) was lessened, presumably because the EBC was also applied to the edges of the liners for this test. There was extensive oxidation and surface recession on the cold-side surfaces of the inner liner (ID). The cracking of the inner liner matched areas of high thermal diffusivity in NDE scans. The high thermal diffusivity that correlates with high thermal conductivity, and therefore higher temperatures on the cold side of the liner, was attributed to CFCC liner processing variations, localized higher density, lower thickness, or higher Si concentration. The higher temperature can be expected to accelerate the degradation on the cold side of the liner. Additionally, the circumferential cracking, which became apparent during borescoping early on in the test, could have resulted in the ingress of hot combustion gases into the liner, and subsequently accelerated degradation throughout the bulk and surfaces of the CFCC. Microstructural evaluation clearly showed the presence of a $\mathrm{SiO}_{2}$ oxidation layer at the (Si/mullite+BSAS) interface (Fig. 5.18). Surface recession of the BSAS layer and phase separation of mullite in the mixed intermediate layer was also observed. The Tyranno ZM fiber in the inner liner CFCC showed no degradation in areas where the fiber was protected. This indicated that the less expensive Tyranno ZM fiber performed similarly to the Hi-Nicalon fiber under the conditions of the field test [19].

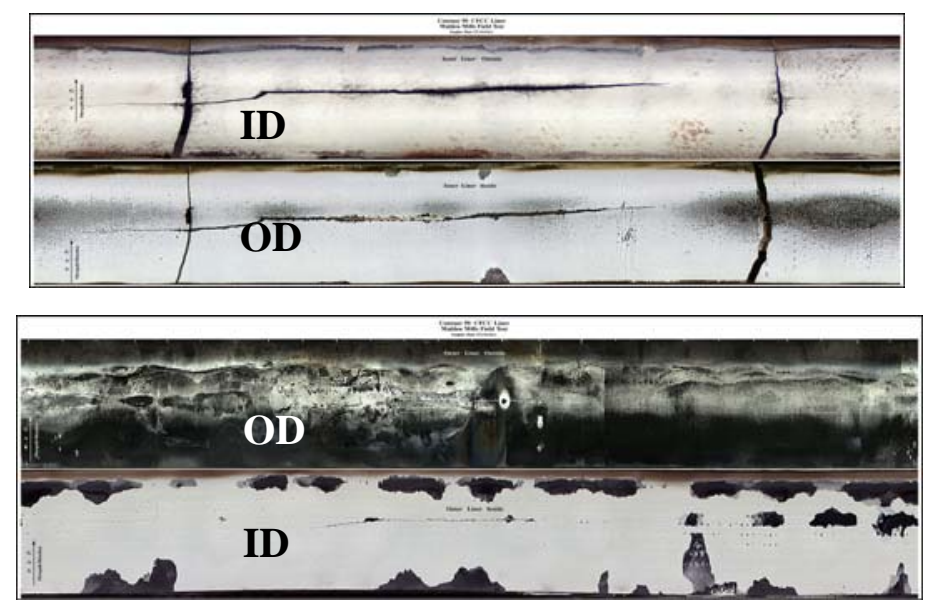

Figure 5.17 Digital Photographs of (a) TyZM/BN/SiC-Si (MI) Inner Liner and (b) HiNi/PyC/E-SiC (CVI) Outer Liner after 15,144-hour Field Test (MM-2); ID/OD: Inner/Outer Diameter 


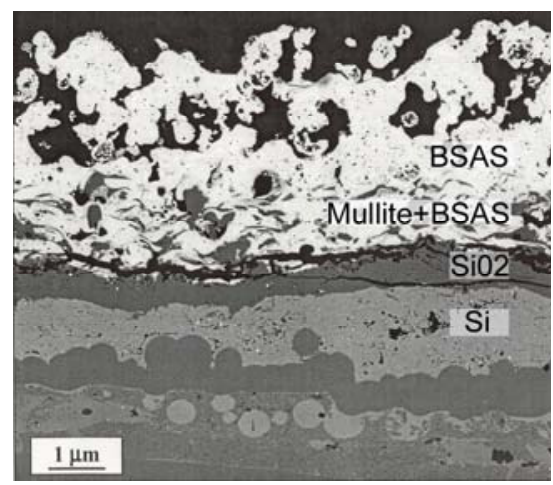

Figure 5.18 $\mathrm{SiO}_{2}$ Layer on EBC at the (Si/Mullite+BSAS) Interface - Inner Liner after 15,144-hour Test

\subsubsection{Engine Field Test MM-3}

The last CFCC liner field test at the Malden Mills site, conducted between July 2002 and July 2003, was the first test in which both inner and outer liner CFCC had been processed by melt infiltration. The TyZMI/BN/SiC-Si CFCC incorporated the Tyranno ZMI fiber of Ube Corp. Both liners had been fabricated by GE Power Systems Composites (PSC), which had acquired HACI in 2001. The details of the field test of this liner set can be found in an ASME paper [20]. Degradation on the cold side of these liners was severe, presumably because no SiC seal coat had been applied to these liners (potential cost saving from CFCC processing simplification). The absence of a $\mathrm{SiC}$ seal coat exposes the porosity of the $\mathrm{CMC}$, leading to significant oxidative degradation. The EBC had been modified from previous tests by replacing the BSAS with SAS, because steam rig testing at UTRC had shown SAS to degrade less than BSAS. The EBC compositions used were $\mathrm{Si} / \mathrm{SAS}$ for the inner liner and $\mathrm{Si} /$ mullite+SAS/SAS for the outer liner. Borescoping at the 3174-hr mark indicated significant spallation of the SAS topcoat on the inner liner. The degradation of the Si/SAS liner EBC resulted in termination of the field test after $8,368 \mathrm{hrs}$ and 32 starts. The liner set after the test is shown in Fig. 5.19. It was concluded that the dual layer Si/SAS EBC was unstable. Interestingly, the low stability of the Si/SAS EBC parallels that of the dual-layer Si/BSAS EBC in the CT-6 field test. Cursory visual inspection indicated the $\mathrm{EBC}$ on the outer liner to be in good condition. However, microscopy revealed significant degradation of the SAS topcoat and $\mathrm{SiO}_{2}$ depletion in the mixed (mullite + SAS) interlayer of the outer liner EBC. The results of the MM-3 field test did not corroborate the favorable results of the steam rig testing at UTRC. Further optimization of the Si/mullite + SAS/SAS process will be required to take advantage of the lower surface recession of SAS compared to BSAS.
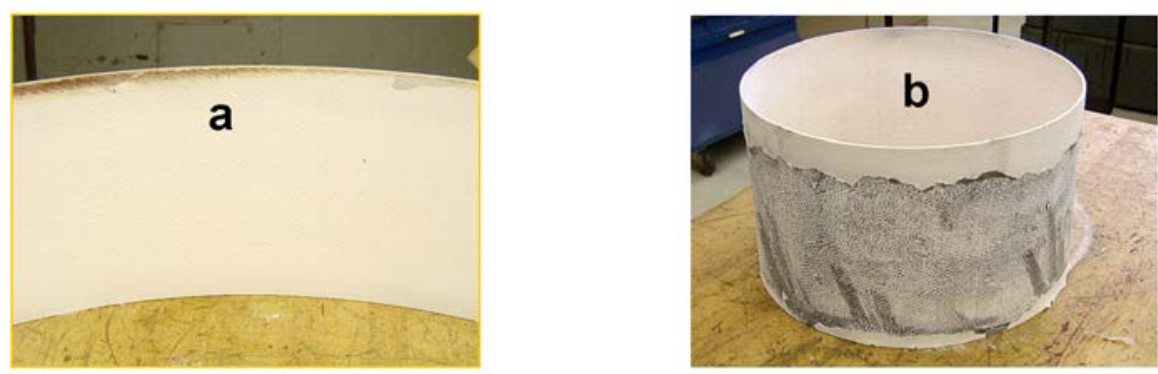

Figure 5.19 TyZMI/BN/SiC-Si (MI) Outer Liner (a) and Inner Liner (b) after 8,368-hour Field Test (MM-3) 


\subsubsection{Engine Field Tests CT-7 and CT-8}

Field test CT-7 was initiated in May 2003 at the ChevronTexaco Bakersfield site to evaluate an oxide/oxide CFCC outer liner that had been developed under an Advanced Technology Program (ATP) project of the U.S. National Institute of Standards and Technology (NIST). The project was collaboration between Siemens Westinghouse Power Corp. (SWPC), ATK COI Ceramics (COIC), and Solar. Under this program, an outer liner had been fabricated based on a hybrid of an $\mathrm{Al}_{2} \mathrm{O}_{3} / \mathrm{Al}_{2} \mathrm{O}_{3} \mathrm{CFCC}$ with a thermally protective Friable Graded Insulation (FGI) surface coating. The FGI, which has an aluminosilicate composition and enables operation at high turbine inlet temperatures, can significantly lower the temperature of the underlying oxide/oxide CFCC substrate. In a high pressure rig test at Solar under the NIST ATP project the temperature gradient over the outer liner reached $\sim 611^{\circ} \mathrm{C}\left(\sim 1100^{\circ} \mathrm{F}\right)$. The maximum outer liner surface temperature was $\sim 1149^{\circ} \mathrm{C}\left(\sim 2100^{\circ} \mathrm{F}\right)$. The combustor primary zone temperature was $\sim 1538^{\circ} \mathrm{C}$ $\left(\sim 2800^{\circ} \mathrm{F}\right)$. Actual liner temperatures were not measured during engine testing but a temperature gradient profile similar to that in the high-pressure rig test can be expected. The development of the hybrid oxide CFCC technology has been described in an ASME paper [21]. Initially, the inner liner in this test was a HiNi/BN/E-SiC (CVI) CFCC, fabricated in the 1998-1999 timeframe by DLC/ACI. A hybrid oxide CFCC inner liner was not available at the time of the test.

In mid-2003, at the conclusion of the NIST ATP project, the liners had been tested for over 1,000 hrs. Since borescoping showed the outer liner to be in excellent condition the NIST program participants and the DOE agreed to continue the field testing under the DOE-sponsored Advanced Materials program. Figure 5.20 shows the liner prior to engine testing. The liner is naturally white in color. The outside of the liner was painted dark to facilitate NDE.

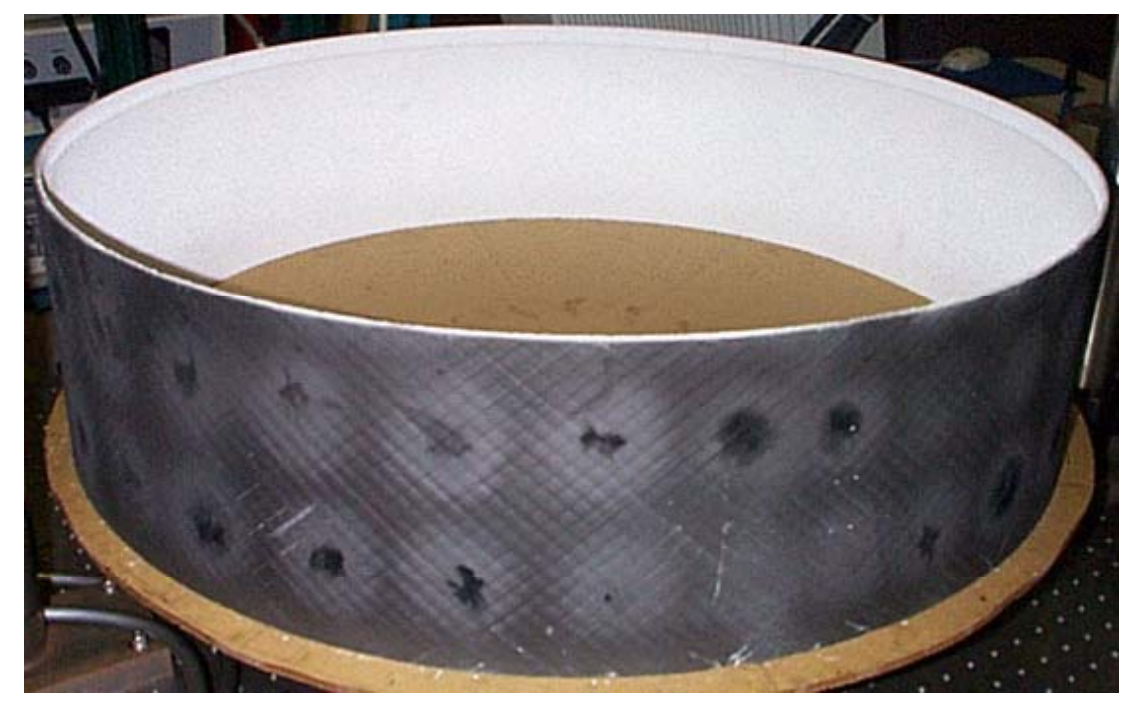

Figure 5.20 Outer Hybrid Oxide CFCC Liner Prior to Engine Field Testing

Figure 5.21 shows borescope images of the hybrid oxide CFCC liner taken at various times during its operation (1,026 hours/19 starts, 5,885 hours/40 starts, 10,667 hrs/61 starts). The images illustrate the condition of the FGI surface. The diagonal line in Fig. 20c represents a step in the FGI thickness to accommodate the liner attachment. While the outer liner did not show 
any apparent signs of degradation, the $\mathrm{SiC} / \mathrm{SiC}$ CFCC inner liner displayed significant EBC degradation at borescope inspections at 5,885 hrs and 10,667 hrs, as expected from a CVI $\mathrm{SiC} / \mathrm{SiC} \mathrm{CMC}$ with an early vintage $\mathrm{EBC}$.
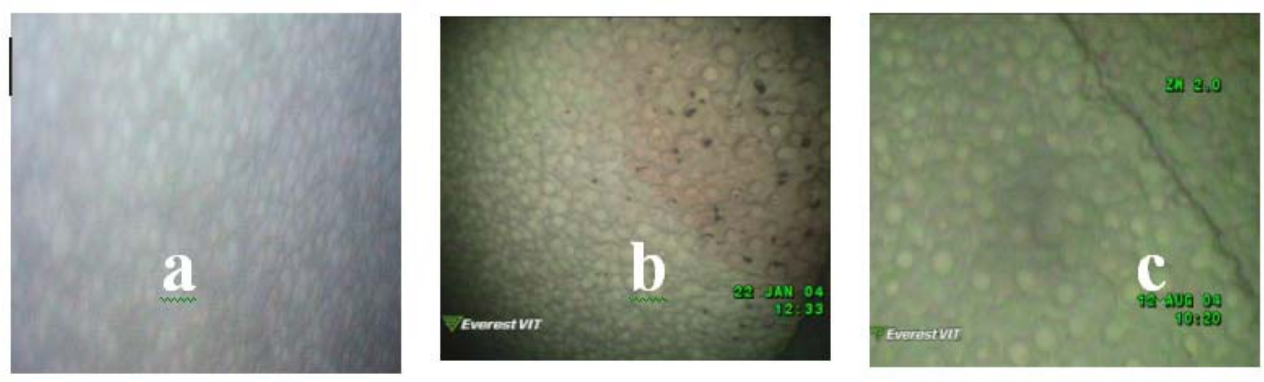

Figure 5.21 Borescope Views of Hybrid Oxide CFCC Outer Liner at (a) 1026 Hours/ 19 Starts, (b) 5,885 Hours/40 Starts, (c) 10,667 Hours/ 61 Starts

In November 2004, Chevron made a decision to temporarily halt the operation at the Fee "C" Lease site, which provided an opportunity to take the Centaur ${ }^{\circledR} 50 \mathrm{~S}$ engine out of service and ship it back to Solar for teardown and inspection. The engine field test was interrupted on November 10, 2004 after 12,582 hrs and 63 starts. Figure 5.22 shows a section of the liner following intermediate teardown. Surface erosion, affecting about $1-2 \mathrm{~mm}$ of the initial $\sim 5 \mathrm{~mm}$ FGI thickness was noticed. The erosion was most noticeable in locations in close proximity to the flame of the fuel injectors. Field testing was resumed after patch repair of one of the eroded areas and an area of FGI degradation near the aft end of the liner.

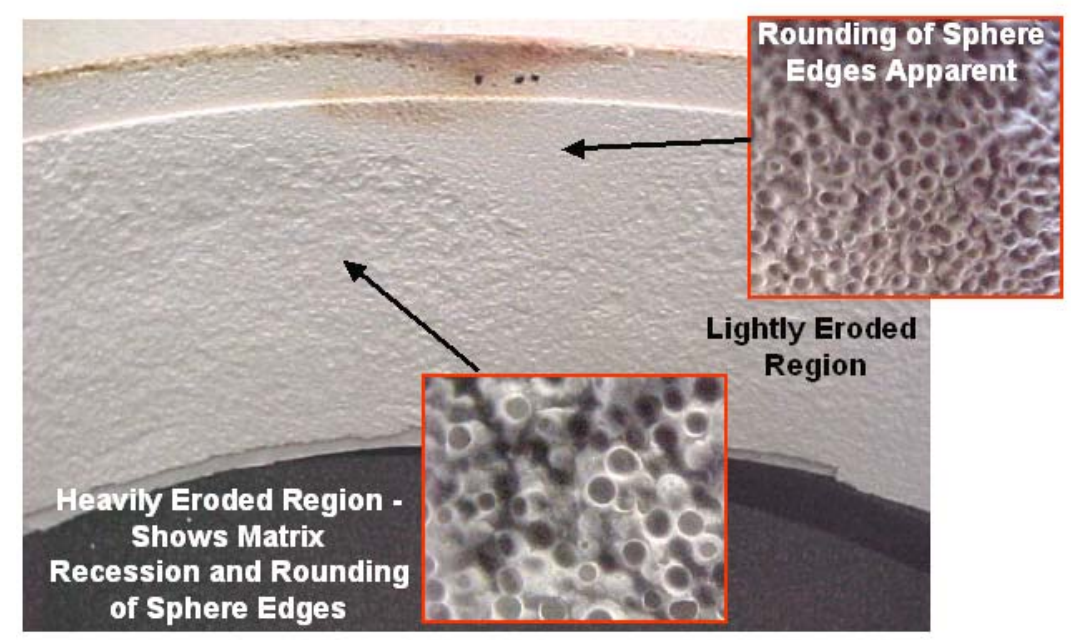

\section{Figure 5.22 Section of the Hybrid Oxide CFCC Liner after 12,582 Hours/63 Starts Showing Surface Erosion}

Figure 5.23 shows the $\mathrm{SiC} / \mathrm{SiC}$ inner liner after 12,582 hours of field testing. No detailed analysis of this liner was conducted since this was outside the scope of the program. Visual inspection showed that large areas of the EBC had degraded. About $20 \%$ of the EBC had 
debonded/spalled. In areas where the EBC had been removed extensive glass formation and surface recession of the $\mathrm{SiC} / \mathrm{SiC} \mathrm{CFCC}$ was observed. The degradation pattern was similar to that for other $\mathrm{EBC}$-coated $\mathrm{SiC} / \mathrm{SiC}$ liners in engine field testing. A white deposit had formed on the inside of the inner liner that had a SiC seal coat, but no EBC. A decision was made not to use this degraded inner liner for continued field testing.

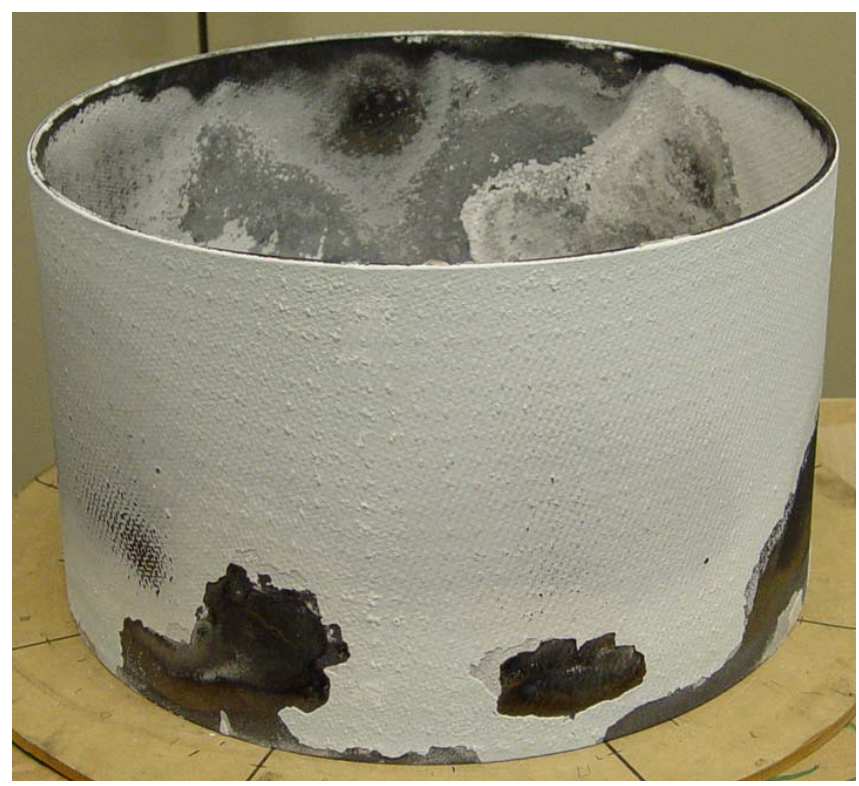

Figure 5.23 SiC/SiC CFCC Inner Liner with EBC after 12,582 Hours of Engine Field Testing

The repaired Hybrid Oxide CFCC liner (Fig. 5.24) was then reinstalled into the Centaur ${ }^{\circledR}$ 50S combustor assembly. A new HiNi/BN/SiC-Si (Hi-Nicalon-reinforced, pre-preg, melt-infiltrated $\mathrm{SiC}$ matrix, BN interface) inner liner supplied by GE PSC (GE Power Systems Composites, currently GE Ceramic Composite Products, GE CPP) was used for the remainder of the test (Fig. 5.25). The engine with the two CFCC liners was shipped back to Chevron Bakersfield for installation, and field testing (test CT-8) was resumed on January 20, 2005. This engine operated for an additional 12,822 hours and accumulated 46 more starts until the test was concluded in November 2006 after the program milestone of 25,000 hours of operation had been achieved. Total time on the hybrid oxide outer liner was 25,404 hours with 109 starts. 


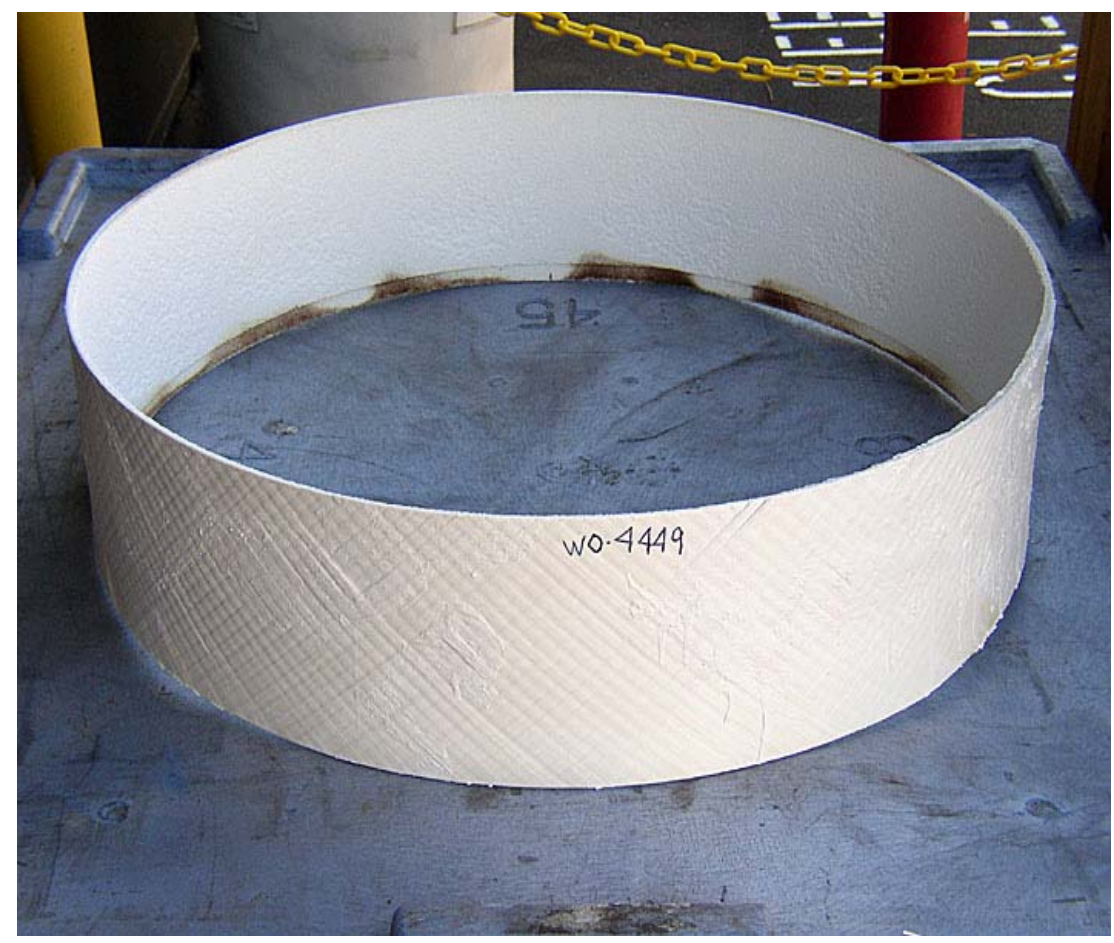

Figure 5.24 Repaired Hybrid Oxide CFCC Liner with FGI Prior to Continuation of the Field Test

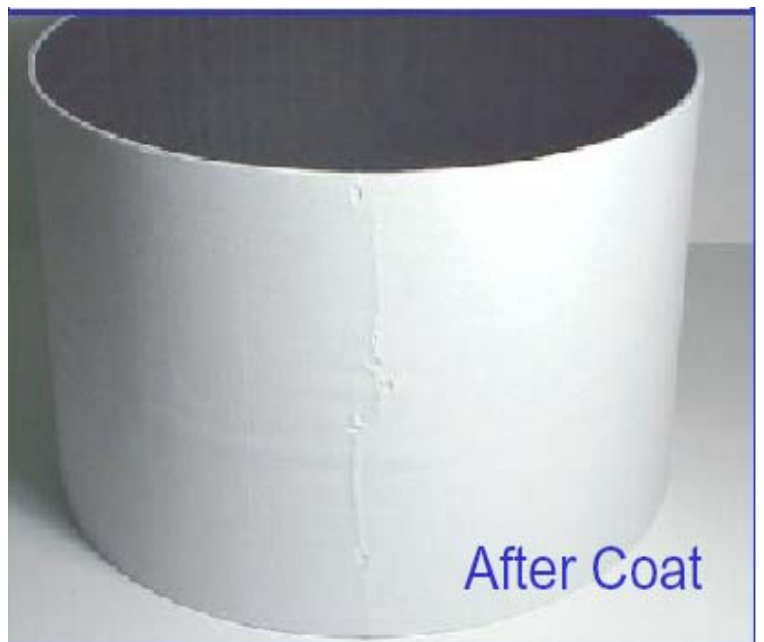

Figure 5.25 New CFCC SiC/SiC (Prepreg) Inner Liner - Photo Courtesy of GE Global Research Center

Three more borescope inspections were conducted after the engine resumed operation in January 2005. Two new features were observed on the Hybrid Oxide CFCC liner during these inspections. Figure 5.26 shows a borescope image taken after 16,565 hours and 81 starts. It was difficult to tell from the borescope images whether this fairly large area was indicative of severe degradation of the FGI coating. However, when the engine was returned after having completed 
25,404 endurance test hours it was determined that this area was in fact the eroded FGI area that had been repaired and was standing proud above the FGI surface. A second feature that was present in all three of the later borescope inspections can be seen in Fig. 5.27. In this large area the FGI appears to have spalled, exposing the CFCC. It is believed that loss of the FGI resulted in overheating of the CFCC and causing it to delaminate.

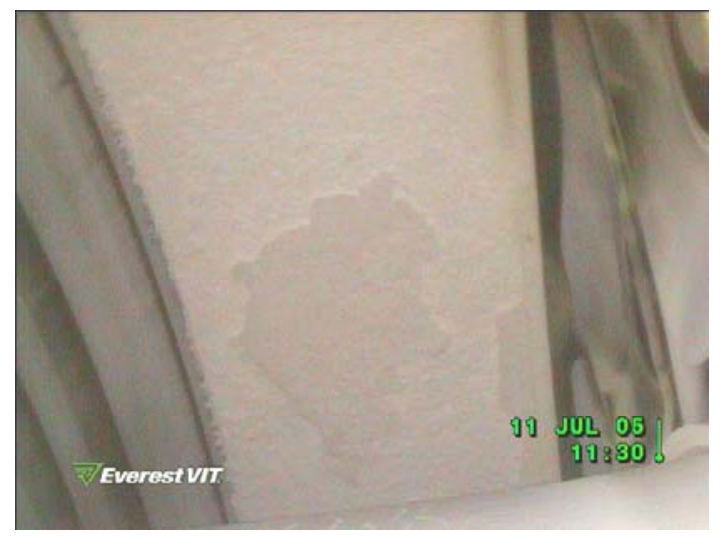

Figure 5.26 Patched Area in Borescope after 16,566 Hours and 81 Starts

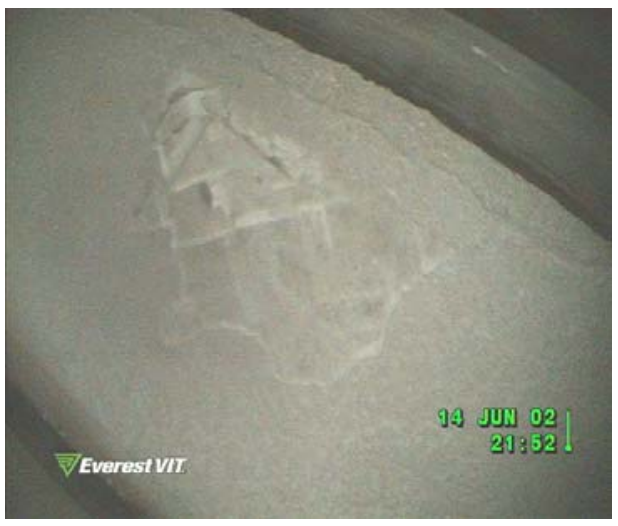

Figure 5.27 Degraded Area in Borescope Taken at 22,132 Hours and 97 Starts

Upon return to Solar in San Diego the engine the CFCC combustor liners were removed after engine tear down and visually inspected. Figure 5.28 shows the hybrid oxide CFCC liner after removal from the engine. Overall, the liner was intact, but did show several signs of distress. The visual inspection indicated that there was continued erosion and loss of FGI from the hot surface of the liner. However, the areas of FGI that had been repaired using a more stable FGI formulation were evidently much more erosion resistant than the base FGI.

This can be seen in Figures 5.29 and 5.30, where the repaired FGI protrudes from the surface. Figure 5.30 also shows the area where the FGI had spalled and the CFCC was exposed to high temperatures, causing plies to separate and curl. Also, there were several areas on the cold side of the liner where the CFCC plies had separated and caused delaminations. Several of these were located on the backside of the areas where FGI had been lost, therefore potentially resulting 
in high thermal gradients. The brown discolorations seen on the end of the liner shown in Figure 27 are a result of contact and contamination with the interfacing metal components.

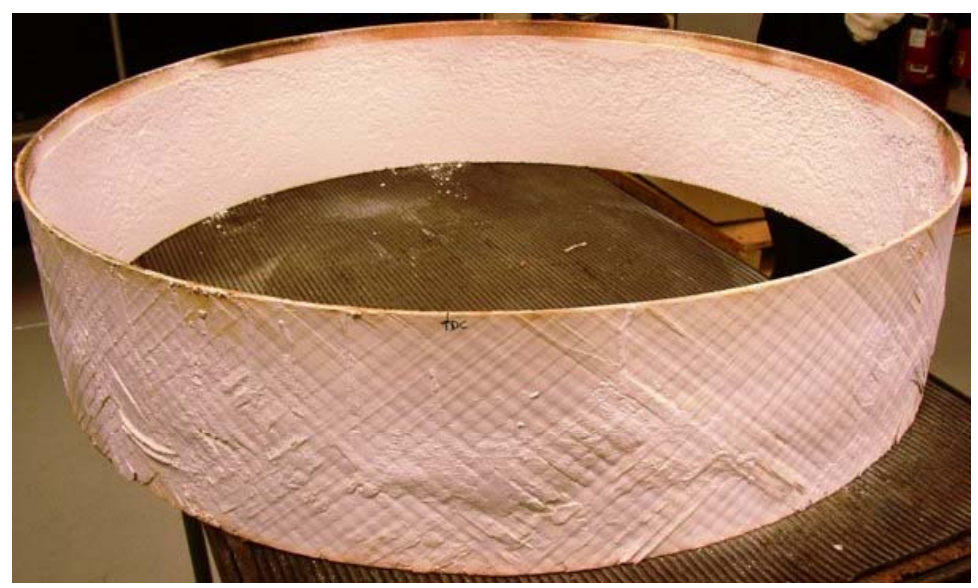

\section{Figure 5.28 Hybrid Oxide CFCC Outer Liner after 25,404 Hours of Engine Testing}

Visual inspection also indicated large areas of considerable CFCC porosity/delamination within a few plies from the cold (OD) surface. These areas were very soft, and showed much lower through-thickness thermal diffusivity and air-coupled ultrasound transmission during NDE. Even in "good" regions (which had relatively higher diffusivities), the diffusivity values were much lower than they were before the engine test, indicating overall damage in the entire liner (increased porosity and cracking within the CFCC).

The evidence supported delaminations in the CMC near the hot surface, rather than debonds between FGI and CFCC. The spallation near the aft edge of the liner, where the overlying FGI was lost, is therefore most likely the result of a near-surface delamination in the CFCC.

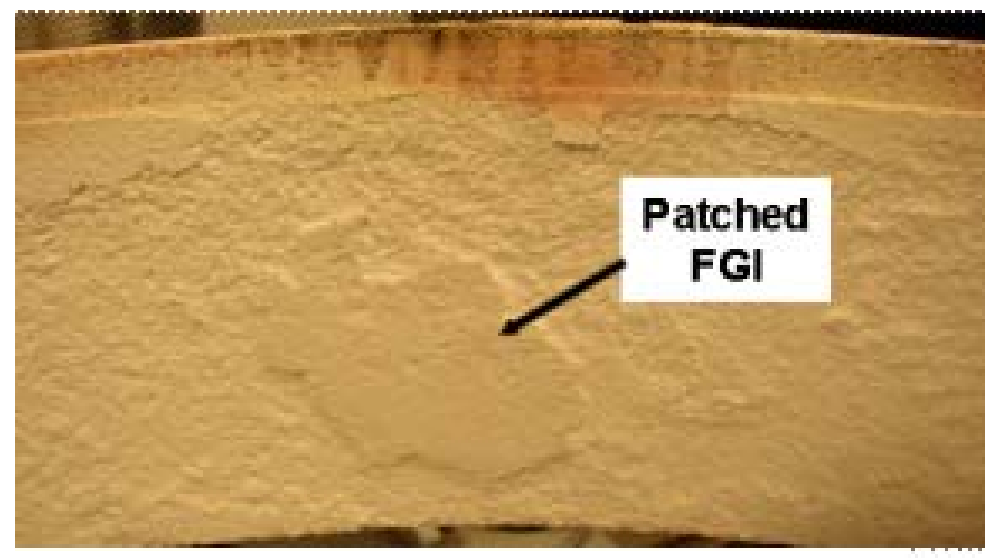

Figure 5.29 Repaired Section of FGI 


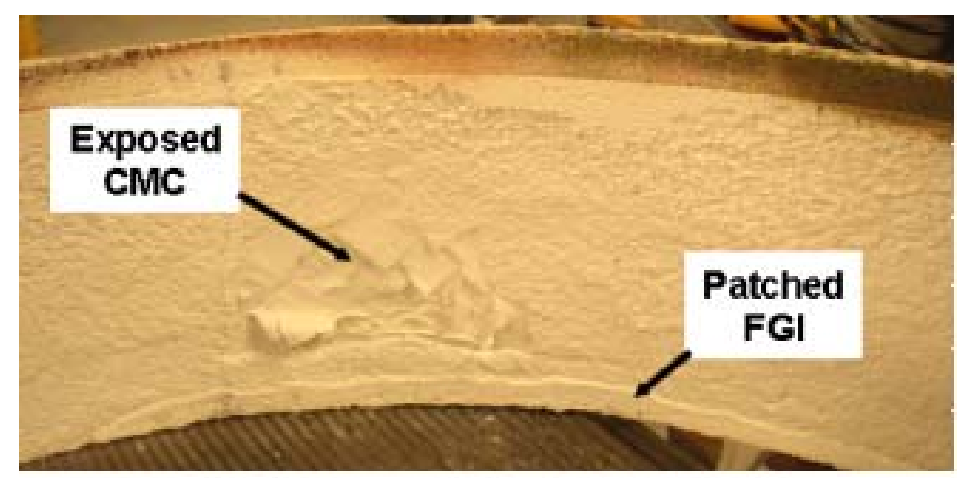

Figure 5.30 Repaired Section of FGI and Exposed CFCC

Figure 5.31 shows digital photographs and a thermal diffusivity NDE scan after completion of the engine test at 25,404 hours. The dark hue of the scan has indicates substantial CFCC porosity and delamination. The area where the FGI was removed had noticeably higher apparent diffusivity, and the spallation of some underlying CFCC layers, had significantly reduced the local thickness.

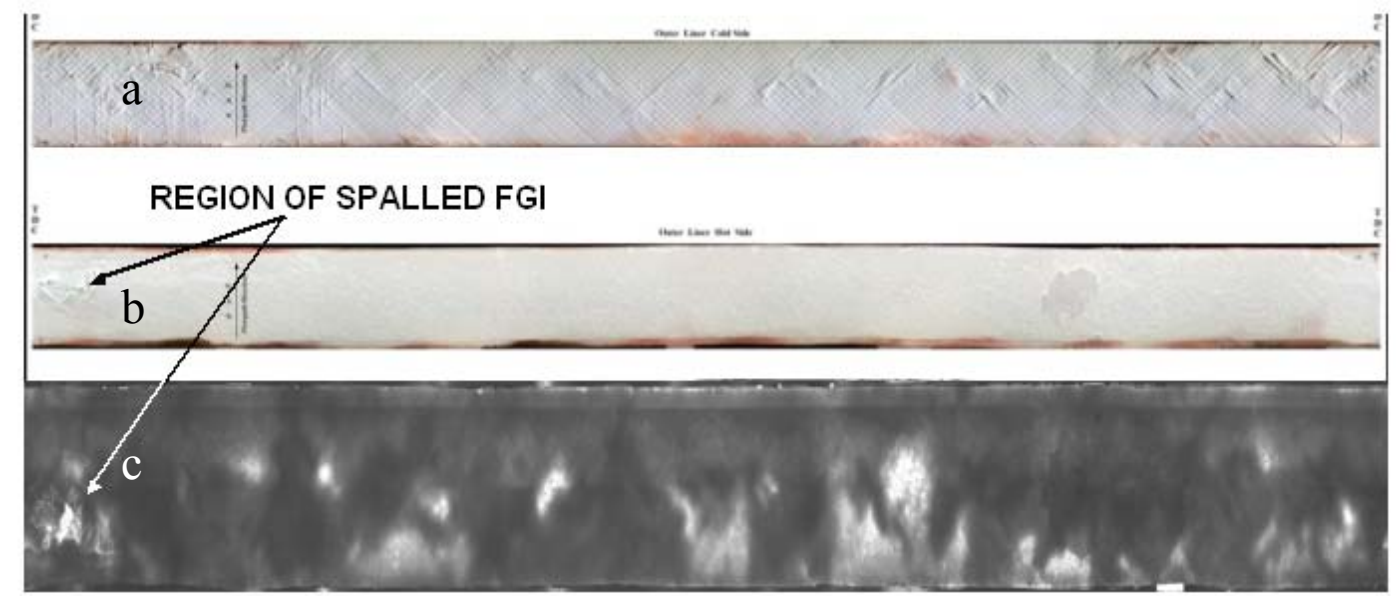

Figure 5.31 Digital Photographs after 25,404 Hours of Engine Field Testing (a) CFCC Surface, (b) FGI Surface, (c) Thermal Diffusivity Scan

Figure 5.32 shows the second $\mathrm{SiC} / \mathrm{SiC}$ CFCC inner liner after the test. This liner, while showing evidence of limited EBC degradation near the central (hot) zone of the liner, was in reasonably good shape, compared to the first $\mathrm{SiC} / \mathrm{SiC}$ inner liner removed at the intermittent combustor teardown. GE estimated that the total EBC spalled area was $\sim 0.6 \%$ of the surface of the liner, with $\sim$ two-thirds of the spalled area confined to the edges, possibly caused by mechanical vibrations. Analysis of this second $\mathrm{SiC} / \mathrm{SiC}$ inner liner is in progress at GE GRC. 


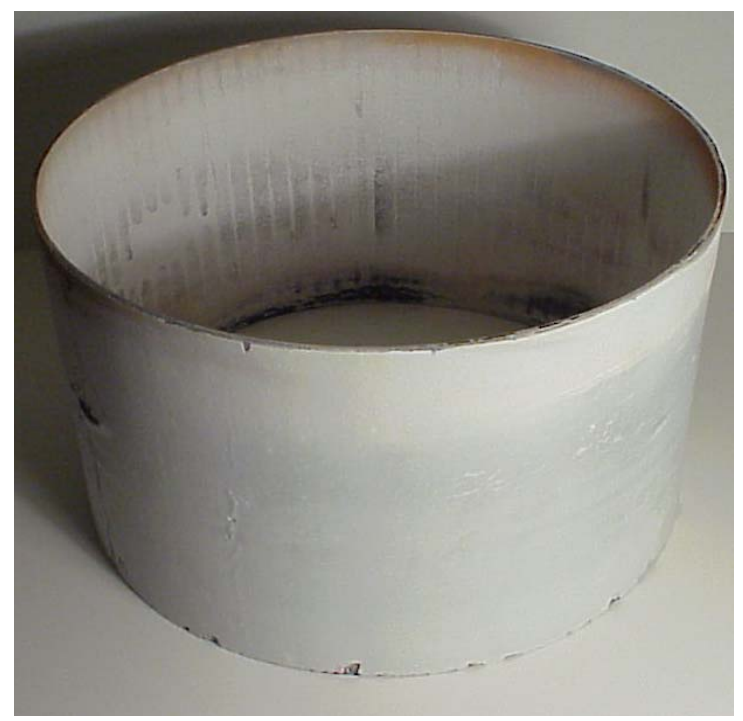

\section{Figure 5.32 SiC/SiC CFCC Inner Liner after 12,822 Hours/46 Starts - Photo courtesy GE GRC}

A meeting was held between technical personnel of Solar, COIC, SPG, ORNL and ANL to review the results of visual inspection of the hybrid oxide CFCC outer liner and to discuss an initial sectioning plan in preparation for metallographic examination and residual property analysis. The liner was subsequently shipped from Solar to ORNL where the liner characterization was conducted under ORNL's contract with DOE. The objectives were to examine the microstructure and mechanical properties of the tested liner, and compare these with those of an as-processed liner of the same composition, which was fabricated at the same time and using the same fabrication process as was used for the tested liner. CMM fore-to-aft thickness profiles of the engine-tested liner were measured. The microstructure-related degradation mechanism that contributed to surface/thickness loss was characterized. Bulk liner features such as eroded areas, holes and patches were also examined. Figure 5.33 shows the liner sectioning plan. Specific areas were selected for residual thickness measurements, examination of patched areas, a hole in the liner and to elucidate defects that had surfaced in NDE scans. 


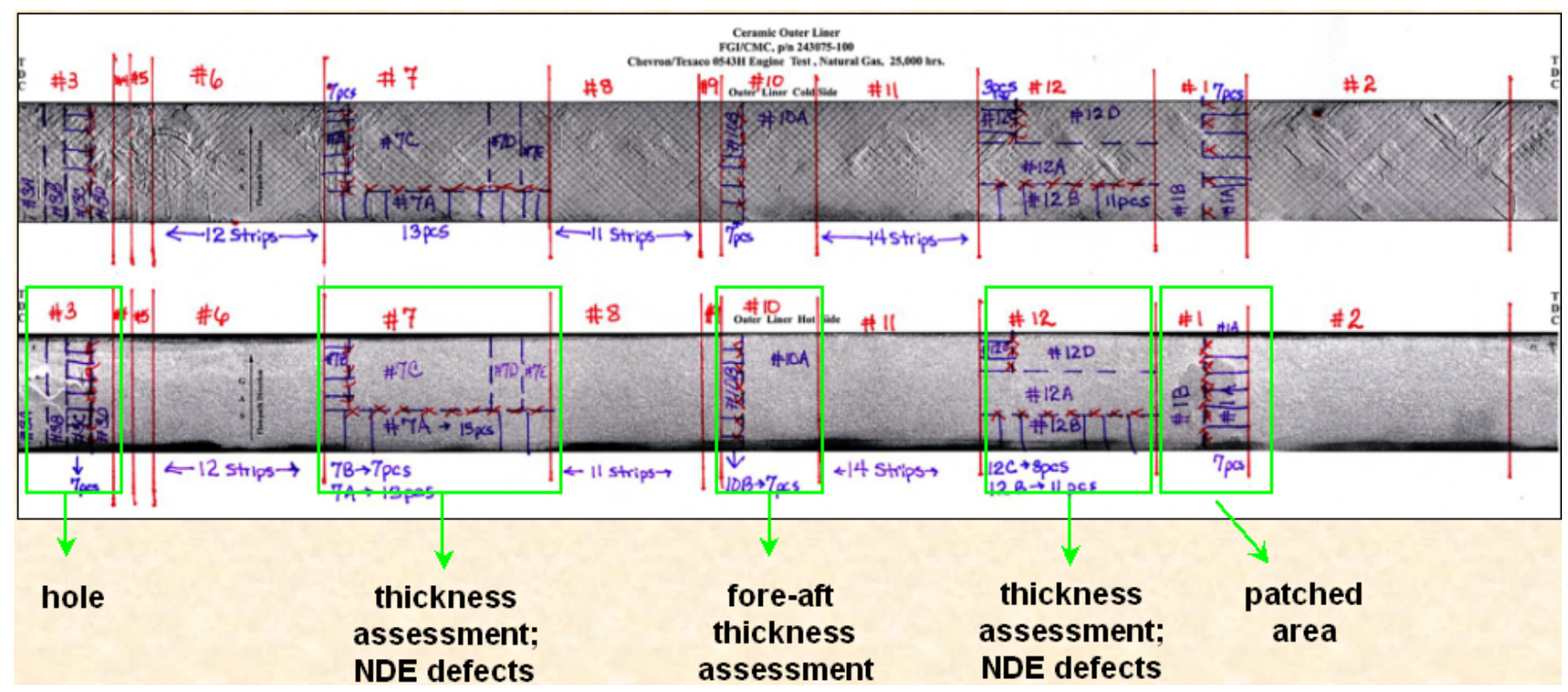

Figure 5.33 Hybrid Oxide CMC Liner Sectioning Plan, Showing Hole and Patch Features
and Areas Delineated for Thickness Measurements and Examination of
Defects that Showed in NDE - Photo courtesy of ORNL

A detailed account of the hybrid oxide CFCC liner field testing has been presented at a 2008 ASME conference [22]. A paper on the microstructural analysis of this liner and its residual mechanical properties, conducted by ORNL under separate contract to DOE, is planned at a 2009 ASME conference [23].

The microstructural analysis of the degradation of the FGI is very apparent in an eroded area near the center of the liner, when compared to a fully intact FGI of an as-processed liner (Fig. 5.34). The FGI thickness in the as-processed liner is $\sim 5 \mathrm{~mm}$. The final FGI thickness in the eroded area of the engine-tested liner is $\sim 2.0-2.6 \mathrm{~mm}$. The percentage of FGI loss due to surface recession is estimated to be $50-60 \%$. In addition to the surface recession there is another $\sim 1.1 \mathrm{~mm}$ of subsurface volatilization damage, i.e. $40-50 \%$ of remaining FGI is affected by volatilization. Figure 5.35a shows the difference in FGI surface texture of an as-processed hybrid oxide CFCC liner and the engine-tested hybrid oxide CFCC liner. Notice the much courser cratered appearance of the eroded surface on the latter. Figure 5.35b is a typical recession profile for three liner areas at heavily eroded FGI surfaces in vicinity to the fuel injector flame hot zones. Note that the greatest thickness loss has occurred near the central zone of the liner. 


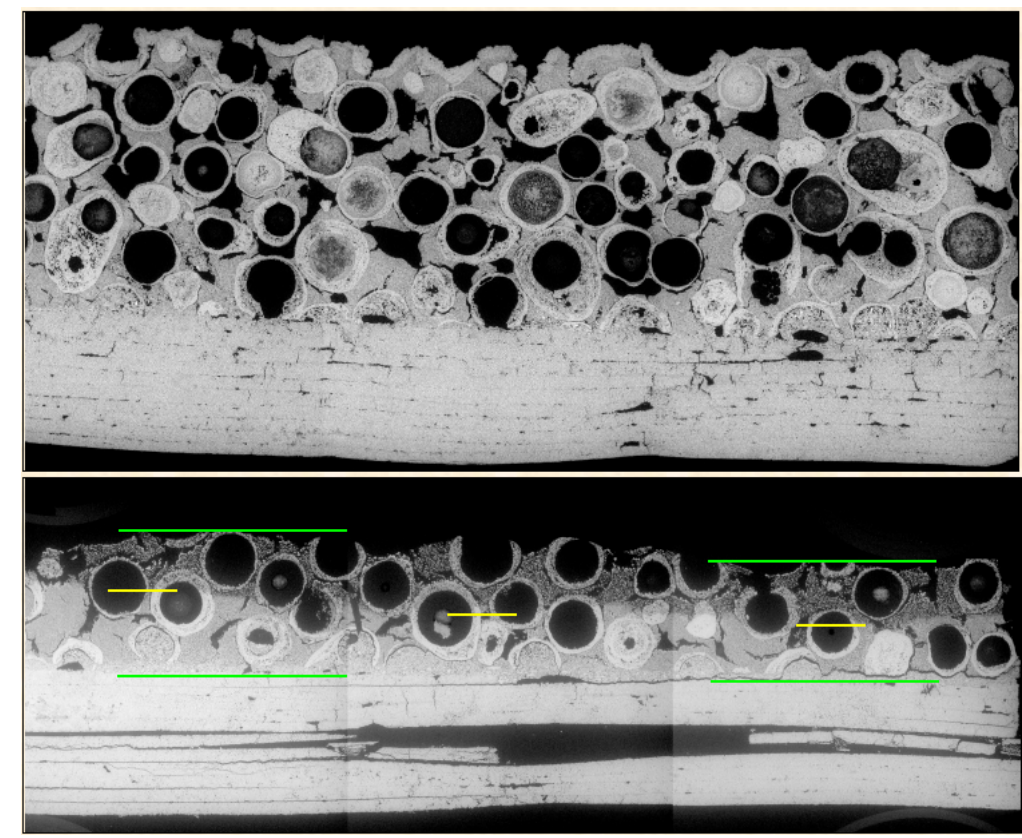

Figure 5.34 As-processed Hybrid Oxide CFCC Liner (Top) and Engine Field Tested Liner Showing Surface Recession (Bottom) - Micrograph Courtesy of ORNL

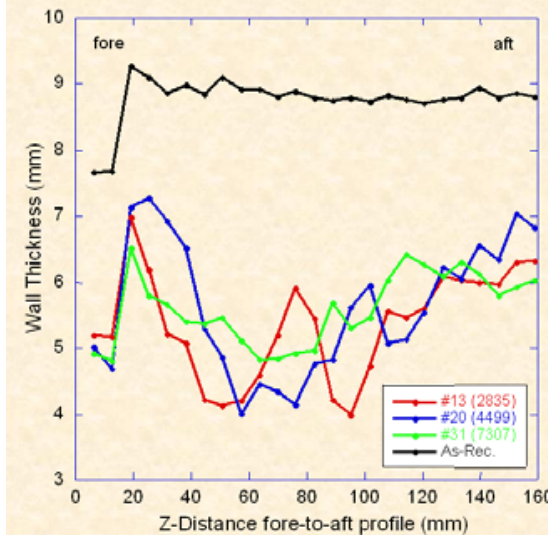

(b)

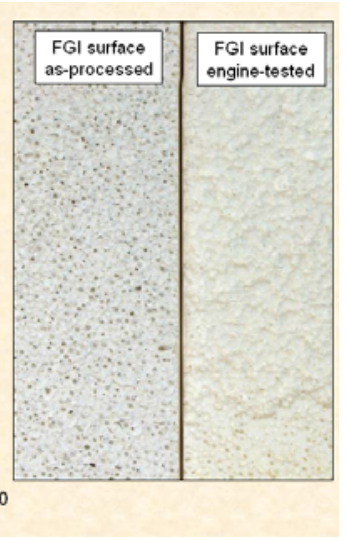

(a)

Figure 5.35 (a) Surface Textures of As-processed and Eroded Engine-tested Hybrid Oxide CFCC Outer Liner Areas (b) Thickness Profile across Three Eroded Areas Compared to As-processed Liner - Photo courtesy of ORNL

Figure 5.36 illustrates the degradation in the FGI. The FGI in the as-processed liner has a dense $\mathrm{Al}_{2} \mathrm{O}_{3}$ surface layer applied by air plasma spray (APS). At the surface of the recessed FGI, no residual APS $\mathrm{Al}_{2} \mathrm{O}_{3}$ remains. The FGI spheres near the surface have lost silica and phosphate, they consist primarily of residual $\mathrm{Al}_{2} \mathrm{O}_{3}$. In the matrix below, the FGI surface spheres are mostly silica and mullite; it is depleted of phosphate. At its base, in the vicinity of the CMC, the FGI has retained its original composition, i.e. $\mathrm{Al}_{2} \mathrm{O}_{3}+\mathrm{SiO}_{2}+$ mullite. Likewise the matrix is similar to the as-processed matrix, i.e. porous, fine-grained phosphate + mullite. 


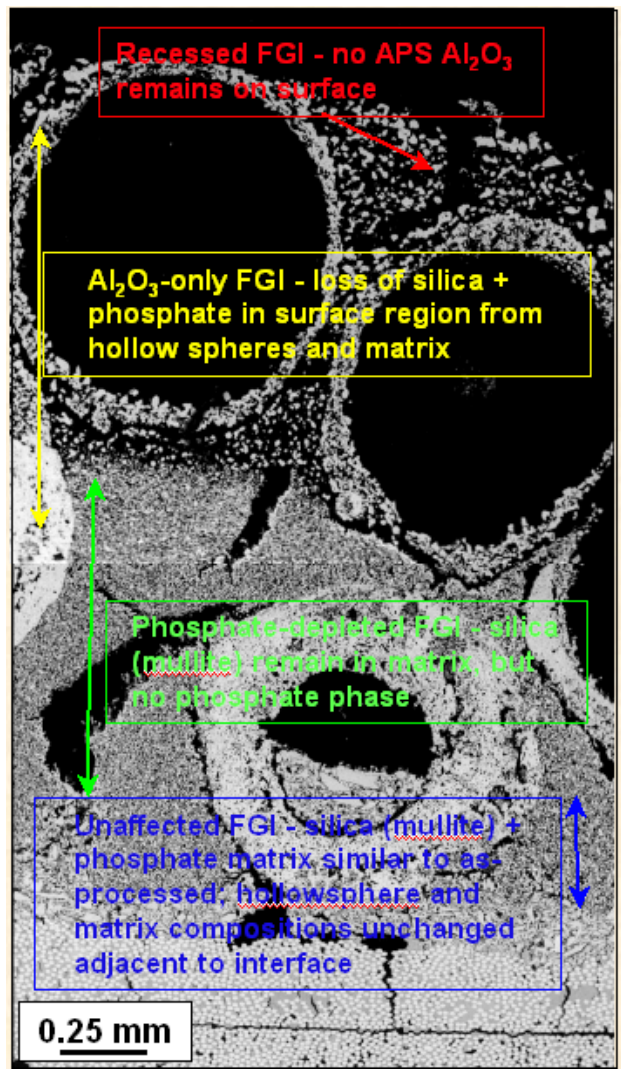

There is a clear delineation between the $\mathrm{Al}_{2} \mathrm{O}_{3}$ surface and silica-containing subsurface region. Greater $\mathrm{Al}_{2} \mathrm{O}_{3}$ grain growth occurs closer to the gas-path surface. The loss of connectivity, observed at the surface between $\mathrm{Al}_{2} \mathrm{O}_{3}$ "particles" due to silica volatilization, was the likely cause of surface erosion (i.e. loss of loose particles). The recession of the FGI appears to occur between depth dependent silica volatilization, which in turn results in loss of connectivity between $\mathrm{Al}_{2} \mathrm{O}_{3}$ "particles", leading to overall erosion of the $\mathrm{Al}_{2} \mathrm{O}_{3}$ particulate surface. This scenario can be directly attributed to the greater volatility of silica compared to alumina. The volatilization is most severe in the hottest areas of the liner, i.e. at the central locations in closest proximity to the flame zone, projected from the fuel injectors. It was noted that the liners showed twelve distinguishable areas of enhanced erosion, corresponding with the twelve fuel injectors in the combustor assembly of the Centaur $^{\circledR}$ 50S gas turbine.

\section{Figure 5.36 Microstructure of Degraded FGI (Courtesy of ORNL)}

Interestingly, the eroded area that was patched with FGI during the intermittent shutdown after 12,582 hours of engine testing, had undergone considerably less degradation, compared to the surrounding area. The patch materials contain fewer hollow spheres and have a much larger $\mathrm{Al}_{2} \mathrm{O}_{3}$ particle size, which more closely resembles the interfacial "glue". It is surmised that the patch was either applied on top of a surface of phosphated FGI or, alternatively, further volatilization of phosphated FGI occurred through the patch. The FGI patch is denser than the areas exhibiting more noticeable volatilization, which may prevent or slow down erosion of the original FGI.

There was heavy surface recession of the FGI in the eroded areas, but there was also significant damage to the underlying CFCC. While the overall CFCC thickness did not change, significant delamination could be observed between the fiber tows (Fig. 5.37). On the other hand little degradation was observed within the fiber tows. The defects were also observed in NDE scans of delaminated areas in the CFCC. The FGI/CFCC interface had remained largely intact. There is some evidence of cracking in the CMC, but not of separation between the CFCC and FGI (Fig. 5.38). 


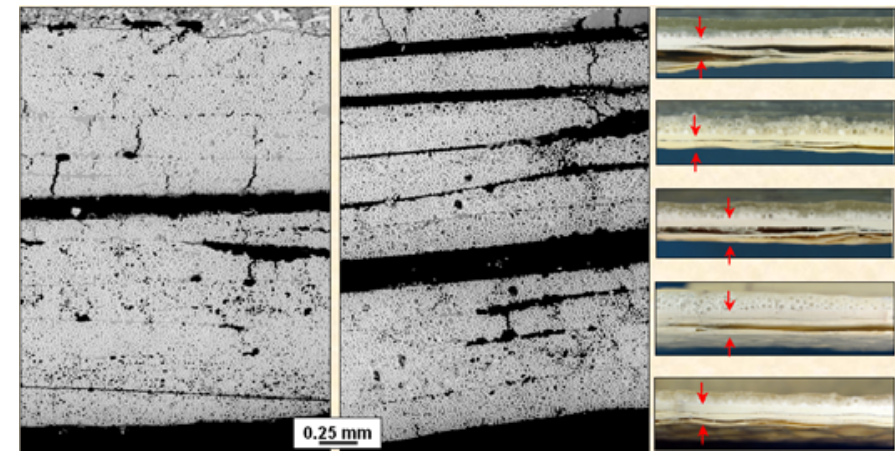

Figure 5.37 Areas of Delamination in the CFCC. Notice cracking in the CFCC . (Courtesy of ORNL)
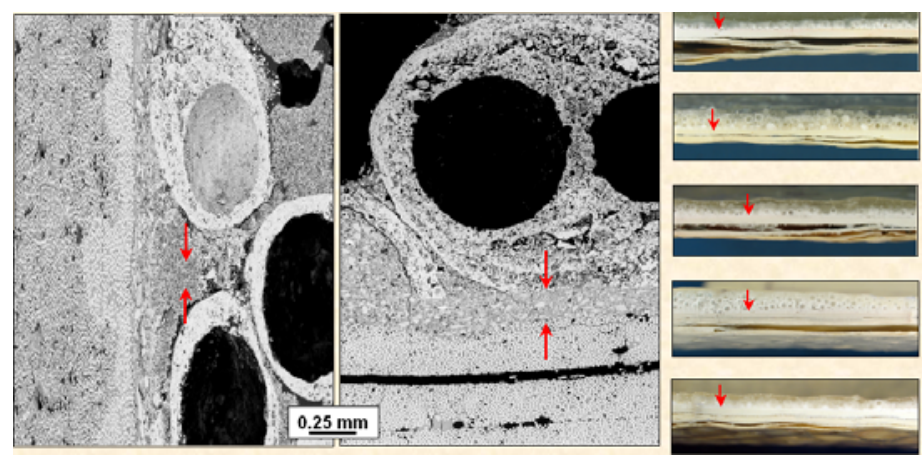

Figure 5.38. FGI/CFCC Interface. The interface has remained intact. (Courtesy of ORNL)

A limited study was conducted to evaluate residual tensile strength in the hybrid oxide CFCC liner following engine testing. Two specimens were sectioned from liner in areas were degradation was apparently minimal, expecting that the residual mechanical properties would be at the higher end of the range of properties for the liner. The maximum room temperature residual tensile strength for both specimens was $19 \mathrm{MPa}$, significantly below the ultimate tensile strength for N720A of $175 \mathrm{MPa}$ (in the x-direction of a 0/90 CFCC).

\subsubsection{Engine Field Test CD-1}

The final field test was conducted at the industrial dairy facility of Cal. Dairies, Inc., at its Tipton, California, dairy processing plant. The test was conducted between June 2006 and May 2007. The test engine was an overhauled uprated Centaur 50S T6201. The CFCC liners, designated TyZMI/BN/SiC-Si MI, had a slurry cast SiC-Si MI matrix, 2D Tyranno ZMI fiberreinforcement, $\mathrm{BN}$ interface, and $\mathrm{SiC}$ seal coat. The liners were supplied by GE Ceramic Composite Products. The outer liner had a novel two-layer Si/YS (silicon/yttrium silicate) EBC while the inner liner had a three-layer Si/mullite/SAS EBC. The EBCs were supplied by UTRC. Figures 5.39 shows the as-processed EBC-coated CFCC liner set. NDE scanning was conducted prior to and after EBC application (Fig. 5.40).

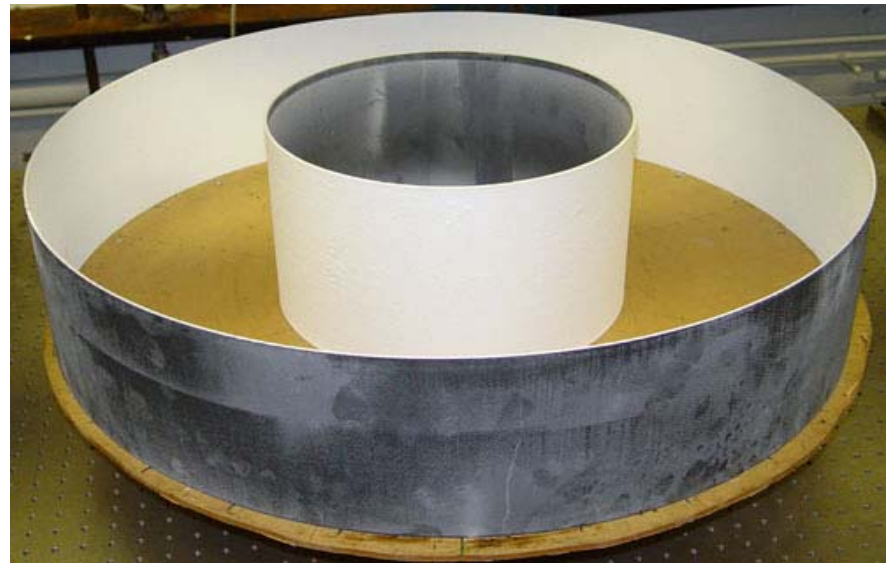

Figure 5.39 As-processed TyZMI/BN/SiC-Si MI Liner Set for Engine Field Test CD-1 


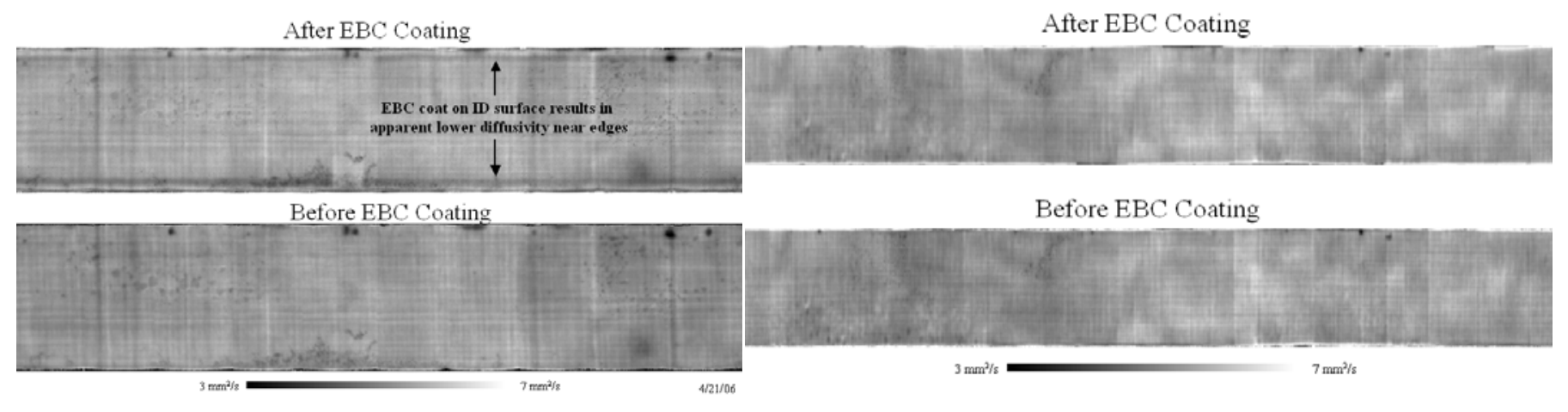

Figure 5.40 Thermal Diffusivity NDE Scans for GE TyZMI/BN/SiC-Si MI Inner (Left) and Outer (Right) As-processed Liners Prior to and After EBC Application (Liners Not to Same Scale) - NDE Scans Courtesy of ANL

The NDE scans indicated the absence of significant defects in the liners. It was noted that some EBC overspray on the inner diameter surface of the inner liner resulted in apparent lower thermal diffusivity for this liner near the edges. Borescope inspections were conducted after $\sim 1,250$, $\sim 2,750$, and $\sim 5,535$ hours. Figures 5.41 and 5.42 show borescope images taken after $\sim 1,250$ and $\sim 5,535$ hours of engine testing. The surface of the outer liner with the Si/YS EBC appeared in excellent condition, but the surface of the inner liner with the $\mathrm{Si} /$ mullite/SAS EBC shows heavy degradation even after the 1,250-hour borescope. Since the inner liner was assesses to be at risk for failure a program decision was made to terminate the test in August 2007 after 7,784 hours and 43 starts.

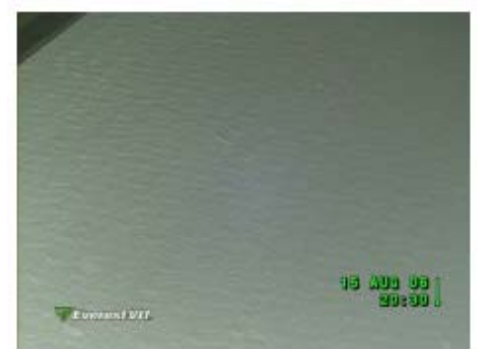

August 15, 2006 $\sim 1,250$ hours

Outer: Si/Yttrium Silicate

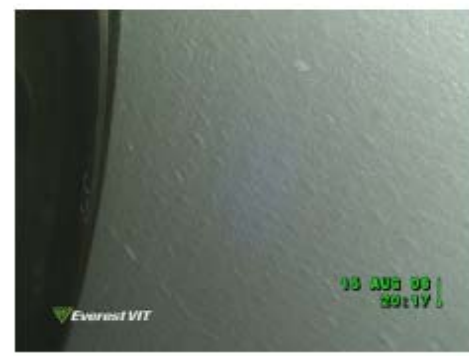

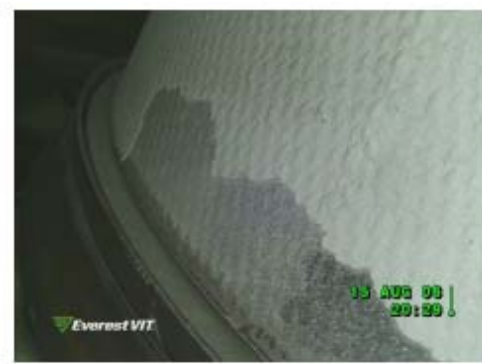

Inner: Si/Mullite/SAS

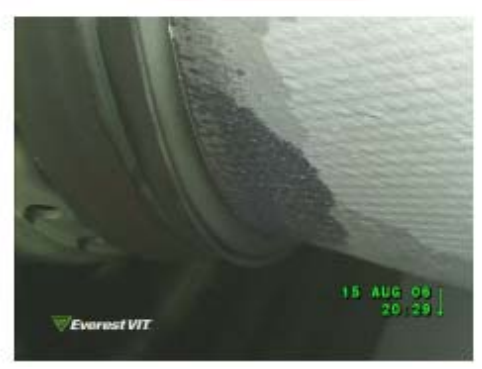

Figure 5.41 Borescope Images of TyZMI/BN/SiC-Si MI Liners After 1,250 Hours of Engine Field Testing; Left: Outer Liner with Si/YS EBC, Right: Inner Liner with Si/mullite/SAS EBC 


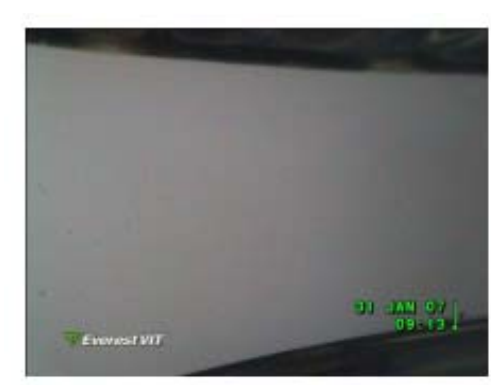

Outer: $\mathrm{Si} /$ Yttrium Silicate

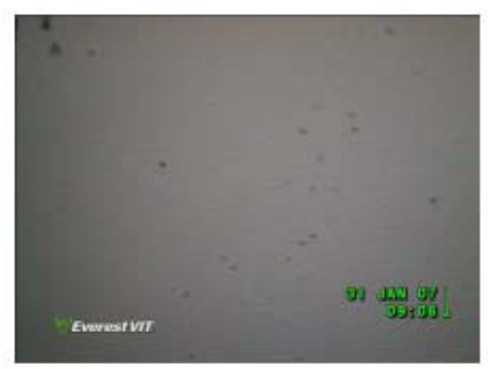

January 31,2007

$-5,535$ hours

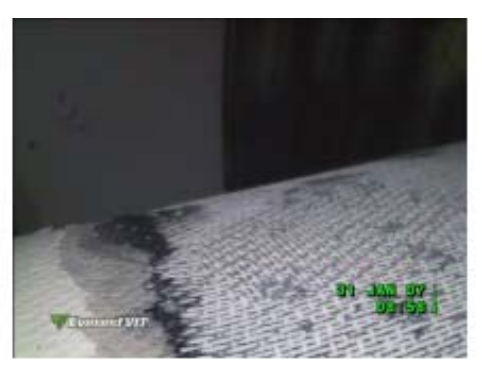

Inner: Si/Mullite/SAS

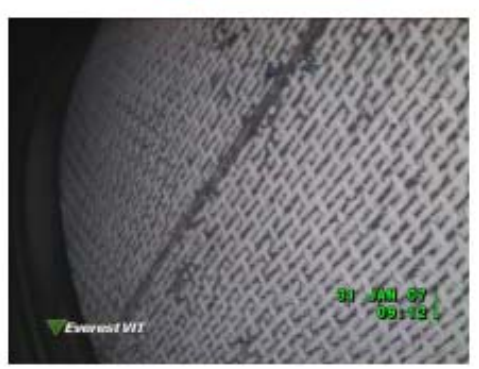

Figure 5.42 Borescope Images of TyZMI/BN/SiC-Si MI Liners After 5,535 Hours of Engine Field Testing; Left: Outer Liner with Si/YS EBC, Right: Inner Liner with Si/mullite/SAS EBC

Figure 5.43 is digital photographs of the hot side (EBC-coated) and cold side (uncoated) of the outer liner. There is some discoloration at the bottom (aft) edge of the liner and localized EBC degradation at the top (fore) edge and towards the center of this liner. But otherwise the liner is well preserved. The Si/YS EBC has provided the best protection of any $\mathrm{EBC}$ for $\mathrm{SiC} / \mathrm{SiC}$ tested thus far. The inner liner shows very heavy surface degradation with EBC spallation over the entire liner surface, except near the edges. It was concluded that a SAS surface coat does not appear to give the protection afforded by a BSAS top coat, a finding also indicated by the results of the MM-3 test (Si/SAS EBC), but unexpected because in laboratory testing SAS had less surface recession than BSAS.

Ohier timer lis side
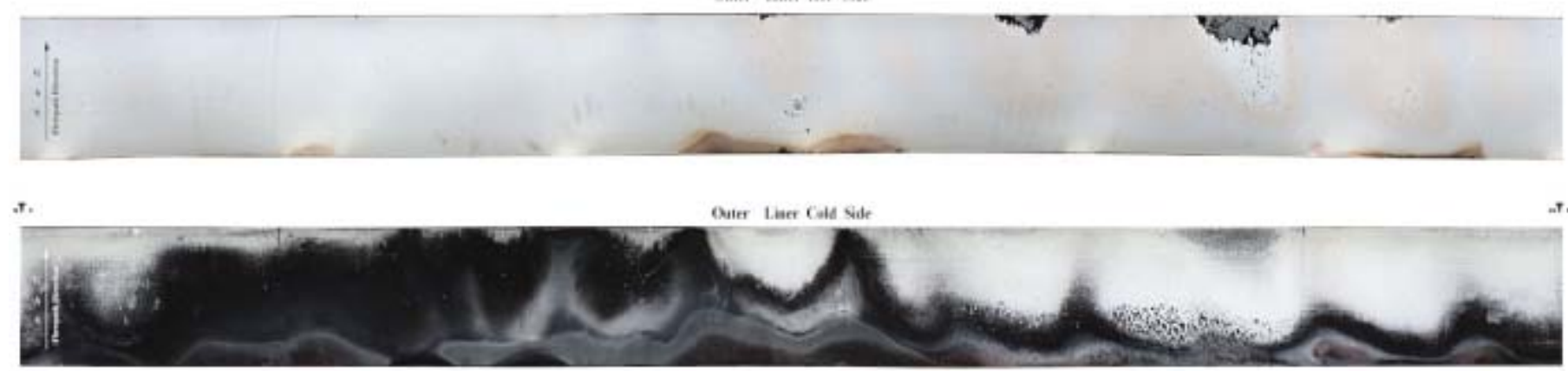

Figure 5.43 Outer TyZMI/BN/SiC-Si MI Liner After 7,784-hour/43 Start Engine Test Top: Hot (EBC-coated) Side - Bottom: Cold (Uncoated) Side 
Since, it is hoped that this liner can be evaluated in future engine field testing, no metallographic evaluation was conducted under the program.

\subsubsection{CFCC Engine Field Test Summary}

Over 88,000 hours of operating experience have been acquired from field testing of CFCC combustor liners since 1997 in Solar Centaur 50S gas turbine engines. At the start of the DOE Advanced Materials program the cumulative field testing hours were about 10,000. Test durations of 15,144 hrs and 13,937 hrs have been logged for SiC/SiC CFCC liners with protective EBCs. An oxide/oxide CFCC liner with FGI protective coating has been tested for 25,404 hrs. NOx and CO emissions were $<15$ ppmv and $<10$ ppmv, respectively.

Ceramic oxide-based environmental barrier coatings (EBCs) improve $\mathrm{SiC} / \mathrm{SiC}$ CFCC liner life by a factor of 2-3. The durability of the baseline Si/mullite/BSAS was found to be enhanced by mixing in BSAS with mullite in the intermediate coating layer.

Microstructural analysis of tested liners indicated enhanced durability of a Sr-rich phase in the EBC top coat, but the replacement of BSAS with SAS did not appear to have improved EBC durability. Heavy degradation of Si/BSAS and Si/SAS EBCs indicates that the elimination of the intermediate layer is detrimental to EBC durability.

Equivalent CFCC liner performance was observed when the Hi-Nicalon was replaced with Tyranno ZM or ZMI fibers. Melt infiltrated (MI) SiC/SiC CFCCs have improved durability compared to $\mathrm{SiC} / \mathrm{SiC}$ CFCCs fabricated by Chemical Vapor Infiltration (CVI) of the matrix, in the absence of an EBC. However, the presence of an $\mathrm{EBC}$ results in roughly equivalent service life for MI and CVI CMCs. An oxide/oxide CMC with protective FGI remains functional for up to 25,000 operating hours in Solar's Centaur 50S engine.

EBC refurbishment for $\mathrm{SiC} / \mathrm{SiC} \mathrm{CMCs}$, and $\mathrm{FGI}$ repair for oxide/oxide CMCs appears to increase liner life. At this time it appears that under the conditions of Solar's Centaur 50S engine hybrid oxide CFCC liners have about a 10,000 hour life advantage over $\mathrm{SiC} / \mathrm{SiC}$ CFCC liners with state-of-the-art EBCs. Hybrid Oxide CFCC liners are approaching the 30,000-hour life target expected for industrial gas turbines. $\mathrm{SiC} / \mathrm{SiC} \mathrm{CFCC}$ liners need to increase durability twofold to achieve that target. The most effective way to achieve this would be to improve EBC durability. 


\subsection{BIBLIOGRAPHY}

A list of presentations and publications given under the program are listed for the Core Program and Subtask 1A below:

Core Program: Advanced Materials for Mercury 50 Gas Turbine Combustion System

1. Chen, X., "Progressive Failure of Air Plasma Spray Thermal Barrier Coating", International Thermal Spray Conference \& Exposition, May 15-18, 2006, Seattle, Washington.

2. Price, J., Kimmel, J., Chen, X., Bhattacharya, A., Fahme, A., and Otsuka, J., 2006, "Advanced Materials for Mercury 50 Gas Turbine Combustion System," ASME Paper GT2006-90568, May 5-8, 2006, Barcelona, Spain.

3. Price, J., "Advanced Materials for Mercury 50 Gas Turbine Combustion System," Microturbine and Industrial Gas Turbine Peer Review Meeting, December 2005, Washington, DC.

4. Franke, B., Sohn, Y., Chen, X., Price, J. and Mutasim, Z., "Monitoring Damage Evolution in Thermal Barrier Coatings with Thermal Wave Imaging", Surface and Coatings Technology, Vol. 200, 2005, p 1292-1297.

5. Chen, X., Feist, J., Heyes, A., Mutasim, Z., Price, J. and Seefeldt, S., "Industrial Sensor TBCs: Studies on Temperature Detection and Durability", International Journal of Applied Ceramic Technology, 2(5) 414-421 (2005).

6. Franke, B., Sohn, Y., Chen, X. and Price, J., "Thermal Wave Imaging Application in Thermal Barrier Coatings," Proceeding of 29th International Cocoa Beach Conference and Exposition on Advanced Ceramics and Composites, January 23 - 27, 2005.

7. Price, J., Thomas, R., Chen, X., Kimmel, J., Bhattacharya, A. and Zozula, G., 2004, "Advanced Materials for Gas Turbine Combustion Systems - Program Summary," ASME Paper GT2004-54250, June 14-17, Vienna, Austria.

8. Chen, X., Almer, J. and Beno, M., "HEXRD Measurements Of In-Plane Residual Stress In Plasma Spray Thermal Barrier Coatings," Jon Almer and Mark Beno, APS Science (The annual report of the Advance Photon Source), May 2004.

9. Chen, X., Price, J. and Ahmad, J., Residual Stresses in Air Plasma Spray Thermal Barrier Coatings," $28^{\text {th }}$ International Cocoa Beach Conference and Exposition on Advanced Ceramics and Composites, January 30, 2004, Cocoa Beach, Florida.

10. Price, J., “Advanced Materials for Mercury 50 Gas Turbine Combustion System,” 2nd Distributed Energy Peer Review, December 2-4, 2003, Washington D.C. 
11. Price, J., Thomas, R., Mutasim, Z., Miriyala, N., Zozula, G. and McClain, J., 2002, "Advanced Materials in Advanced Gas Turbine Combustion Systems," Presentation at ASME Turbo Expo, June 3-6, Amsterdam, The Netherlands.

12. Price, J., "Advanced Materials for Mercury 50 Gas Turbine Combustion System," Microturbine and Industrial Gas Turbine Peer Review Meeting, March 12-14, 2002, Fairfax, VA.

13. McClain, J.C. and Price, J.R., "Advanced Materials - The Ceramic Gas Turbine and Beyond," paper presented at the $14^{\text {th }}$ Symposium on Industrial Applications of Gas Turbines, October 17-19, Banff, Alberta, Canada.

\section{Subtask 1A: Extended CFCC Materials Durability Testing}

1. "Ceramic Stationary Gas Turbine Development Program," Phase III Final Progress Report, Solar Turbines Incorporated, DOE Contract Number DE-AC02-92CE40960, September 30, 2003.

2. van Roode, M., Price, J.R., Kimmel, J., Miriyala, N., Leroux, D., Fahme, A., and K. Smith, "Ceramic Matrix Composite Combustor Liners: A Summary of Field Evaluations, ASME Paper GT2005-68420, presented at the ASME TURBO EXPO, Power for Land, Sea \& Air, Reno/Tahoe, NV, USA, June 6-9, 2005. Transactions of the ASME, J. Eng. Gas Turbines \& Power, 129[1], 21-30, 2007.

3. Brentnall, W.D., van Roode, M., Norton, P.F., Gates, S., Price, J.R., Jimenez, O., and Miriyala, O., "Ceramic Gas Turbine Development at Solar Turbines Incorporated," Chapter 7 in "Ceramic Gas Turbine Design and Test Experience - PROGRESS IN CERAMIC GAS TURBINE DEVELOPMENT, Volume I," M. van Roode, M. K. Ferber, D. W. Richerson, eds., ASME PRESS, New York, NY, USA, pp. 155-192, 2002.

4. Smith, K. and Fahme, A., "Testing of a Full Scale, Low Emissions, Ceramic Gas Turbine Combustor," ASME paper 97-GT-156, Int. Gas Turbine and Aeroengine Congress \& Exhibition, Orlando, FL, USA, June 2-5, 1997.

5. van Roode, M. and Price, J.R., "Ceramic Stationary Gas Turbine Program Overview," ATS Annual Program Review Meeting, Washington, D.C. December 4-6, 2000.

6. Miriyala, N., Fahme. A., and van Roode, M., "Ceramic Stationary Gas Turbine Development - Ceramic Matrix Composite Component Development Summary," ASME paper 2001-GT0512, ASME TURBO EXPO, LAND, SEA, \& AIR, New Orleans, LA, USA, June 4-7, 2001.

7. Price, J.R., Jimenez, O., Faulder, L., Edwards, B., and Parthasarathy, V., "Ceramic Stationary Gas Turbine Development Program - Fifth Annual Summary," ASME paper 98-GT-181, Int. Gas Turbine and Aeroengine Congress and Exhibition, Stockholm Sweden, June 2-5, 1998. Ibid, Transactions of the ASME, J. Eng. for Gas Turbines and Power, 121[4], 586-592, 1999. 
8. Price, J.R., Jimenez, O., Parthasarathy, V., Miriyala, N., and Leroux, D., "Ceramic Stationary Gas Turbine Development Program - Seventh Annual Summary," ASME paper 2000-GT0075, ASME TURBO EXPO, LAND, SEA, \& AIR, Munich, Germany, May 8-11, 2000.

9. Miriyala, N., Simpson, J.F., Parthasarathy, V.M., and Brentnall, W.D., "The Evaluation of CFCC Liners after Field-Engine Testing in a Gas Turbine," ASME paper 99-GT-395, Int. Gas Turbine and Aeroengine Congress and Exposition, Indianapolis, IN, USA, June 7-10, 1999.

10. More, K.L., Tortorelli, P.F., Ferber, M.K., Walker, R.L., Keiser, J.R., Brentnall, W.D., Miriyala, N., and Price, J.R., "Exposure of Ceramics and Ceramic Matrix Composites in Simulated and Actual Combustor Environments," ASME paper 99-GT-292, Int. Gas Turbine and Aeroengine Congress and Exposition, Indianapolis, IN, USA, June 7-10, 1999.

11. Jacobson, N.S., "Corrosion of Silicon-Based Ceramics in Combustion Environments," J. Am. Ceram. Soc., 76[1], 3-28, 1993.

12. Price, J.R., Jimenez, O., Parthasarathy, V., and Miriyala, N., "Ceramic Stationary Gas Turbine Development Program - Sixth Annual Summary," ASME paper 99-GT-351, Int. Gas Turbine and Aeroengine Congress and Exposition, Indianapolis, IN, USA, June 7-10, 1999.

13. Miriyala, N., and Price, J.R., "The Evaluation of CFCC Liners after Field-Engine Testing in a Gas Turbine - II," ASME paper 2000-GT-0648, ASME TURBO EXPO, LAND, SEA, \& AIR 2000, Munich, Germany, May 8-11, 2000.

14. Eaton, H., Linsey, G., More, K., Kimmel, J., Price, J., and Miriyala, N.,"EBC Protection of $\mathrm{SiC} / \mathrm{SiC}$ Composites in the Gas Turbine Combustion Environment,“ ASME paper 2000-GT0631, ASME TURBO EXPO, LAND, SEA, \& AIR, Munich, Germany, May 8-11, 2000.

15. More, K.L., Tortorelli, P.F., Walker, L.R.W., Kimmel, J.B., Miriyala, N., Price, J.R., Eaton, H.E., Sun, E.Y., and Linsey, G.D., "Evaluating Environmental Barrier Coatings on Ceramic Matrix Composites after Engine and Laboratory Exposures," ASME paper GT-2002-30630, ASME TURBO EXPO, LAND, SEA \& AIR 2002, Amsterdam, The Netherlands, June 3-6, 2002.

16. Price, J., Jimenez, O., Miriyala, N., Kimmel, J.B., Leroux, D.R., and Fahme, T.,"Ceramic Stationary Gas Turbine Development Program - Eighth Annual Summary," ASME paper 2001-GT-517, ASME TURBO EXPO, LAND, SEA, \& AIR, New Orleans, LA, USA, June 4-7, 2001.

17. Miriyala, N, Kimmel, J., Price, J., More, K., Tortorelli, P., Eaton, H., Linsey, G., and Sun, E., "The Evaluation of CFCC Liners after Field Testing in a Gas Turbine III," ASME paper GT2002-30585, ASME TURBO EXPO, LAND, SEA \& AIR, Amsterdam, The Netherlands, June 3-6, 2002.

18. Eaton, H.E., Linsey, G.D., Sun, E.Y., More, K.L. Kimmel, J.B., Price, J.R., and Miriyala, N., "EBC Protection of SiC/SiC Composites in the Gas Turbine Combustion Environment - 
Continuing Evaluation and Refurbishment Considerations," ASME paper 2001-GT-0513, ASME TURBO EXPO, LAND, SEA, \& AIR, New Orleans, LA, USA, June 4-7, 2001.

19. Kimmel, J., Sun, E., Linsey, G.D., More, K., Tortorelli, P., Price, J., "The Evaluation of CFCC Liners After Field Testing in a Gas Turbine IV," ASME paper GT2003-38920, ASME TURBO EXPO, Power for Land, Sea \& Air, Atlanta, GA, USA, June 16-19, 2003.

20. Kimmel, J., Price, J., More, K., Tortorelli, P., Bhatia, T., and Linsey, G., "Evaluation of CFCC Liners with EBC in a Gas Turbine," ASME paper GT2005-68961, ASME TURBO EXPO, Power for Land, Sea \& Air, Reno/Tahoe, NV, USA, June 6-9, 2005.

21. Szweda, A., Butner, S., Ruffoni, J., Bacalski, C., Layne, J., Morrison, J., Merrill, G., van Roode, M., Fahme, A., Leroux, D, and Miriyala, N., "Development and Evaluation of Hybrid Oxide/oxide Ceramic Matrix Composite Combustor Liners," ASME paper GT2005-68496, ASME TURBO EXPO, Power for Land, Sea \& Air, Reno/Tahoe, NV, USA, June 6-9, 2005.

22. van Roode, M., Price, J.R., Otsuka J., Szweda, A., More, K.L., and Sun, J.G., 25,000-Hour Hybrid Oxide Combustor Liner Field Test Summary, GT2008-51379, ASME TURBO EXPO 2008: Power for Land, Sea \& Air, Berlin, Germany, June 9-13, 2008.

23. More, K., Walker, L.R., Brummett, T., van Roode, M., Price, J.R., Szweda, A., and Merrill, G., "Microstructural and Mechanical Characterization of a Hybrid Oxide CMC Combustor Liner after 25,000-Hour Engine Test, ASME Paper GT2008-59223, to be presented at the ASME TURBO EXPO 2009: Power for Land, Sea \& Air, Orlando, Florida, June 8-12, 2009. 